\title{
WestVirginiaUniversity
}

THE RESEARCH REPOSITORY @ WVU

Graduate Theses, Dissertations, and Problem Reports

2004

\section{Development of a program to gather and process data from oil and gas fields}

Joshua R. Cook

West Virginia University

Follow this and additional works at: https://researchrepository.wvu.edu/etd

\section{Recommended Citation}

Cook, Joshua R., "Development of a program to gather and process data from oil and gas fields" (2004). Graduate Theses, Dissertations, and Problem Reports. 1532.

https://researchrepository.wvu.edu/etd/1532

This Thesis is protected by copyright and/or related rights. It has been brought to you by the The Research Repository @ WVU with permission from the rights-holder(s). You are free to use this Thesis in any way that is permitted by the copyright and related rights legislation that applies to your use. For other uses you must obtain permission from the rights-holder(s) directly, unless additional rights are indicated by a Creative Commons license in the record and/ or on the work itself. This Thesis has been accepted for inclusion in WVU Graduate Theses, Dissertations, and Problem Reports collection by an authorized administrator of The Research Repository @ WVU. For more information, please contact researchrepository@mail.wvu.edu. 
Development of a Program to Gather and Process Data from Oil and Gas Fields

\author{
by \\ Joshua R. Cook \\ Thesis submitted to the \\ College of Engineering and Mineral Resources \\ at West Virginia University \\ in partial fulfillment of the requirements \\ for the degree of \\ Master of Science \\ in \\ Petroleum and Natural Gas Engineering
}

Approved by

H. Ilkin Bilgesu, Ph.D., Chair

Samuel Ameri, M.S.

Daniel E. Della-Giustina, Ph.D

Department of Petroleum and Natural Gas Engineering

Morgantown, West Virginia

2004

Keywords: Petroleum Engineering, Natural Gas, Oil, Production Operations, Data Management, Field Reporting 


\section{Abstract}

Development of a program to gather and process data from oil and gas fields. By Joshua Cook

In this thesis new software is developed to examine the needs and available options to gather information from oil and gas fields and to analyze data in an efficient manner. The program outlines potential setups as well as practical analysis techniques. The result is a program to store field data and capability to analyze input in different formats.

The developed system uses accounting, economics, engineering, and management concepts to process data. The program uses the relationships between field data gathered in a number of methods. The developed program provides a useful tool for the engineer to gather oil and gas field data and to analyze information for making a sound engineering judgment. 


\section{Acknowledgements}

I would like to thank the members of my thesis committee: Sam Ameri, Daniel E. DellaGiustina, and H. Ilkin Bilgesu. Their support and guidance through the process has been very helpful.

A special thanks to the committee chair, Dr. Bilgesu; who selflessly made an exceptional effort to give direction and suggestions to me on my thesis. Words cannot express the gratitude which I possess for their help.

I would also like to thank my family, friends and professors who have helped me through with this project and the education and guidance which have led up to it. There are far too many to list in a reasonable amount of space. 


\section{II - Table of Contents}

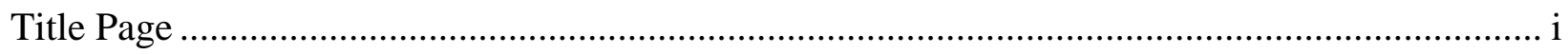

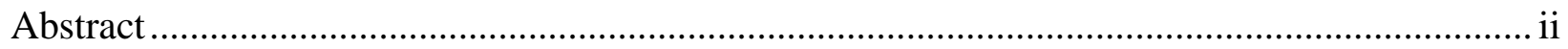

Acknowledgements .......................................................................................................

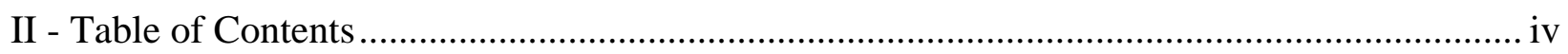

III - List of Figures............................................................................................................. vi

IV - List of Symbols, Abbreviations, or Nomenclature.................................................................. viii

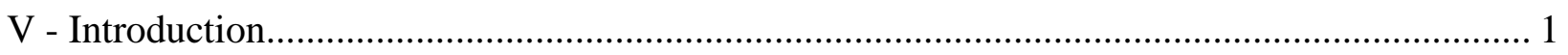

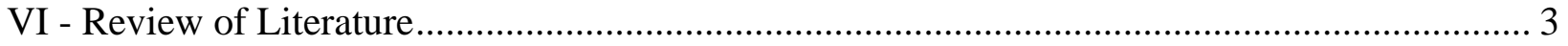

A. Computer Technology................................................................................................ 3

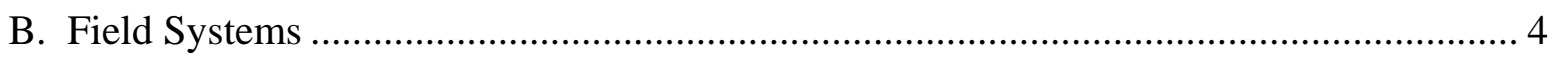

C. Reservoir Engineering................................................................................................... 5

D. Reporting........................................................................................................... 9

E. Operator's Records and Practices................................................................................ 10

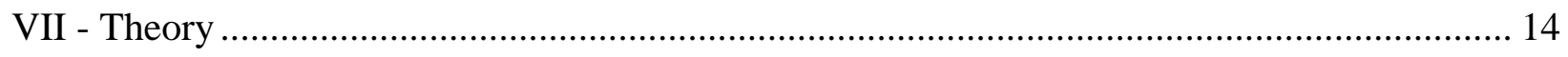

A. Relevant Data ............................................................................................................ 14

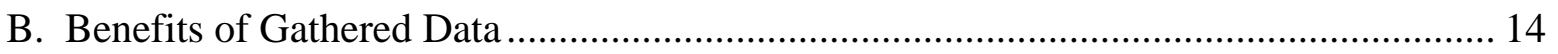

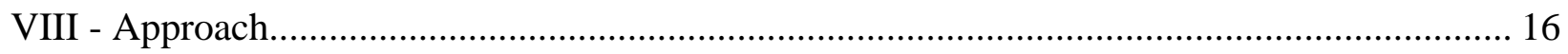

A. Gathering Mechanisms …………………………………................................................. 16

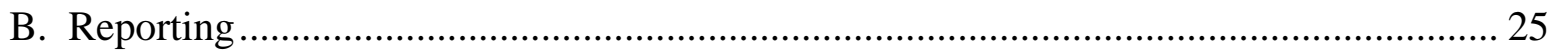

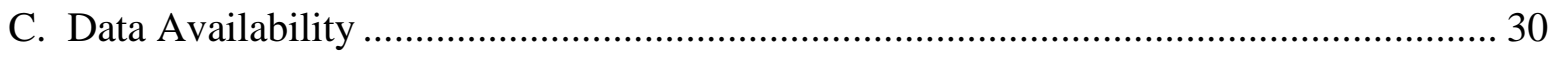

IX - Results and Discussion.................................................................................................. 31

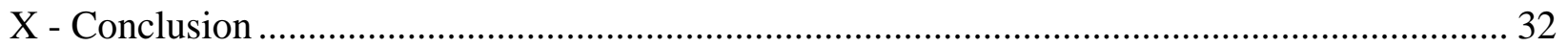

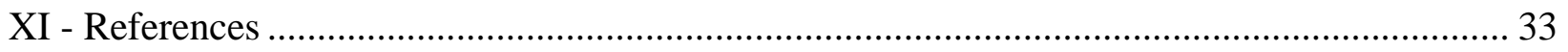

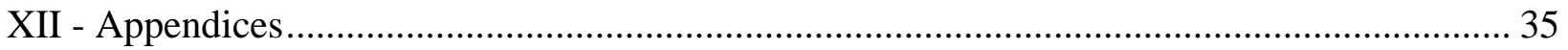

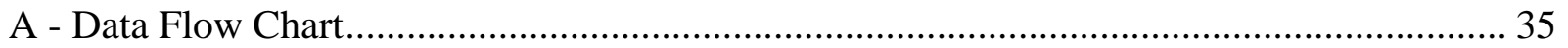

B - Tables and Data Explanation ......................................................................................... 36

C - Access Database Screenshots ............................................................................................ 39

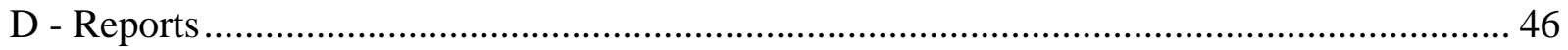

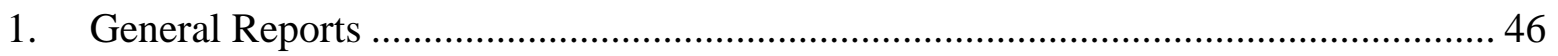




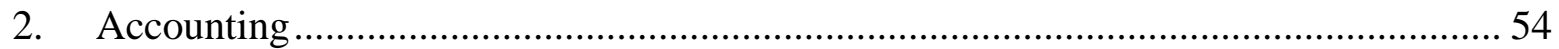

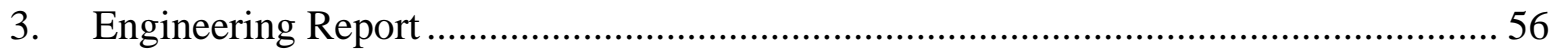

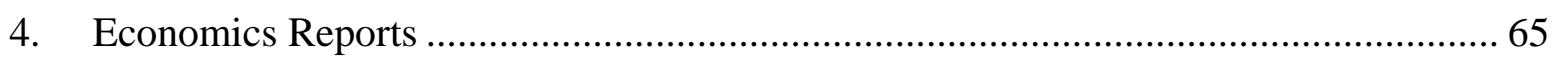

E - PDA Program Screenshots and Description ............................................................. 71 


\section{III - List of Figures}

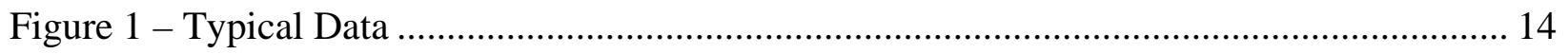

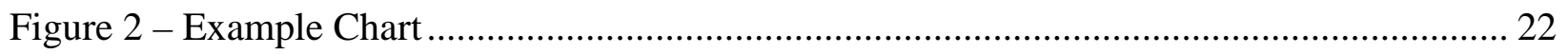

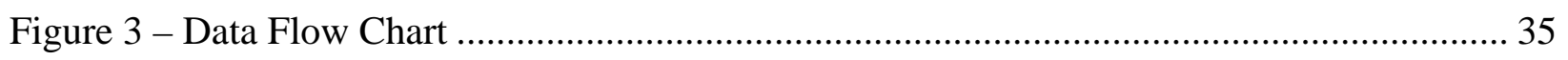

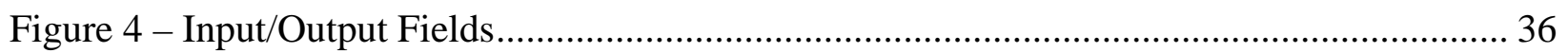

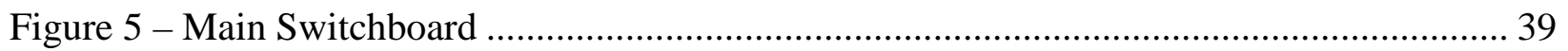

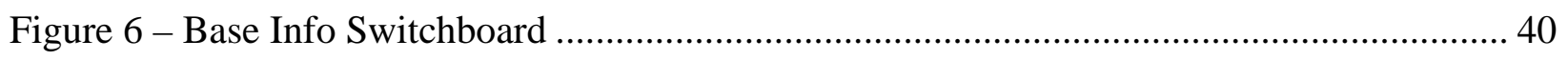

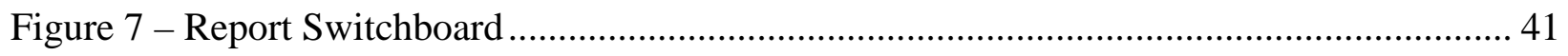

Figure 8 - Meter Records: Form......................................................................................... 42

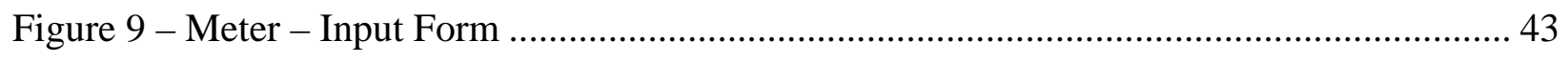

Figure 10 - Well - Input Form .............................................................................................. 44

Figure 11 - Tank - Input Form .................................................................................................. 44

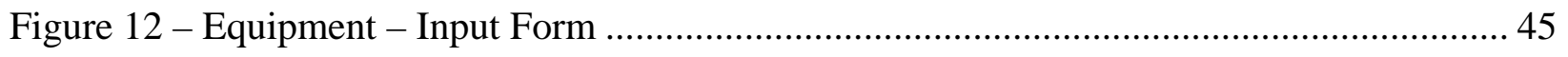

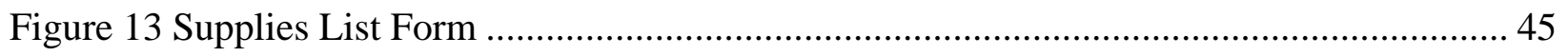

Figure 14- Time and Mileage Report................................................................................... 47

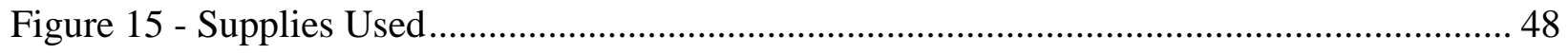

Figure 16 - Well Site Report ............................................................................................... 49

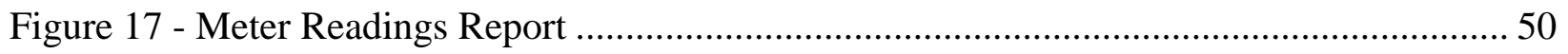

Figure 18 - Tank Records Report..................................................................................... 51

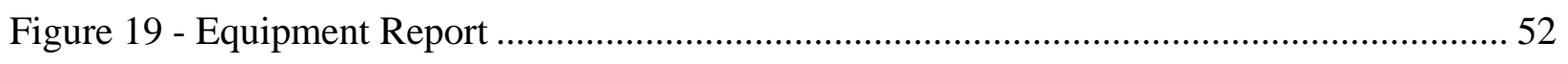

Figure 20 - Pit Records Report ………………………......................................................... 53

Figure 21 - Gas Transport Cost ......................................................................................... 54

Figure 22 - Water Disposal Cost ............................................................................................. 54

Figure 23 - Effective Price Calculation.................................................................................... 55

Figure 24 - Pump Efficiency Analysis ................................................................................... 57

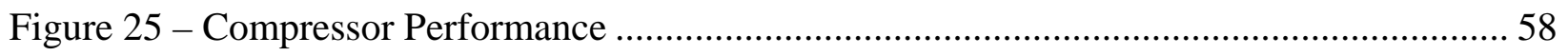

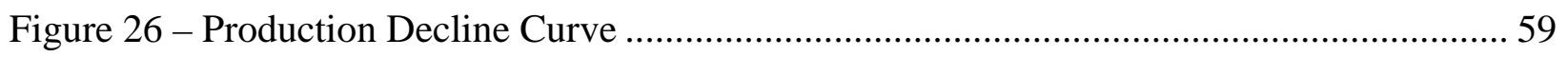

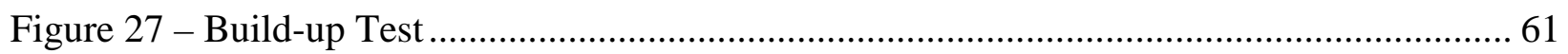

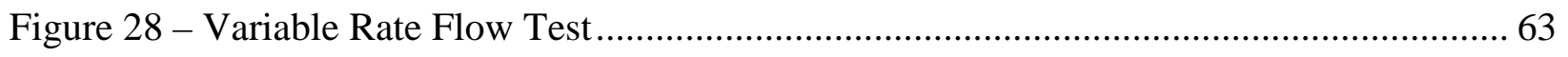




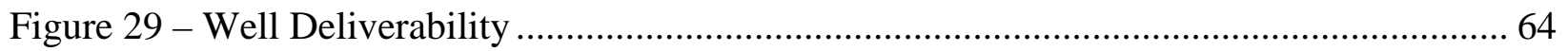

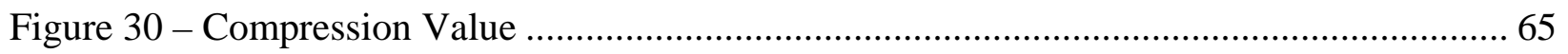

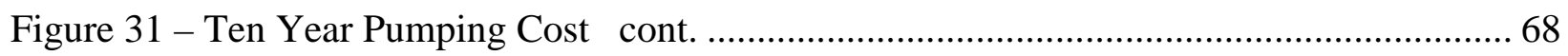

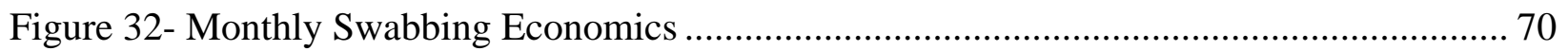

Figure 33 - Program Flow Chart ........................................................................................... 71

Figure 34 - Center Form .................................................................................................. 72

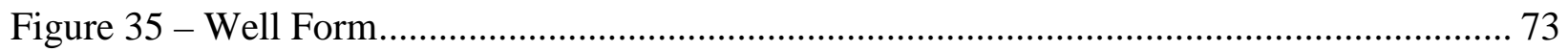

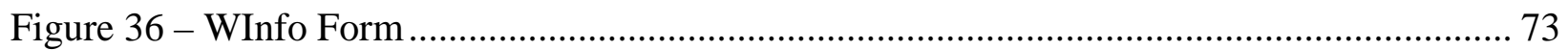

Figure 37 - Tank Form ........................................................................................................... 74

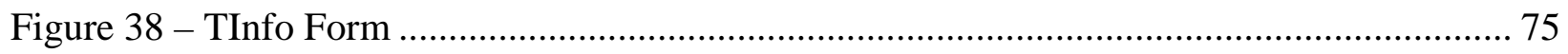

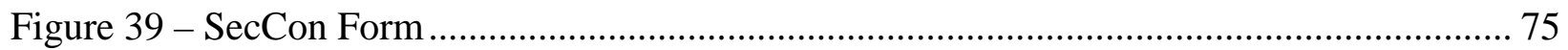

Figure 40 - Meter Form ................................................................................................. 76

Figure 41 - MInfo Form .......................................................................................................... 77

Figure 42 - Equipment Form .......................................................................................... 78

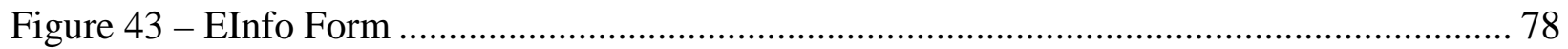

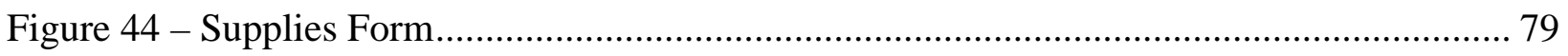

Figure 45 - Mileage Form ............................................................................................. 80

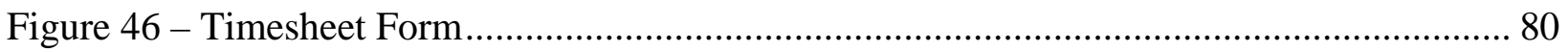




\section{IV - List of Symbols, Abbreviations, or Nomenclature}

Service Rig - Equipment used to perform maintenance work on a well after it is drilled. For example: Swabbing, repairing down hole pumping equipment.

Swabbing - Using a service rig to pull liquids out of a well.

Roots Meter - Meter used to measure the volume of gas that passes through it by measuring the pressure and the volume of gas passed across a vane.

Orifice Meter - Meter used to measure the volume of gas that passes through it by measuring the difference in pressure across an orifice plate.

Orifice - A metal plate with a hole of a specific size at the center. Used in orifice meters.

Orifice Factor - Number used in calculation of flow rate across an orifice plate.

PDA - Personal Digital Assistant: Small computer that is about the size of a hand.

GPS - Global Positioning System: Devices that use satellites to determine their position on the earth.

Decline Curves Analysis - Graphing techniques used to predict future production of a well.

Type Curves - Graphed lines that are used to fit production to decline curve values (also in well test analysis and other things).

Artificial Lift - Systems that are used to lift liquid out of wells. (pumps, plungers,...)

Pumping Jacks - An artificial lift system.

GOR - Gas-to-Oil ratio

BBL. - Barrels (barrels of oil) = 42 gallons.

MCF - Thousand Cubic Feet, used to refer to gas volume.

Permeability - (k) - The ability of a formation to permit fluid to flow through it. (mdmilidarcy)

Skin Factor - A dimensionless quantity used to quantify the additional pressure difference from a zone of altered permeability in a formation immediately adjacent to the wellbore.

STB/d - Stock Tank Barrels per day

SCF/d - Standard Cubic Feet per day

$\mathrm{q}=$ Producing rate at time $\mathrm{t}$. (STB/d or SCF/d)

$\mathrm{q}_{\mathrm{i}}=$ Producing rate at initial time. (STB/d or SCF/d) 
$\mathrm{D}_{\mathrm{i}}=$ Initial nominal decline rate $(\mathrm{t}=0)$.

$\mathrm{D}=$ Instantaneous decline rate,

$\mathrm{b}=$ Hyperbolic exponent. ( $\mathrm{n}$ is also used instead of $\mathrm{b}$ )

$\mathrm{t}=$ Time (units must agree with units of $\mathrm{D}_{\mathrm{i}}$ )

$\mathrm{p}=$ Pressure, $\mathrm{psi}$

$\mathrm{p}_{\mathrm{i}}=$ Initial pressure, $\mathrm{psi}$

$\mathrm{p}_{\mathrm{p}}=$ Pressure, $\mathrm{psi}$

$\mathrm{p}_{\mathrm{wf}}=$ Well flowing pressure, $\mathrm{psi}$

$\mathrm{z}_{\mathrm{i}}=\mathrm{z}$-factor at initial pressure

$\mathrm{z}_{\mathrm{f}}=\mathrm{z}$-factor at well flowing pressure 


\section{V - Introduction}

"The successful companies of the next decade will be the ones that use digital tools to reinvent the way they work.” - Bill Gates

The background of this research is rooted in the mature oil and gas fields of the Appalachian basin. Like many fields, the majority of the wells in this area require a large amount of work to maintain per unit of production. This is due to low reservoir pressures, equipment deterioration, and location remoteness. These wells often have little oil and/or gas production. A large portion of the production income from wells will go into maintenance making many of the wells only marginally profitable. Certain data may be specific to this area. However, with slight variations in the systems and concepts, it will be applicable to any situation.

Most common production work done on wells is done by welltenders. Welltenders will perform various tasks including starting and/or stopping pumps, measuring tanks, regular maintenance, checking equipment, checking pipelines, and various other related tasks. Each welltender will likely take care of 10 to 100 wells depending on the work requirements of each well.

A group of wells will generate thousands of dollars in production each month. It is therefore justifiable to expend considerable resources in tracking these wells.

Although gathering data is a simple and fundamental concept, an effective system is not easy to operate or simple to set up. An effective system will help well operators to produce wells in the most beneficial manner possible. Due to the vast amount of data and the limited technical knowledge of the field employees, data collection in the field is difficult.

Data from the various parts of the operation is gathered together into one central system. By combining all of the various parts, each individual area is better understood. Correlations are made with operations, production, accounting, economics, logistics, production predictions, and various other areas.

This paper separates areas of data gathering and processing. It should be understood that an operation will bring these areas together such that this division is not apparent. By its nature this thesis will only discuss data processing on a limited scale. Due to logistical constraints it is 
not possible to discuss all of the potential uses of this data in this thesis. There is an exceptional amount that can be done with data such as this. Additionally, new processes will become available as more detailed data-gathering processes become more popular and our knowledge base on the subject increases.

The primary focus of this thesis is to identify and gather the necessary data such that a foundation is created for high quality, speedy, and large volume data retrieval. Consequently, more detailed processing and analysis can be performed.

A chart (Figure 3) given in the appendix A, explains the representation of the flow of data. 


\section{VI - Review of Literature}

\section{A. Computer Technology}

The majority of the infrastructure is in place to implement systems that will allow businesses to run almost entirely paperless. The networking, database programs, and other required hardware are already in place. Technological and social knowledge has been building toward these systems for many years.

With an all digital system, information is gathered on a massive scale and made available to everybody that would benefit from it. Computers will be used to collect and format data from the user, then will transfer the information to the appropriate system, where it is processed and then stored or reported.

Businesses will only be successful in the future if they utilize technology that will allow for quick and useful information exchange. As improvements are made throughout industries, companies who can react quickly to different situations will be superior to their competitors. Additionally companies that can best utilize their employees' time and operating expenses will have a comparative advantage.

The system should be simple; a concept central to most any design. A simple system will require less in development, training and operation relative to a complex system that performs the same functions.

Data collection and presentation will change the responsibilities of employees. Ideally employees will spend less time entering data into systems and more time doing productive work.

By providing data to employees, they can gain knowledge allowing them to better understand the operation. As a result, the employee will be able to do his or her job in a more efficient manner.

Creating a "paperless” system holds potential to greatly improve the efficiency and productivity of an operation. Ironically, it would probably still increase paper consumption due to the number of reports that will be created. However, it will eliminate the bottleneck of inputting and processing data. ${ }^{(1)}$

Mobile technology has advanced to allow for an extensive array of available hardware. Many wireless capabilities allow for communication between desktop computers, Personal 
Digital Assistants (PDA), Global Positioning System (GPS) devices, cell phones, printers, and various other devices; all of which allow for great connectivity and ease of use. Data transfer is done very easily with modern mobile devices.

New technologies will increase the power of mobile devices. They will be able to perform more functions and become more user-friendly. Future technology holds the potential of communicating data in a much more efficient manner than current technology allows.

An understanding of the limits of technology is necessary to develop any application. Even with the recent increases in technology, there are still limitations in processing, storage and communication of data. These limitations vary with the situation and have to be identified. ${ }^{(2-5)}$

\section{B. Field Systems}

The use of handheld computers to gather information in oil and gas production operations has been used since the late 1980's. Relative to technologies that are available today, these programs were primitive.

Handheld computers used in the early nineties were limited in memory. Programs were designed with a memory limit of $600 \mathrm{~K}$ bytes. This would limit the system to mostly a recording device. Still, large amounts of information could not be stored.

The implementation of such a system requires considerable planning and thought. Consideration must be made to the data that is required to be collected. The system must then be set up to gather all of this data in an organized format.

The handheld computers are not the most commonly used method of obtaining information from petroleum fields, but they have progressively grown in popularity and hold great potential for many operators.

The systems are now available that will allow for oil and gas field data to be gathered on handheld computers. Systems can be built to be efficient, and to function very well. The use of an internet based system can greatly enhance the productivity of an information system.

Information is gathered and reported much more quickly and easily than by other means. Data that is collected is only 12 hours old; opposed to data that is 7 days old.

The total operating expenses can be greatly reduced from implementation of a good field data collecting system. Through both the reduction in employee time and better monitoring of assets the cost of an operation can be reduced. ${ }^{(6-12)}$ 


\section{Reservoir Engineering}

\section{i. Production Rates and Decline Curve Analysis}

Production forecasting methods are used to predict future production. Production decline analysis (as discussed below), a tank type reservoir model and a reservoir simulator are used to predict production. Each of these methods require certain data and has certain limitations.

Depending on the situation one method may be better than another. (13)

Predicting the future production of a well is fundamental to planning future operations and estimating future income. An accurate estimate of future production will help the operator determine the most profitable method in which to produce the well. It will also give them a projection of the value of wells or fields.

Numerous methods of analysis can help to give a good projection of production. Some of these methods or techniques are discussed. These predictions are only as good as the data that is used and if the conditions change significantly, so will the production. These changes may or may not be predictable.

Decline curves are used to predict gas, oil, and water production. Decline curve analysis uses production history to project the future production. Historical data is plotted and a line is fit to the data which best represents the production values. Assuming conditions are not changing, accurate predictions are made on future production.

An equation has been developed that is found to represent the rate of production as the rate decreases. The equation is the hyperbolic decline equation:

$$
q=q_{i}\left(1+b D_{i} t\right)^{-1 / b}
$$

$\mathrm{q}=$ producing rate at time $\mathrm{t}$.

$\mathrm{q}_{\mathrm{i}}=$ producing rate at time 0 .

$\mathrm{D}_{\mathrm{i}}=$ Initial nominal decline rate $(\mathrm{t}=0)$.

$\mathrm{b}=$ Hyperbolic exponent. ( $\mathrm{n}$ is also used instead of $\mathrm{b}$ )

$\mathrm{t}=$ time (units must agree with units of $\mathrm{D}_{\mathrm{i}}$ )

The initial producing rate $\left(\mathrm{q}_{\mathrm{i}}\right)$ is not necessarily the rate at the first time unit of production. It is estimated in the analysis of the data. When the value of $b$ is 0 or 1 , the equation is simplified mathematically.

When $\mathrm{b}$ is equal to 0 the decline is called exponential decline. The rate equation simplifies to: 


$$
q=q_{i} e^{-D t}
$$

When $\mathrm{b}$ is equal to 1 , the decline is called harmonic decline. The rate equation simplifies to:

$$
q=\frac{q_{i}}{\left(1+D_{i} t\right)}
$$

There are different methods of determining the appropriate values of $\mathrm{q}_{i}, \mathrm{D}_{\mathrm{i}}$, and $\mathrm{b}$. One method is to use type curves. With this, production data is plotted on appropriate tracing paper. The paper is overlain on a chart of type curves. A match point is determined. Using the appropriate calculations, the values are determined.

Another method is to use a computer to plot a line on the production data. First the production data is plotted on a graph. Next, the equation is used to create a line through the production data. The values of $\mathrm{q}_{\mathrm{i}}, \mathrm{D}_{\mathrm{i}}$, and $\mathrm{b}$ are adjusted until a suitable match is made. This is a trial-and-error process. ${ }^{(14,15)}$

Computer programs have been developed to automatically match a line to production data. They use a trial-and-error process to find the best fit. The best fit is determined by the difference in production data and the created line. Often a human touch is needed to remove erroneous data.

Chen ${ }^{(16)}$ utilized the decline curve equations to predict the decline rate early in the life of the well. Using Fetkovich-Arps type curves is sometimes difficult in the early stages of production.

The instantaneous decline rate, $\mathrm{D}$, is defined as the fractional instantaneous change in flow rate with time.

$$
D=-\frac{1}{q} \frac{d q}{d t}
$$

The instantaneous decline exponent, $b$, is defined as the instantaneous time-rate change of the inverse of $\mathrm{D}$.

$$
b=\frac{d D^{-1}}{d t}
$$

Equations are used to help predict the decline for insufficient or scattered data.

Parameters such as reservoir pressure, z-factor, wellbore pressures, and gas compressibility are 
necessary in order to calculate the b-value with this method. When required parameters are available, it is possible to estimate the b-value much sooner than by using type-curve analysis.

Decline curve analysis is commonly done with $b=1$ (harmonic) or 0 (exponential) or with b-values between one and zero. Exponential values tend to underestimate and harmonic values tend to over estimate the actual production. Through mathematical derivations Agbi ${ }^{(15)}$ suggests there should be no upper or lower limit of b. Negative b-values and b-values greater than 1 are valid.

Statistical analysis is performed on oil production decline data by using a computer. A curve is created to establish both upper and lower confidence limits of the production data. Plots are made on both semi-log and log-log paper. The amount of variance increases with the increasing irregularities of production data and conditions. This analysis can give a good indication of the maximum and minimum values that are expected at any time if conditions do not change. (17)

Jochen ${ }^{(18)}$ used decline curve analysis to create a probability function of the production that is expected. The bootstrap method of Monte Carlo analysis was performed. The bootstrap method is a type of Monte Carlo analysis which does not require a prior knowledge of many parameters. The objective is to create a probability function of the reserve estimate based on the decline curve. The changes in operations could account for changes in production.

Locke $^{(19)}$ developed a program to match the decline curve to fit hyperbolic or exponential declines. This program applies the least squares method to determine the best fit of the data. A function is created by the program which fits the decline equation to the data. The study compared two different methods of obtaining results determining that a nonlinear leastsquares technique has the advantage over the linear method which could have errors of as much as 70 to $200 \%$.

Representation of variations in the wellbore parameters can cause significant error in decline curve analysis. Harrison ${ }^{(20)}$ derived ordinary differential behavior modes for semisteady state of gas and oil production. These models are used to characterize slowly-varying time-function of production or bottom-hole pressure. The model type curves were charted to predict decline rates under these varying conditions. The type curve was derived using a constant pressure-driven reservoir. Non-Darcy coefficient was incorporated in the analysis. 
To better estimate decline curves Aminian ${ }^{(21)}$ introduced new type curves for gas wells under variable conditions. For this model factors including non-Darcy flow effects, skin factors, and pressure dependent gas properties were considered. The model was used to predict the decline behavior of gas wells when the drainage area and back pressure are changed. A relationship between initial flow rates and backpressure was created.

$\mathrm{Li}^{(22)}$ used decline curve analysis and various reservoir parameters to model a naturally fractured oil reservoir developed by water flooding. This model used oil recovery predictions to better predict the rate of production. The model used proves that a linear relationship is accurate. The frequently-used nonlinear relationship type curves could be transformed to linear relationships using a log-log plot.

Formations that exhibited dual porosity characteristics are unlikely to demonstrate commonly expected. Poston ${ }^{(23)}$ used mathematical equations to approximate the geological model of a dual fracture-matrix reservoir. Type curves were created which characterize these models.

With multiphase flow, generally one phase is predominate. The other phase(s) is considered a secondary stream. A number of different methods for creating a decline curve for a secondary stream exist. The secondary stream is more difficult to predict than the primary. Small changes that minimally affect the primary stream can significantly affect the secondary stream.

A second decline curve can be fit to the secondary stream, just like it is of the primary stream. A constant Gas-to-Oil ratio (GOR) can be used; therefore corrections are made for the changing GOR.

The log of cumulative gas production versus the log of cumulative oil production can be

plotted. The result is often a straight line. From this the gas rate is projected over time. ${ }^{(14)}$

\section{ii. Well Testing}

Well testing includes various procedures that are performed to obtain values for reservoir parameters. Depending on the test, parameters such as reservoir pressure, permeability, skin factor (wellbore damage / enhancements), reservoir radius, drainage area, size, shape, or the presence of faults could be found. These parameters are necessary in order to better predict 
future production, monitor damage, identify problems, model the reservoir, and create predications for future projects.

There are several different types of well tests that can be performed. Production or deliverability tests and several pressure-transient tests are conducted.

For example, a drawdown test is performed by producing the well at a constant rate. The pressure at the formation face is monitored. The pressure data along with other parameters of the formation are used to analyze the formation. This type of test is useful in new wells or in wells that have been shut in for a considerable amount of time. Key results in this analysis are the reservoir permeability, skin factor, and reservoir pressure.

Another common well test is a pressure buildup test. This test is based on the drawdown test. With this test the well is produced for a period of time and then shut in. The formation face pressure is monitored. The pressure data and other parameters are used to perform the analysis. Like the drawdown test, key results in this analysis are the reservoir permeability, skin factor, and reservoir pressure.

Productivity index is the ratio of flow rate to pressure drop. This value or equation for this value is calculated based on well test data. It can also come from production data itself. This number is helpful in estimating production, given variable conditions.

An exceptionally large amount of work has been done on various types of well tests. Each method of well testing has a unique set of operations and analysis techniques. Situations exist where certain tests are more suitable than others. ${ }^{(24)}$

\section{Reporting}

Reports should be written to meet the audience's needs. It is important to understand who the audience is and what they need to get out of the report. This will help to determine the leeway in use of technical terms.

The document should be as short as possible and should convey all of the necessary data in an understandable format. The format should be simple and should explain all of the necessary data. 
Well formatted data is essential to the presentation of a report. The use of correct graphs and tables can greatly enhance the report by providing a visual image of the topic. The subject matter should be clear and concise. ${ }^{(25)}$

\section{E. Operator's Records and Practices}

The objective of a system is to be able gain benefit from its application. Aspects of the following companies are described as examples to give insight into common practices and situations.

\section{i. $\quad$ Top Drilling Corporation ${ }^{(26)}$}

Top Drilling Corporation is an oil and gas well operating company. It oversees the production operations of over 300 wells. About fifteen employees are employed by the company to fulfill the various required duties.

Approximately half of the company's wells require some form of artificial lift. To optimize production these mechanisms are required to remove liquids from the well. Consequently, considerable expenditure is made in artificial lift mechanisms.

About 50 wells have pumping jacks, all of which are started manually between 1 to 16 times a month depending on the situation. The time required to do the necessary preliminary work and engine starting takes 10 to 30 minutes per well. Supplies necessary to complete the pumping operation vary from well to well. The most common items used are: gasoline, electric, wellhead gas (not metered or compensated for), motor oil, belts, engines, sparkplugs, and various other engine parts.

Occasionally, the components of the downhole pumping mechanisms will have to be repaired. This will require a service rig. Most wells will average approximately five years between needing major service rig work. Wells that carry sand in the produced liquids or are pumped a disproportionate amount more, may need to be serviced about every two years. However, some wells have gone thirty to forty years without the need of service rig work.

For $2000 \mathrm{ft}$ deep wells, representing 90\% of the company's inventory, a service rig will take around 8 hours (\$100/hour) to complete the service work. Additionally, supplies will cost around $\$ 200$. If a dozer is needed, an additional $\$ 500$ can be expected. Deep wells or wells that 
are located a long distance from the field office will add additional cost. There is some risk that considerably more work may be required, which would increase the expenses even more.

Around 20 wells use a casing plunger lift tool (rabbit). This tool is dropped down the well where it will be returned by gas pressure and carry liquids ahead of it (1/4 to $4 \mathrm{bbl}$.). These tools are run 1 to 10 times a month. Running these tools and doing preliminary work takes about 10 minutes.

A small service rig is sometimes used to retrieve lost tools. This will take around 4 hours at $\$ 65 /$ hour. However, proper maintenance and operation of the tools will reduce the frequency of service rig work. The cost to operate this type of mechanisms is considerably less than a pump, but it can still amount to considerable costs.

Multiple costs are associated with travel to locations. Travel time from one well to the next will average approximately ten minutes. Mileage is expensed to company vehicles or paid out to the employee along with their wages. Each trip to a well will cause some deterioration to the well roads. Since most of the roads are dirt, vehicle use can create rough, hazardous roads. These roads increase the danger to employees and equipment. Consequently, equipment and supplies will be used occasionally to repair these roads.

By maintaining accurate and detailed information, the company can reduce unnecessary costs and optimize production.

This company and related companies date back to 1900. Written records on production operations were limited to the information that was required for distribution to investors and to royalty owners.

In the early 1980s, a paper to computer system was created to record data. With this system, welltenders turn in reports on each of their wells on a weekly basis; additionally, job orders, trucking tickets, and mileage sheets were used to collect the necessary data. The data were then entered into the computer and reports were created.

The reports presented the last four entries for each well (the last four weeks). The information displayed included pumping dates, tank volumes, meter rates and readings, supplies used, and any notes.

Unfortunately, with the downturn in the markets and a lack of administrative interest in the system, the computer entry portion of the system was abandoned. The weekly reports were still kept in a filling cabinet and otherwise used for necessary accounting. 
In 2003 an interest was gained in re-implementing a paper to computer information system. A new form was created to replace the one that had been updated minimally in the past 20 years. It consolidated several other forms that were being used. It requested meter, well, tank, mileage, supplies and time related information. These forms were then entered on a computer system.

This type of data entry requires considerable time. Also for the welltenders to maintain records for field use, they had to write the information twice.

In 2004 a PDA - computer system (similar to the one to be discussed in detail later) was implemented. This system allows data to be entered on PDAs in the field. It will then be retained on the PDA for future use. The PDAs are connected to the office computer once a week during the weekly welltender's meeting. When connected, the PDAs will send all of the new data to the office computer and will receive any updated information, including records of the other welltenders. Detailed reports are created for various purposes from this information.

In the future, the company hopes to utilize this system in conjunction with new technologies in metering and well monitoring. The handheld units will be used to gather data to track supplies, track inventory and make correlations with operations and measured volumes. This data will be used in retrospective studies to assess production and operations.

Currently, written job orders are used to bill out trucking, service rig work, and other jobs which are performed in the field. The handheld system will eventually be used to automatically create electronic job orders for work completed. These will be sent to the distribution software and will automatically be billed to the appropriate party.

\section{ii. Term Energy Corporation ${ }^{(27)}$}

Term Energy is also a well operating company. They operate about one hundred wells. Conditions are similar to Top Drilling's wells. Half of their wells require a lifting mechanism. Most of their wells have proven to be marginally profitable.

Well records are kept with considerable deal on paper. Records of pumping, work done, meter readings, tank measurements, and other relevant data are collected. This leads to a sizable amount of paperwork. 


\section{iii. Key Energy Corporation ${ }^{(28)}$}

Key Energy Corporation uses handheld computers in the field. The handheld units resemble large calculators. The appropriate well is selected from a list, and then information is entered. The information gathered includes dates, meter readings, tank measurements and well operations.

Information is downloaded onto the office computer, where well information can be updated. From the office computer, the records are sent to investors and other interested parties. 


\section{VII - Theory}

\section{A. Relevant Data}

The first step of gathering data is to identify what information needs to be obtained. The following table illustrates information found to be relevant based on typical Appalachian operator's records and analysis techniques. It should be noted that all of this information may not be necessary and that other information may be needed depending on the situation.

\begin{tabular}{|l|c|}
\hline Well & General Accounting \\
\hline Well Number/Name & Employee Time \\
\hline Operations Done & Mileage \\
\hline Wellhead Pressures & Travel Time \\
\hline Pumping Speed and Time & Supplies \\
\hline Time of Employee & \\
\hline General Notes & Tanks \\
\hline & Tank Number/Name \\
\hline Meters & Volume \\
\hline Meter Number/Name & Secondary Recovery \\
\hline Pressure & System's Condition \\
\hline Differential & General Notes \\
\hline Feet per Minute & \\
\hline Meter Reading & Other Equipment \\
\hline Calculated Rate & Various Changeable Fields \\
\hline General Notes & \\
\hline
\end{tabular}

Figure 1 - Typical Data

\section{B. Benefits of Gathered Data}

The gathered data will be used for various purposes. The overall objective is to increase profits by creating a more efficient operation through better data management.

For accounting purposes the data is used to bill supplies and labor to wells or equipment. This will feed into the accounting elements of the system. Employees' time and mileage are 
tracked. Additionally other expenses such as supplies and trucking are managed. An efficient accounting module is useful so that each well will be billed its expenses.

Field data will also be used for engineering. Data from the field is used to estimate benefits of various operations. It can also be used to monitor the condition of equipment and identify existing or potential problems. For example, data is used to monitor the efficiency of a pump. As the pump wears it will not work as well, therefore corrective action may need to be taken.

By combining information from both the accounting and engineering, economic analysis is done. By taking the cost and benefits of various scenarios, an accurate presentation of the operation is made. The result will show the possible courses of action and the resulting profit.

Management will assess the reported information from all of the categories to make appropriate decisions. They will have an accurate picture of the operation and the expected results of actions. The decisions can then be sent back to the field personnel.

An example for a flow of information is given as follows:

- A well makes a small amount of liquid. Data such as wellhead pressures, gas flow rates, past liquid production, operation times, and other conditions are gathered from the field. Swabbing has been determined to be the best method to produce this well.

- Accounting would be done to determine the price of production, cost of normal operations, and the cost of swabbing. Engineering would create an estimate of the wells production if the well was swabbed at different intervals, for example every $1 / 2,1,2,3,5$, 9, and 12 months.

- Economics would then put the data together. It would take into account the possible changes in prices of production and expenses. A graph would be created of the potential profits at the predetermined intervals.

- Management will look at the reports from each of the departments. They can then ensure that the service rig will be sent to the well at the most opportune time. They must also consider the availability of the rigs and other resources that may be required.

- Example calculations are presented in the Appendix.

To demonstrate economic justification the following example is provided. 
As a result of better analysis from the use of the system, changes were made in operations. It is found that pumping one well once a week instead of twice is more economical. This saves the pumper a half hour a week. Another well was not pumping enough. The pumping time was increased. The net increase in the two wells' production is $1 / 2 \mathrm{bbl}$ of oil and 1 thousand cubic feet (mcf) of gas per week.

- $1 / 2 \mathrm{hr}$. $\$ \$ 10 / \mathrm{hr} \times 50$ weeks $=\$ 250$

- 1 mcf x $\$ 5 /$ mcf x 52 weeks $=\$ 260$

- $1 / 2$ bbl x $\$ 25 /$ bbl. X 50 weeks $=\$ 625$

- Pumping costs cancel out.

Result $=\underline{\$ 1035}$ per year

\section{VIII - Approach}

\section{A. Gathering Mechanisms}

\section{i - Overview}

The earliest and most basic method of collecting data is for the welltender to remember the field information. When information about the well is required, it is exchanged verbally. This method results in significant error and is difficult to communicate. It can also be stressful to remember and communicate information. This approach works reasonably well in a very small operation, but becomes unreasonable with a larger one.

The more common method of recording information in the field is to write it in a small book or tablet. A welltender can look back on what they have done and found in the field. Problems quickly arise when the book is full, lost, or destroyed (grease, water, oil, etc.)

The information from the field is rewritten on a report and sent to the office. This requires a large amount of time and effort both in the field and in the office. In addition, if the information is going to be used for accounting, engineering or management, it will likely have to be rewritten or typed into a computer, thus having been handled three times. This reporting method requires considerable resources to enter data and results in many errors.

Another option is to provide the welltender with laptops, which will allow them to record information in the field. This would eliminate some or all of the paperwork. The welltender 
would be able to keep very large amounts of information about the field. The gathered information could be easily moved to an office computer.

The cost of implementing laptops in the field would become significantly high. Costs include the equipment, software, and training. Most welltenders do not have significant knowledge of or desire to use a computer. Consequently, they may be reluctant to use them. Laptops would be easily ruined in the rough conditions and they would be cumbersome to use in the field.

The centerpiece of this research is the use of handheld devices (PDAs) in the field. PDAs are relatively inexpensive, highly mobile, easy to operate, and very versatile. Programs can be written for PDAs, which will allow the user to enter all of the required information relatively easily. The PDA can connect to the office computer and information is automatically exchanged.

Although employee training will be required, it is likely that the system will not take more than a few hours of training and a few weeks to become proficient in the use of the system.

GPS, barcode readers, modems, smart phones and hundreds of other products can be used to expand the system to fit the operator's needs as they arise. Most of these products can be used in the field.

Liquid production is commonly measured in the field by welltenders. Measurements of stock tanks are made from a stick or tape measure. These measurements are later correlated with shipping tickets. Alternatively, volumes can be measured by computerized pressure sensors.

Various types of orifice and roots meters are used to measure gas. The most accurate and detailed method of gathering production data in the field is by the use of computerized meters and monitoring devices.

\section{ii - PDAs}

For this project a program was developed which utilizes the latest in mainstream handheld computer technologies to communicate and store oil and gas field data.

\section{a) Software Programs}

The Window CE platform was selected to develop the program. Windows CE is a version of Microsoft Windows specifically designed for PDAs. It allows for the use of many 
peripherals and programming is relatively simple. This platform is available in many brands and models from major computer companies such as Dell and HP.

Visual CE is a PDA database program that makes development of the system possible. This database program allows the programmer to create forms that are used to display and record information. A host of features are available and compatible with the system.

Visual CE allows for easy synchronization to Microsoft Access (Access). Data is transferred seamlessly from the PDA to the Access file or vice verse. Depending on the setup, the data can be manipulated on either the PDA or the Desktop computer. The system can maintain multiple handheld devices.

\section{b) Field Requirements}

The environmental conditions that the devices will be used in should be well understood such that appropriate hardware can be used. It is assumed that the device will be transported to the field and exposed to all the conditions that are commonly found. Wells commonly have rough lease roads resulting in the devices being beaten around. It is also assumed that the device will be outside in extreme temperatures and wet conditions. Therefore, the device will need to have waterproof protection and insulation against inclement temperatures.

There are a few models of PDAs that are ruggedized and can withstand these difficult environmental conditions. These will likely work very well, but they are considerably more expensive than similar standard models.

A hard, crush-resistant, padded, waterproof, airtight PDA case is available from a vendor. The device can even be used through the case. This is the most economical approach. Most PDAs will have adequate protection and will work in these cases. ${ }^{(25)}$

\section{c) Office Equipment}

The requirements of the office computer must be met in order for the system to function properly. The office computer must have appropriate software. With the software developed Access and PDA synchronization software are needed. PDAs generally connect via USB cable. Many other mechanisms can be used to connect the PDA to the office computer.

Some PDAs have Bluetooth wireless hardware. This will allow wireless synchronization to take place with the PDA $100 \mathrm{~m}$. away from the desktop. The office computer will need a Bluetooth card if these types of devices will be used. 
Modems can be used. The office computer will have to have a modem that is available. A modem will also be required for the PDA.

Network synchronization can also be set up. In network synchronization the PDA is connected to one office computer on the network and then it is passed through to a server. This would possibly allow for multiple offices to connect into one network. However, it also would add considerable complexity to the setup.

The office computer will also need the capability to produce its reports. This would require a printer, email access and/or faxing ability.

\section{d) Setup}

The largest task required in setting up the system will be getting the data into the correct tables on the Access database. A large amount of data is entered into the system about wells, tanks, meters, and equipment. After identifying the necessary parameters of gathered data, tables will need to be set up in Access. These tables will be used for storing and recording information.

The necessary tables were created in Access. However, separate tables were needed for informational and recording purposes.

Next, forms were created based on the tables. A list of the tables and fields is given in Appendix B, followed by their description. The information in the tables is stored and recorded in boxes. The forms are created with the objective of gathering all of the necessary data. Screenshots and a description of each form are given in Appendix E.

The forms, queries, tables, and reports were set up. However, if other items (fields, calculations) are required, they will have to be created at some point. If new reports are needed, they are created.

Each of the handheld devices is connected to the computer and set up based on the synchronization manager. Next, the program is installed on each of the devices. In order to make the access to the program easier, a button on the PDA should be programmed to go to the main page of the program. 


\section{iii - Metering}

Many types of meters are used in the oil field. Some of the more common ones will be discussed to show how they are used in the project. Traditional means of metering gas is to use a roots meter or an orifice meter.

Older style meters have charts which are changed periodically (usually monthly). The charts are then integrated to determine how much gas was produced in that period. This method usually results in one number (total volume) per period. Accuracy can easily be hampered if the meters are not calibrated correctly or are otherwise not functioning properly. Chart damage due to water, or highly fluctuating production can also decrease accuracy.

Computerized meters offer the most accurate and detailed information. Sensors are used to record pressures and temperature. The computer will take the parameters and calculate and record various flow rates and line pressures. The measurements are kept digitally on the device. Several calculations are performed and alarm points are set.

This same computer can also be used in other functions such as tank measurements, casing pressures and various other measurements to meet the operator's need. It can be used to operate pumps or plunger lift devices and create alarms when certain values are met. It can also be used to control valves and other equipment.

Data is gathered from computerized meters in various ways. Meters are hooked to laptop computers or certain PDAs. More sophisticated communications can be used such as satellite, radio, phone lines and cellular. The data is transferred to the office computer where it will be stored and accessed for analysis.

Information is taken from the meters and then compared to the operations that have been performed and conditions of the system. For instance, if a well is pumped a meter will show what the resulting gas production is.

Data that has been gathered is used to accurately estimate both the amount of gas that is going into a gas pipeline and also the amount going through the sales meter(s). An estimate of gas line loss is created from the data. This loss can account for gas leaks or usage by compressors or other equipment.

Good pipeline data is useful in determining pressure losses over certain distances. In complex pipeline setups, this data can prove beneficial to determine what will be the likely result from certain events. It may also indicate where bottlenecks are occurring. 
With casing pressure monitors on computerized meters, wellhead casing pressure is recorded. In the natural course of operations, it is common that wells be shut-in for a period of time. This shut-in period could last for a few days to a few weeks. If the pressure is recorded electronically during this time period, reasonably accurate pressure transient test data may be obtained. There are significant factors that may affect the test. These factors will have to be considered when doing the analysis. However, this data may be very useful in identifying problems, or potential improvements.

\section{iv - Tank Measurements}

The traditional means of measuring liquid levels in tanks is to use a stick or tape measure. The level of the liquid is measured manually and recorded. The measurements are usually taken on routine visits by the welltender.

The same computer that is used to meter the gas can often be used to measure the hydrostatic pressure of the liquid column in the oil tank. It can then calculate the approximate liquid level in the tank. With computers, measurements are taken much more frequently, resulting in more detailed information.

Tank data are used to correlate the operations which have been done to the well. 


\section{v. - Example}

The following is an example of a well and the data that has been gathered from it and the potential data that was not gathered. The data that has been gathered is combined to give a more accurate representation of the well.

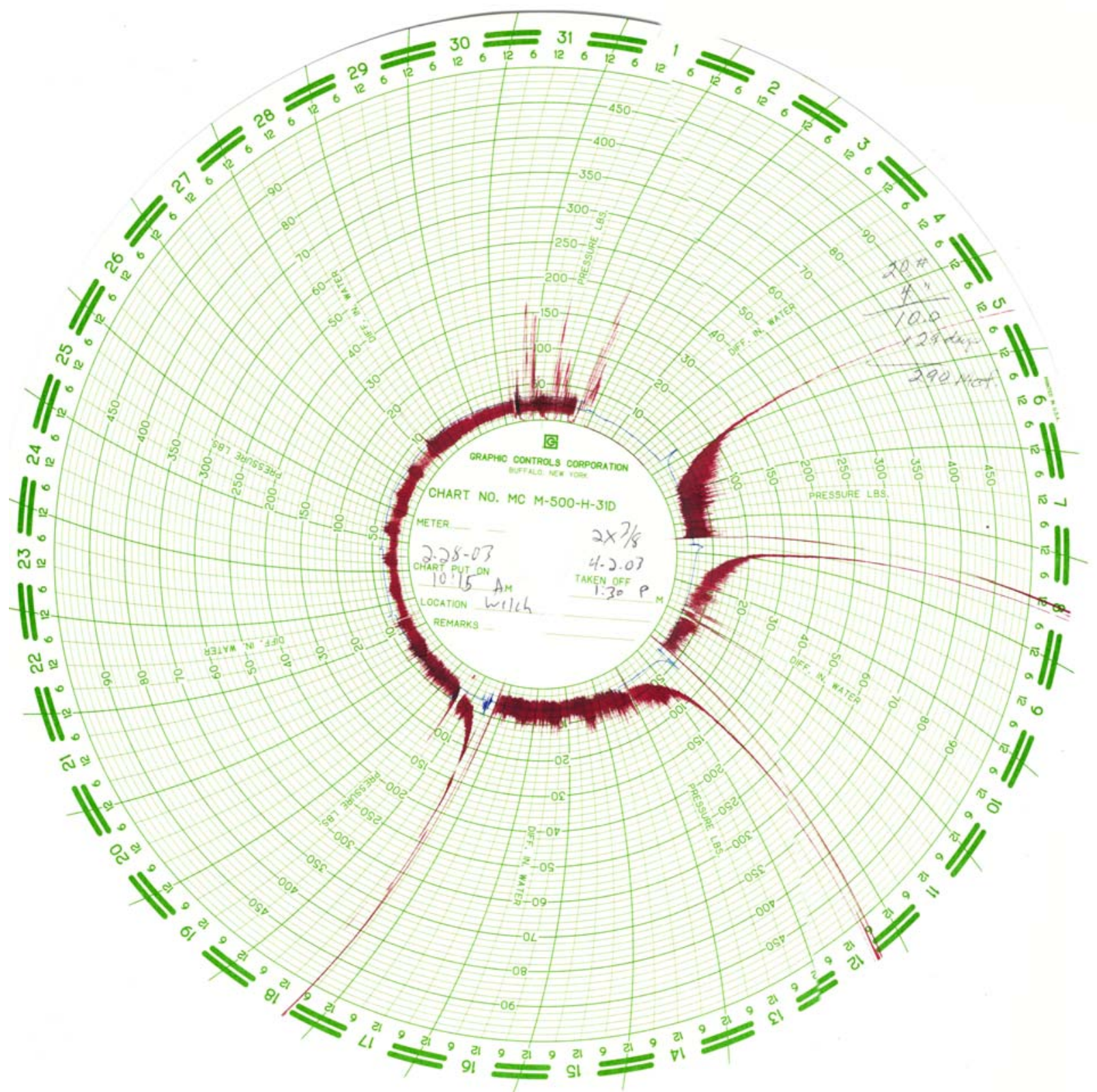

Figure 2 - Example Chart 
Above is an orifice meter chart from the Welch well. The chart was put on the meter on 2-28-03 and taken off on 4-2-03 as recorded. The meter run is 2 in. in diameter with a $3 / 8$-inch orifice plate. The red line represents the differential, which ranges from 0 to 100 inches of water. The blue line represents pressure, which ranges from 0 to 500 psig. The date is on the outer edge of the chart. The dark green lines represent night hours. Below the date and dark green lines is the time.

The welltender changed the chart and measured the tank. The $210 \mathrm{bbl}$. tank measured 5 ft. 1 in. or 70.76 bbl.

When the differential increases as it did on this chart on the $5^{\text {th }}, 8^{\text {th }}, 12^{\text {th }}$, and $18^{\text {th }}$ of the month, the gas rate has increased significantly. In this case the gas rate increase is due to the well being pumped.

Starting on the first day the chart is on the meter (there is an overlap from the end of the month). The differential is spiking which is due to the well producing liquid and gas. The liquid is flowing with the gas up the well between the tubing and casing. A significant amount of gas is required to bring the liquid to the surface. In this case there is not enough gas to lift the liquid. Consequently, the liquid is falling back down the well. The liquid will create hydrostatic pressure on the producing zone. This pressure will not allow for the well to produce as is the case from midnight on the $3^{\text {rd }}$ until the well is pumped on the $5^{\text {th }}$ of the month.

On the $5^{\text {th }}$ the well is pumped for $2 \mathrm{hrs}$. The measurements from the meter were read and the tank was measured again. The tank measured $5 \mathrm{ft} .1 \mathrm{in}$. or $70.76 \mathrm{bbl}$. The chart shows the result of the well's pumping. The differential increases above 100 in. and the pressure increases to 50 psi. For this short period of time the well is producing about $75 \mathrm{mcfd}$. In the 6 hours after the well is pumped, it produced $15 \mathrm{mcf}$ or around $5 \%$ of the month's production. The gas rate decreased rapidly as gas was produced and the well again filled up with liquids.

After midnight on $6^{\text {th }}$ the gas rate has stabilized. This indicates that liquid production has slowed significantly. Liquid has been built up in the annular section of the well causing hydrostatic pressure. This pressure is at the point that mostly gas will be produced.

On the $8^{\text {th }}$ the well is visited again. The tank is measured at $6 \mathrm{ft}$. or $83.52 \mathrm{bbl}$. $12.8 \mathrm{bbl}$. of liquid were produced on the $5^{\text {th }}$. Based on past information, approximately $1 \mathrm{bbl}$ of water and $11.8 \mathrm{bbl}$. of oil were produced. The well was pumped for $2 \mathrm{hrs}$. The resulting rate peak is seen 
again. This peak is slightly smaller than the one on the $5^{\text {th }}$ because the well was not producing gas on the $5^{\text {th }}$ and on the $8^{\text {th }}$ the well had been producing gas.

The well was pumped again on the $12^{\text {th }}$ with similar results to the pumping on the $8^{\text {th }}$. The tank measured $7 \mathrm{ft} .1$ in. or $98.6 \mathrm{bbl}$. $15 \mathrm{bbl}$. of liquid were produced on the $8^{\text {th }}$.

On the $18^{\text {th }}$ the well was pumped again. The well was again pumped for $2 \mathrm{hr}$. However, before the time was up a problem occurred with the engine. The problem was not fixed until the next month. Gas production during the peak was less than what resulted from other pumping operations.

Gas production continued without interruption until the end of the month. The rate was stable since no liquid production affected production.

This interpretation and explanation of this well as been done based on a small amount of information from the welltender and a meter chart. The question left is what information was missed that could have been helpful.

The chart was recorded by an orifice meter. The chart is the only form this data is in. The fluctuating differential value makes it hard to read and likely inaccurate. Comparatively, a computerized meter would have all of the same information already in a computerized format. This data is easily calculated to determine flow rate and total volume. These values could be used to optimize pumping times or frequency.

Tank measurements were taken manually on the next visit to the well. The result was one value that is only as accurate as the person taking the measurement. If a computer sensor was used to measure the liquid in the tank, accurate values would be obtained all the time. From this data the operator could determine if the pumping time was correct.

The amount of time that the employees spent at the well was not recorded. The value of the employee's time cannot be evaluated. By using a PDA in the field this data would have been gathered automatically.

The data that has been gathered does present a picture of the well and an understanding is developed. Although more information would be helpful, the data that was presented is very useful. 


\section{B. Reporting}

A host of reports can be created from the Access database. Additionally, the information can be exported to or linked to various other applications. This availability makes the information versatile and easy to work with and study.

\section{i - Basic Reports}

The basic reports that were created will report the data as it is in the database. These reports will help in maintaining accurate records and in better understanding of the system. Basic reports for the system created can be found in the Appendix D.

\section{ii - Accounting Reports}

Some of the information that is gathered in the field is used in the accounting process. Basically, this information is used to determine expenses and income. Supplies including gasoline, oil, belts and other similar products are billed to each well. The well tender's time and other expenses are billed in some manner to each well. Additionally, equipment expenses such as service rig work or water disposal are added. It would be most-efficient for a considerable amount of this information to go directly to the distribution module. In this manner it would not have to be reentered.

Accurate estimations of overhead costs and an estimate of costs of different operations are created. These numbers are used in economic analysis to determine the best course of action. All of the accounting becomes important to ensure that proper payout is made to investors and adequate records are produced for audits or reviews. Accounting reports are given found in Appendix D.

\section{iii - Engineering}

Production history of wells can be used to predict future production. It is commonplace that the only data to be kept for a long period of time is monthly production data. It is therefore necessary to have several months of production history to create a decline curve. In the case where the well produces a small amount of oil that is shipped months apart, it may take a year to get an accurate picture. 
If record of production is kept digitally on a near daily basis, a decline curve can be created much sooner. The office computer can create the decline curve automatically. Next, it can predict future income based on the decline curve and the previously input price estimates. This data is passed on to economics.

Information that is gathered in the field will become very beneficial in determining possible future projects. Accurate production and expense estimates will help identify areas that have been profitable in the past and may be profitable in the future.

There are usually several things that can be done to a well which hold promise to increase production. The question always becomes whether any of these operations will be profitable.

For instance, a well's production has declined more than expected. The cause is attributed to paraffin accumulation at critical points. Possible treatments include hydraulic fracturing, solvent injection, hot oil treatment, and doing nothing. Each of the options will have some cost and some effect. Being able to accurately estimate the production and cost of the operation will allow a better decision to be made.

Field data is used to identify problems before they become too detrimental. Accurate records of equipment, pumps, and other things, will hold the possibility of taking corrective action at the time when it will be most economical.

Data is used to track the efficiency of its pumping jack mechanisms. For example, wells are set on timers and run for a certain period of time every few many days. The welltenders will record the speed of the pumps, as well as the time that the pumps are running. This data are then used in conjunction with data about the well's setup to track the efficiency of each pump. In this manner, if a pump gradually operates with less efficiency, adjustments to the duration can be made. Additionally, speed adjustments can be made to ensure better pump life and efficiency.

Another consideration for a company is to ensure that their compressors are being cared for properly. Often, different people will check and do maintenance on compressors. It is therefore necessary to keep records and to make those records available. Engineering reports are given in Appendix D. 


\section{iv - Economics}

Economic analysis is a fundamental part of any business. A good economic report will present the financial status of operations. It will show where money is being made or lost and show potential modifications and their results.

The basis of an economic report is to accumulate gathered data. It brings together information from accounting and engineering reports to create a comprehensive report. These reports project the future income, project potential incomes or net present value. The amount of production is gathered along with the proceeds from its sale. The amount that is spent on royalties, taxes, supplies, labor, and several other expenses is factored in. The current prices as well as predicted prices, future production and expense estimates are needed.

All of the information that has been gathered is put into reports and graphs so that it is easily understood and managed. The end result is presented to a management team, who will review it and make changes or decisions based on the information available to them. Accounting reports are given in Appendix D.

\section{v - Investor Updates and Reports}

Companies will often have outside investors or work in conjunction with outside companies. Therefore, there is great importance in providing an accurate and detailed summary of the operation.

Investor reports can be automatically sent from the office computer at specified times. They may report production figures, expenses or any number of other items. They can be set up to be sent through email, fax, or mail.

Ideally the system should provide an easy-to-understand summary of the operation, then would follow up with a very detailed, nearly overwhelming amount of data. As long as the reports are easy to understand and explain themselves, the investor should be satisfied that they are well informed.

In instances where potential buyers are looking at the operation or at certain assets, easily accessible data becomes very valuable. Detailed and summarized data is presented quickly and at minimal cost. This will add value to the assets in question to the buyer, since it will reduce the uncertainty. 


\section{vi - Environmental}

As part of the Spill Prevention Control and Countermeasure plan (SPCC), it is necessary to keep accurate records of operations related to crude oil storage, rain water removal, and well waste water disposal. Conditions of secondary containment systems (such as dikes and pits) are monitored to ensure they are operating properly and would work if a spill were to occur.

Detailed and accurate records will also be useful to prove proper precautions are being taken to protect the environment.

The SPCC plan outlines the possibility of spills that may result on any location. A plan is developed on how to deal with such spills and the possible ramifications of them. Measures are taken to minimize the environmental impact.

\section{vii - Safety}

An accurate representation of time required to do operations will point to excessive speed in doing things. This suggests that employees are rushing to finish their job, cutting corners, or traveling to fast.

Employees' exposure to certain chemicals or noise also should be accounted for. Since some field situations may be hazardous to the health of an employee, it is important to know the extent to which the employees are exposed to these situations.

\section{viii - Employee Relations}

Tracking the actions of employees can also be beneficial. It is important to know how they manage their time. There may be simple steps that could be taken to improve their overall efficiency.

When hiring a new employee a detailed analysis of what other employees are doing will help to represent what will be expected. Records of how many hours are spent doing different types of work is a useful tool to present to the new employee.

\section{ix - Management}

Management will use the information that has been gathered and analyzed to make decisions. The intention of the system is to obtain the most profit from the operation as possible. 
The economic and logistical information is made available such that the decision making process is substantially easier.

The responsibility of management reports is to communicate decisions to the appropriate employee. These reports will include instructions as well as a detailed explanation of why. 


\section{Data Availability}

The gathered data should be made available to anyone that might find benefit from it. The head of the operations should have access to all of the information gathered in the system and everyone else should have access to all of the information on the projects they work on.

This availability of data will give everyone involved in the operation a better understanding of the business. They will be better informed and better able to do their job because of their increased knowledge. Data is made available in the form of printed reports, viewable databases, and/or internet databases. 


\section{IX - Results and Discussion}

The system which was developed to gather data from oil and gas field operations obtains vital information. The system is extremely useful in monitoring operations and planning future developments. In spite of the complexities of the system, it is easy to use and to gain necessary data. A database is used to store and sort data based on user input.

The result of this work shows that data is obtained from the field in a petroleum production operation. The use of handheld computers proves to be the best way to obtain data. Through all of the difficulties from the situation, they offer the more efficient manner of obtaining data. The other methods are also available, but for the most part the amount of detail and flexibility of handheld computer devises will be better.

The programs created in this study can be used to gather a large amount of data. This data is detailed, accurate, and can be recorded quickly. By using the system, the data can be used to perform analysis and create reports.

The data that is gathered from the system is used for many different processes in the areas of engineering, accounting, economic, etc. With the availability of data that was previously disregarded or unobtainable, new processes can be developed. These processes may not be complex, but they will likely present data in a understandable, useful manner. All of these processes should work to bring data and knowledge together into a comprehensive report.

The result of this study shows the utmost importance that information be gathered and used. Data is the basis for most of the decisions that are made in daily operations. More accurate data will result in better decisions. 


\section{$\mathrm{X}$ - Conclusion}

The technology and resources are available to create a sophisticated and detailed information-gathering system for oil and gas field data. The data is used in a number of different ways. Detailed analysis is performed with data from different disciplines.

Considerable development can be done to develop progressively better information systems in the oil and gas field. These developments hold promise to enhance the profitability of the current operations.

Business of the future will necessitate the use of progressive, technological innovations to stay competitive. These technologies will increase efficiency of the business. In a complex business such as oil and gas production operations, technological advancements are essential.

In this paper, the development of a software system, which sets the groundwork to gather data necessary to perform detailed analysis of an oil and gas field operation was developed for handheld computers and a database program was set up to manage and store the data that was gathered in the field. 


\section{XI - References}

1. Gates, Bill. Business @ the Speed of Thought, Warner Books, Inc. 1999.

2. Mallick, Martyn. Mobile and Wireless Design Essentials, Wiley Publishing, Inc. 2003.

3. Mobile Planet, www.mobileplanet.com, 2004.

4. Syware, Inc., Visual CE v8.0 - Software and Help Sections. 2003.

5. Microsoft Corporation. Microsoft Access 2000. 1999.

6. Greenhill, K.L. and J.A. Dennison, Texaco Inc. "Programming Considerations of a Production Data-Acquisition System” SPE paper 22289, Dallas, TX. 1991.

7. Boone, Douglas M. “Experience of Collecting Daily Production Data Using Handheld Devices and the Internet” SPE paper 67264, Oklahoma Cit, OK. 2001.

8. Butler, T.G. and R.C. Hedges, Texaco Inc., and L. Gonsalves and N.S Bowlin, Texaco U.S.A. “A Management System for Gas-Gathering Systems” Paper SPE 21726, Dallas, TX. 1991.

9. Boone, D. M. “Field Reporting Through the Internet” SPE paper 52181, Oklahoma Cit, OK. 1999.

10. Schlumberger website, http://www.sis.slb.com.

11. Moore, J.B. “Oilfield Surveillance with Personal Computers.” Shell California Production Inc. SPE paper 13632, Silver Creek, CO. 1986.

12. Quentin, K. M. and A. D. Creamer. "Rig Site Drilling Program Hand-Held Computer.” SPE paper 15284, Silver Creek, CO. 1986.

13. Caswell, G.R., A.C. Mogensen, and M.D. Trick. “A Comparison of Forecasting Methods for Gas Production,” SPE paper 56694, Houston, TX 1999.

14. Thompson, Robert S. and John D. Wright. Oil Property Evaluation, Thompson - Wright Associates, 1985.

15. Agbi, B. and M.C. Ng. “A Numerical Solution to Two-Parameter Representation of Production Decline Curve Analysis” SPE paper 16505, Montgomery, TX. 1987.

16. Chen, Her-Yuan, Lawrence W. Teufel. "Estimating Gas Decline - Exponent Before Decline - Curve Analysis.” SPE paper 75693, Alberta Canada. 2002. 
17. McCray, A. \& W., A. G. Comer, "Statistical Basis for Choice among Hyperbolic Decline Curves and Computer Application in Calculating Confidence Limits of Reserve Prediction,” SPE paper 1930, Houston, TX. 1967.

18. Jochen, V. A, and J. P. Spivey, "Probabilistic Reserves Estimation Using Decline Curve Analysis with the Bootstrap Method,” SPE paper 36633, Denver, CO. 1996.

19. Locke, C. D., and L. A. Schrider, “A Unique Approach to Oil-Production Decline Curve Analysis with Applications,” SPE paper 2224, Houston, TX. 1968.

20. Harrison, G.H. “A Generalization of Production Decline Type Curves,” SPE paper 11020, New Orleans, LA. 1982.

21. Aminian, K., S. Ameri, N. Beg, and A.B. Yost. "Production Forecasting for Gas Wells Under Variable Conditions,” SPE paper 16939, Dallas, TX. 1987.

22. Li, Kewem, and Roland N. Horne. "A Decline Curve Analysis Model Based on Fluid Flow Mechanisms,” SPE paper 83470, Long Beach, CA. 2003.

23. Poston, S.W., H.Y. Chen, "Fitting Type Curves to Austin Chalk Wells," SPE paper 21653, Oklahoma City, OK. 1991.

24. Lee, John, and Robert A. Wattenbarger. Gas Reservoir Engineering, Society of Petroleum Engineers inc. 1996.

25. Sides, Charles H. How To Write \& Present Technical Information. The Oryx Press, 1991.

26. Top Drilling Corporation and related companies (primarily, Whittle Corporation, Petrolux Energy Corporation). Various records, reports, interviews, experiences, and software packages. Smithville, WV. 2000 - 2004.

27. Term Energy Corporation. Harrisville, WV (Interview with employees.) August 2004.

28. Key Energy Corporation. Weston, WV (Interview with employees.) August 2004. 


\section{XII - Appendices}

\section{A - Data Flow Chart}

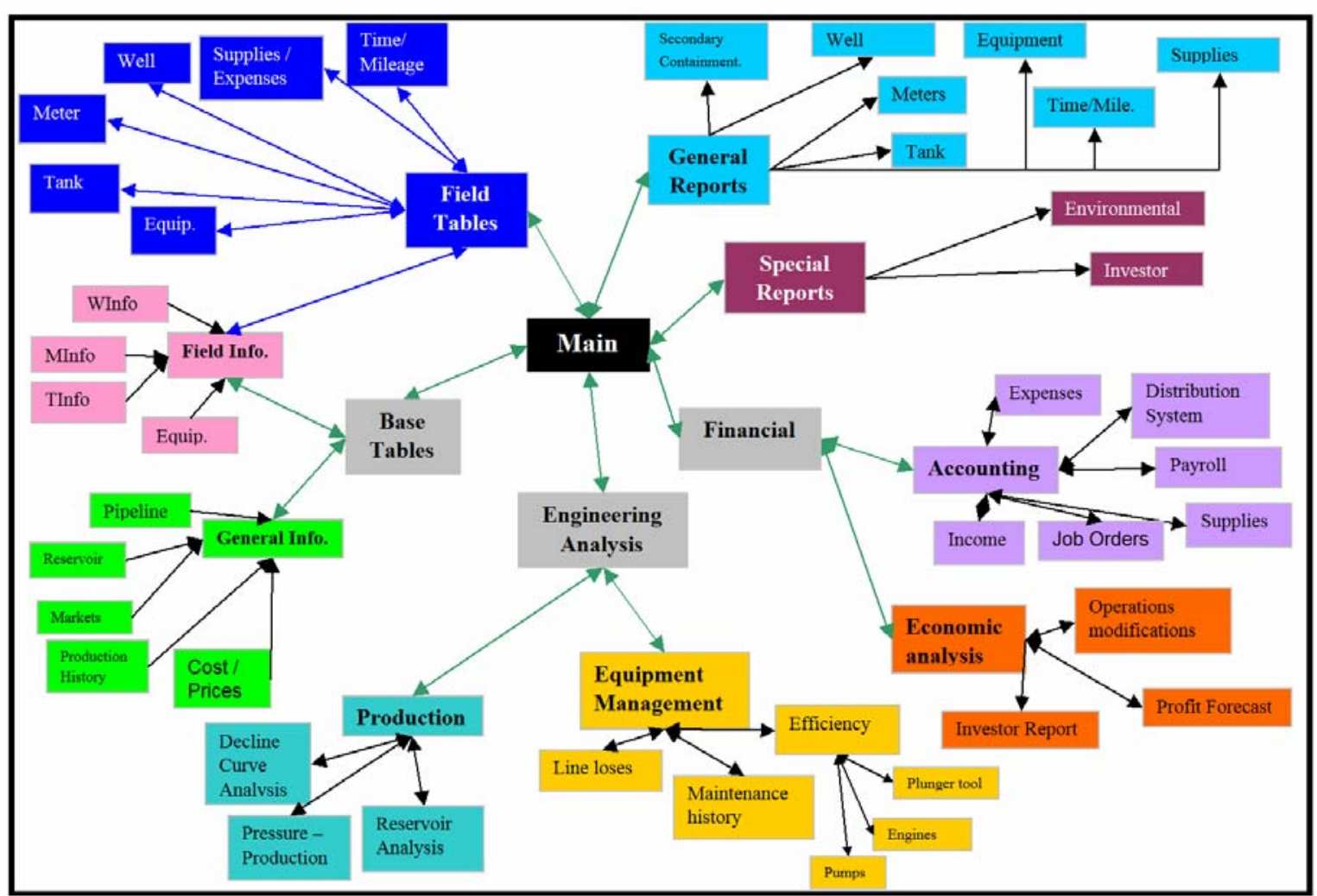

Figure 3 - Data Flow Chart

Figure 4 represents an ideal flow of data through the system. Information should flow automatically from one point to the destination; however in this project, completion of this system is not possible due to the logistical complexities. Certain areas were completed to demonstrate the possibility of the data gathering system.

The center box "Main” is the central point of the system and the individual areas are accessed. The field tables represented above were developed for the data gathering portion of this project. These tables have data that is gathered and/or used in the field. This information will be accessed by other areas. The "Base Tables" portion contains information that is input in the office and used by other areas.

“General Reports” is a section that creates simple reports based on field information. 


\section{B - Tables and Data Explanation}

\begin{tabular}{|c|c|c|c|c|c|c|c|c|c|c|c|c|c|c|c|c|}
\hline & Input Tables & & & & & & & & & & & & & & & \\
\hline$a$ & Mileage & & Date & Number & Name & Miles & $\mathrm{Em}$ & loyee & & & & & & & & \\
\hline$b$ & SecCon & xcount & Date & Number & Name & Note & Drain & Condition & & & & & & & & \\
\hline c & Supplies & & Date & Number & Name & Note & Supply & Amount & & & & & & & & \\
\hline$d$ & Timesheet & & Date & EmpN & umber & Employea & Note & Hours & Mileage & & & & & & & \\
\hline e & Wells & xcount & Date & Number & Name & Note & Work & Pump & Time & Spe & $\mathrm{ed}$ & $\mathrm{Cas}$ & sing & Tub & ing & \\
\hline$f$ & Equipment & xcount & Date & Number & Name & Note & 1 & 2 & 3 & 4 & 5 & 6 & 7 & 8 & 9 & 10 \\
\hline$g$ & Meters & xcount & Date & Number & Meter & Note & MCFD & $a$ & $b$ & $\mathrm{C}$ & $d$ & & & & & \\
\hline $\mathrm{h}$ & Tank & xcount & Date & Number & Name & Note & $\mathrm{Ft}$ & $\ln$ & Water & $\mathrm{BC}$ & & & & & & \\
\hline & Output Tables & & & & & & & & & & & & & & & \\
\hline i & Einfo & Number & Name & Note & $\mathrm{n} 1$ & $\mathrm{n} 2$ & n3 & $\mathrm{n} 4$ & n5 & $\mathrm{n} 6$ & $\mathrm{n} 7$ & t8 & t9 & t10 & & \\
\hline j & Minfo & Number & Name & Note & MID & Sale & Type & O. Size & O.Factor & $a$ & $\mathrm{~b}$ & $\mathrm{C}$ & $\mathrm{d}$ & & $\mathrm{nPrC}$ & Cor \\
\hline k & Supplies List & Supply & Code & & & & & & & & & & & & & \\
\hline I & Tinfo & Number & Name & blin & Size & Height & & & & & & & & & & \\
\hline $\mathrm{m}$ & WInfo & Number & Name & $\mathrm{API}$ & perviceRid & TD & Perfs & Casing & Tubing & Rod & Otl & her & & LOCa & ation & \\
\hline
\end{tabular}

Figure 4 - Input/Output Fields

Figure 4 is an outline of the parameters in each table that is used in the database. The "Input Tables" contain data recorded in the field. The "Output Tables" are the tables that store basic data for reference in the field and office. Each of the tables contains the "OID” and “Timestamp” fields, but they are not shown in the above outline. They are automatically updated by the program. "OID” is the identification number used by the handheld software to identify each record. "Timestamp" is used by the handheld software to determine if a record has been updated.

\section{Input Tables:}

All of the input tables contain a section labeled "Date" which records the date and time that the record was created. All but the “Timesheet” table contain the fields "Number" and "Name". These specify the number and name of the respective item. "Note" is a field that will store a short text message about the record. "xcount” is used in many of the tables. It stores a time based number which will allow the tables on the recording forms to be sorted in reverse date order. The program writes to this field.

a. Mileage: This table runs the Mileage form, which stores the mileage records of each employee. The miles and employee number are recorded in their respective fields.

b. SecCon: This is the table that stores data for the Secondary Containment form. The amount of water drained from the pit is recorded as well as the condition of the pit. 
c. Supplies: This table runs the Supplies form, which records the supplies that are used, such as gasoline or motor oil. "Supply" is the name of the unit which is used. "Amount" is the quantity that was used.

d. Timesheet: This is the table that records similar to a traditional paper timesheet. “EmpNumber” and "Employee” contain the number and name of the employee. "Hours" records how long the employee has worked and "Mileage” records the amount of mileage, which the employee is submitting.

e. Wells: This table contains records for the Well form. They are recorded specifically from the well. "Work" records the type of operations which were performed such as pumping or location maintenance. "PumpTime" is used to record the amount of time which a pump was run. "Speed" is the speed at which the pump is running. "Casing" and "tubing” are the pressures which are on the casing and tubing respectively. .

f. Equipment: This table stores records for the Equipment form. The name, number, and a note is recorded. Additionally, ten other fields are used to record data. The fields can change how the number is step up on the "Equip" table. When a number is entered on the "Equipment” form the program matches that number on the "Equip” table and displays the fields that will be recorded.

g. Meters: This table stores records from the "Meters" form. "MCFD” is the calculated gas rate in thousand standard cubic feet per day. “a”, “b”, “c”, and "d” are fields that may vary depending on the meter. Similar to the "Equipment" form the field names are looked up on the "MInfo" table. For instance, “a” will be pressure, "b” will be differential, and the others will be blank. At the next meter, "a” will be pressure, "b” will be feet per minute, and "c" will be the reading. In this manner different type of meters is recorded on the same form.

h. Tank: The "Tank" table stores data from the "Tank" form. "Ft" is the height in feet of the liquid in the tank and "In" is the remaining inches of the measurement. These two are added together in inches and multiplied by the barrels per inch of the tank to determine the calculated "BOL” or barrels on location. 


\section{Output Tables}

All but the "Supplies List" table contain a "Number" and "Name” field. These are the number and name of each respective item. "Note" is a field that will store a short text message about the record.

i. Equip: This table stores information about equipment that is not covered by the other tables. The fields "n_" and "t_" are ten fields that store the field names of the data to be stored on the "Equipment” form. The first seven that begin with " $n$ ” are number fields and the last three that begin with " $\mathrm{t}$ ” are text fields.

j. Minfo: This table stores data about the meters. It runs the "MInfo" form and is used on the "Meters" form. The MID number which is commonly assigned to meters. It is used for identification purposes often outside the company. "Sale" is the company which is purchasing the gas. "Type” is the type of meter (orifice, roots). "OrificeSize” is the size of the orifice plate in the meter. "OrificeFactor" is the orifice factor which will be used to calculate the gas rate. “a”, "b”, “c”, and "d” are the four fields that tell what is to be recorded in the "Meter" form. "AtmPrCor" is the atmospheric pressure correction, which is needed in the gas rate calculation.

k. Supplies List: This table stores the supplies that appear on the "Supplies" form. "Supply" is the name of the supply. "Code" is used for accounting purposes but is not necessary.

1. TInfo: This table stores data about the tanks. "blin” is the barrels per inch number used to calculate BOL. "Size" contains the size of the tank and "Height" contains the height of the tank.

m. WInfo: This table stores data about the wells. "API” is the API number of the well. "ServiceRigNotes" is a field that is used to keep notes that would be beneficial to a service rig. "TD" is the total depth of the well. "Perfs" is the depth of the perforations in the casing. “Casing”, “Tubing”, and "Rods” are the sizes of each, if present. “Other” is an open field that is used to record other equipment that may be in the well. "Location" gives directions to the location of the well. 


\section{C - Access Database Screenshots}

The following is a description of the Access Database that was set up for the system. The key concepts of the basic operation of the system will be described. Pictures of important parts will be displayed.

All of the forms and queries are unlocked for editing. New items are created to meet new demands. All of the information can be exported to another program or copied from the tables.

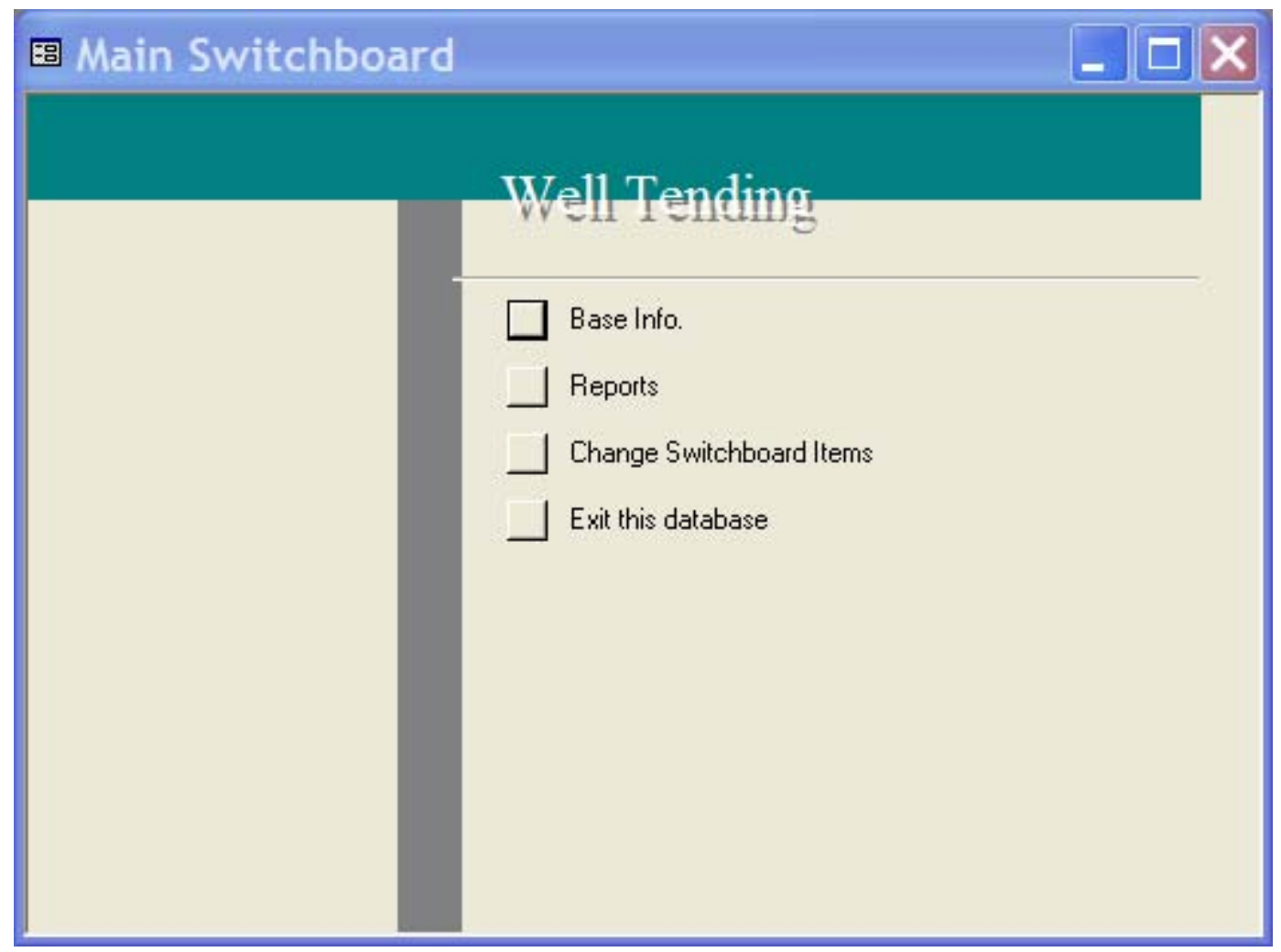

Figure 5 - Main Switchboard

The database will open displaying the Main Switchboard. The first two options will open their respective switchboards. The third option will go to a program that will change or add functions on the switchboard. The final option will close the database. 


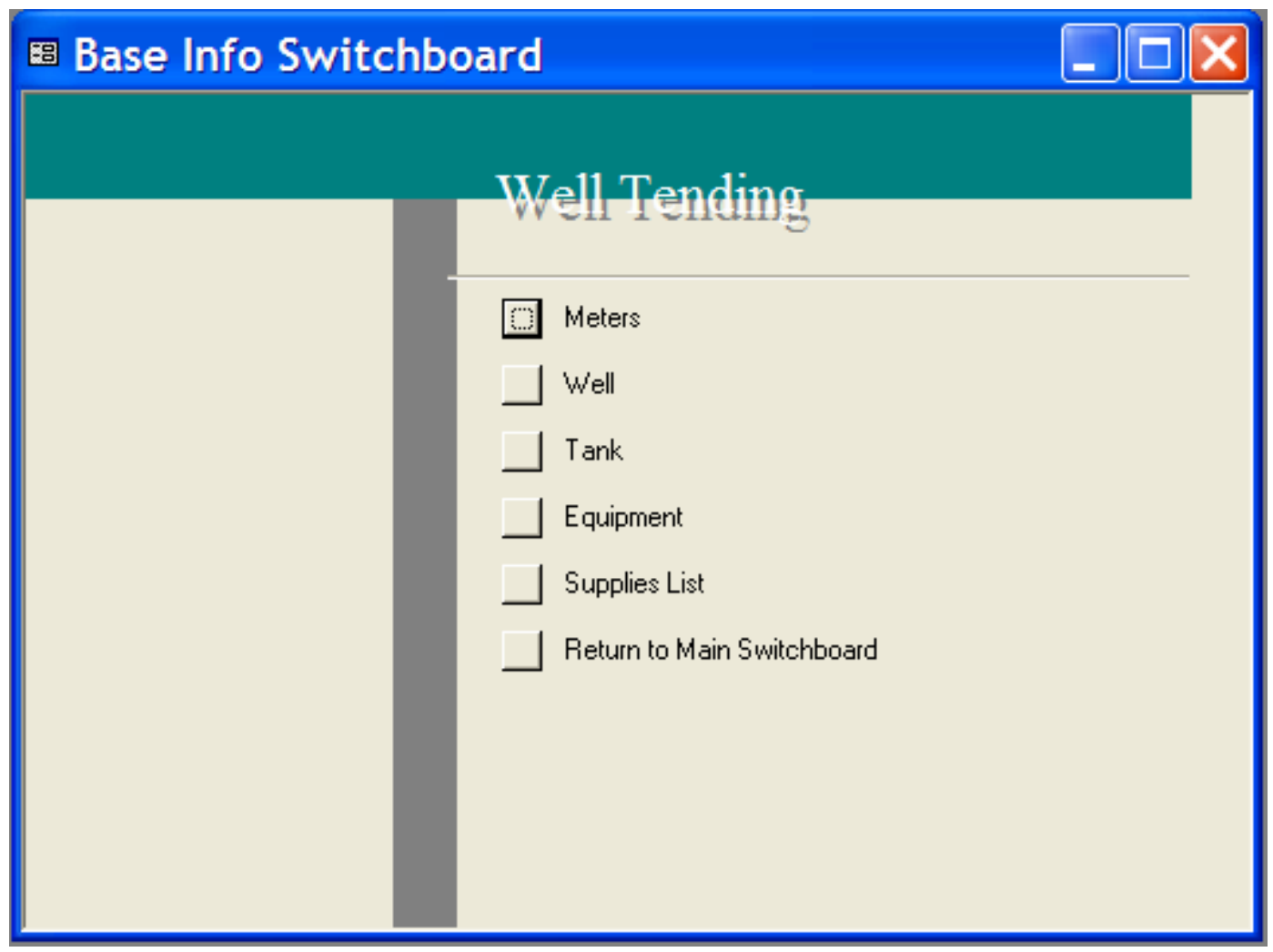

Figure 6 - Base Info Switchboard

The options on the Base Info Switchboard open the various forms which run the tables containing the basic information on each of the parameters. These make up the input tables. They contain the basic information that is used to match the name and other information to the number.

Each of the forms will be described later and the related tables were described in Appendix B. 


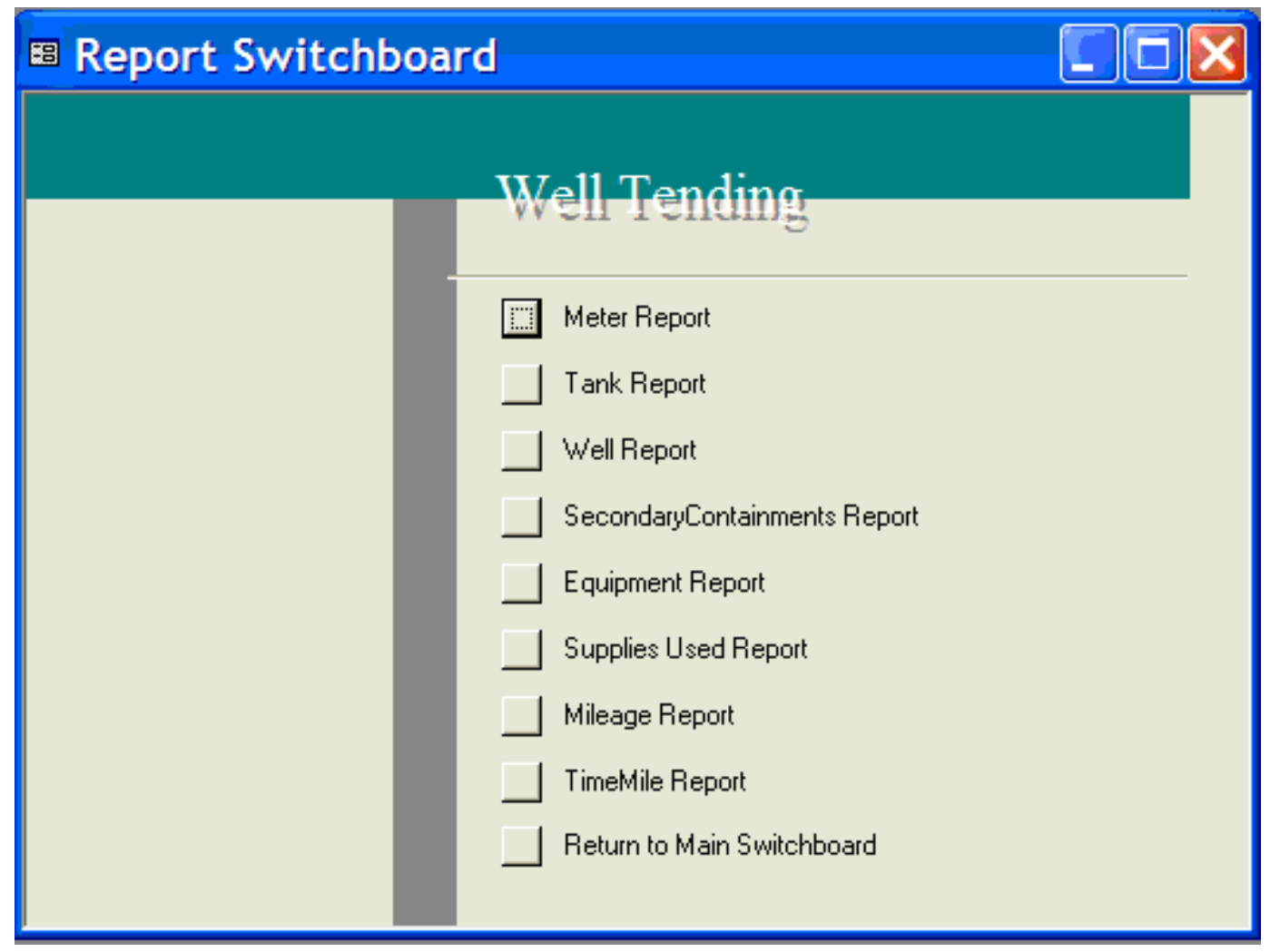

Figure 7 - Report Switchboard

The Report Switchboard contains options to open various reports. The first box (Figure 8) that is opened is a form in which the limiting dates are entered. The report is then opened. Pictures of these reports are in Appendix D. The final Option will return to the Main Switchboard. 


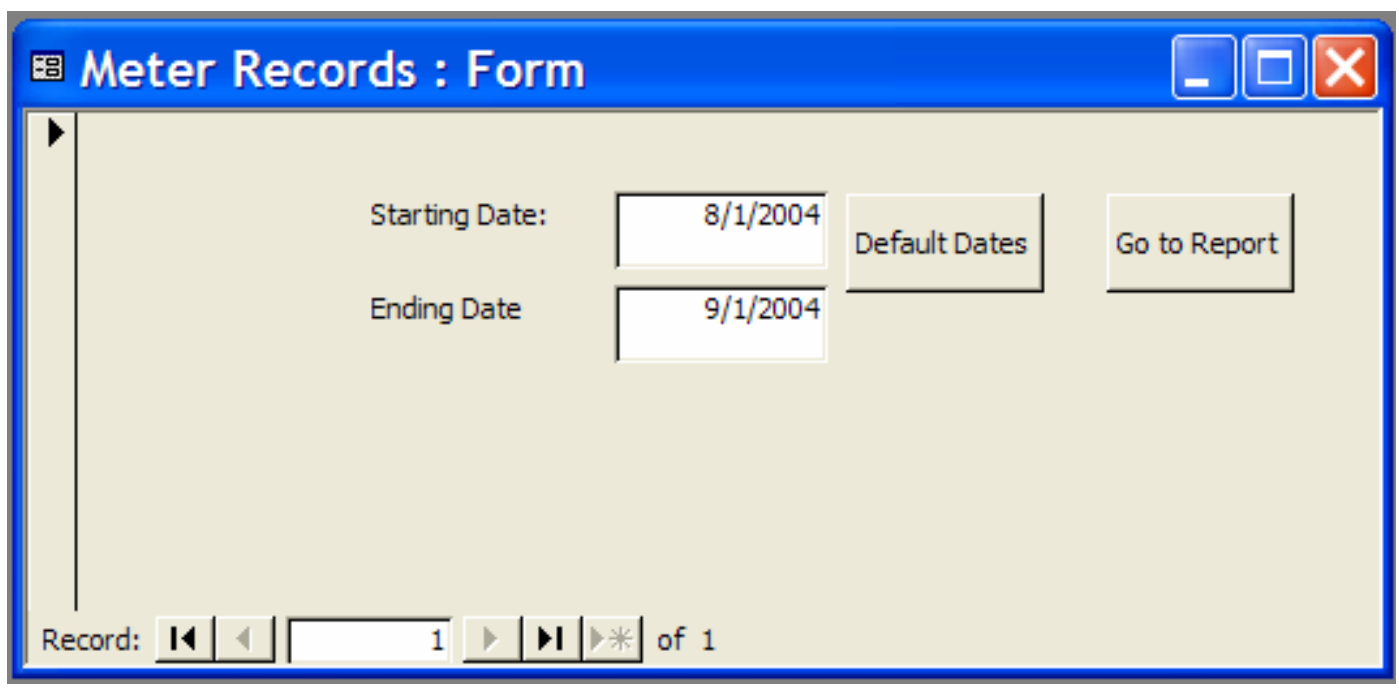

Figure 8 - Meter Records: Form

This form is used to specify the date range of reports and then to open that report.

Forms were created for entering and editing data on the output tables. Each of the text boxes are labeled appropriately with their respective field name. The "Update” command button which is found on all of the forms will place the current time and date in the "Timestamp" field. The “Timestamp” field must be updated whenever the record is added or updated so that the handheld computer will be updated. 


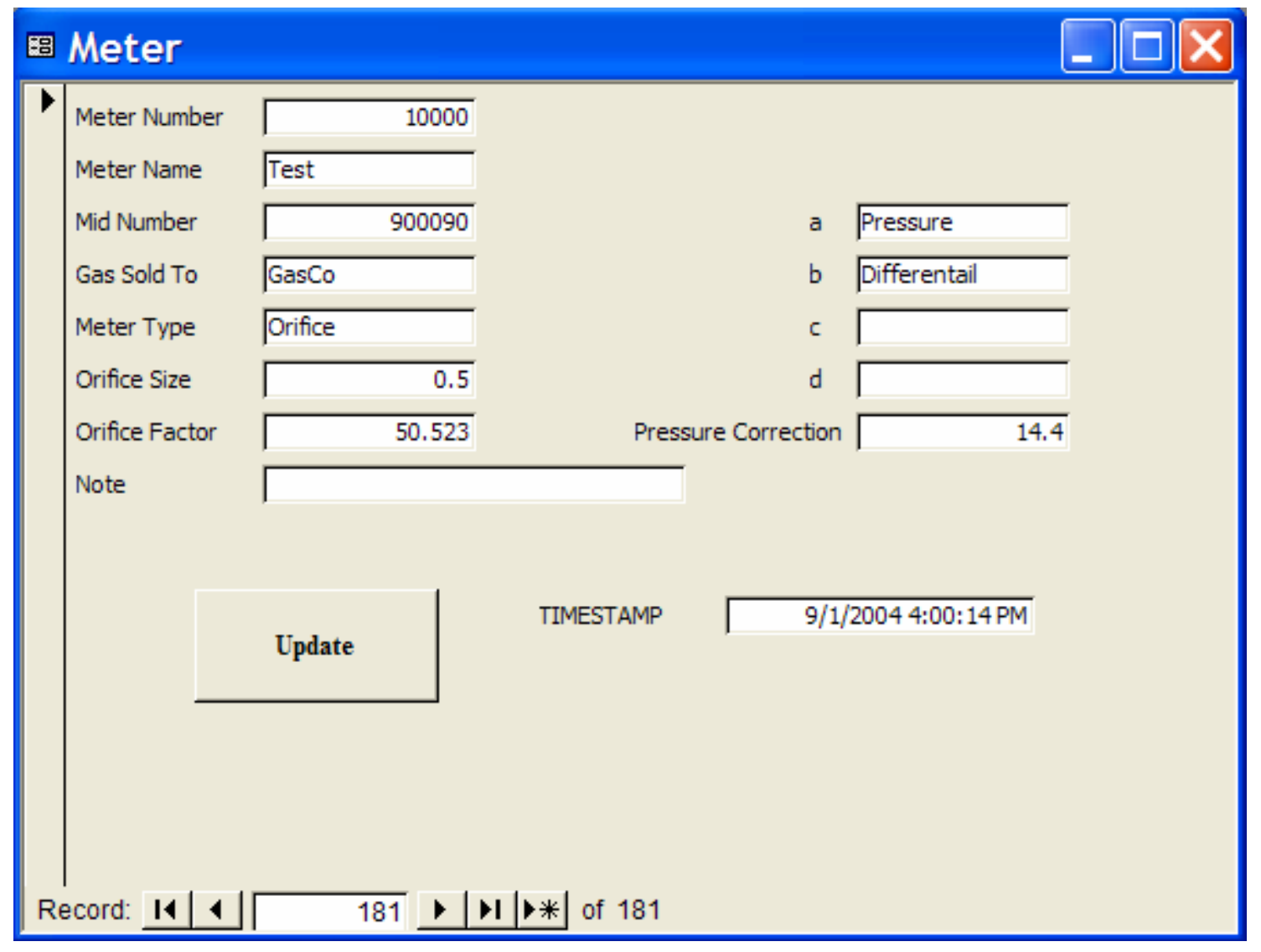

Figure 9 - Meter - Input Form

Figure 9 shows the form that runs off of the MInfo table described in Appendix 2.j. The information about the meters is changed or added from this form. 


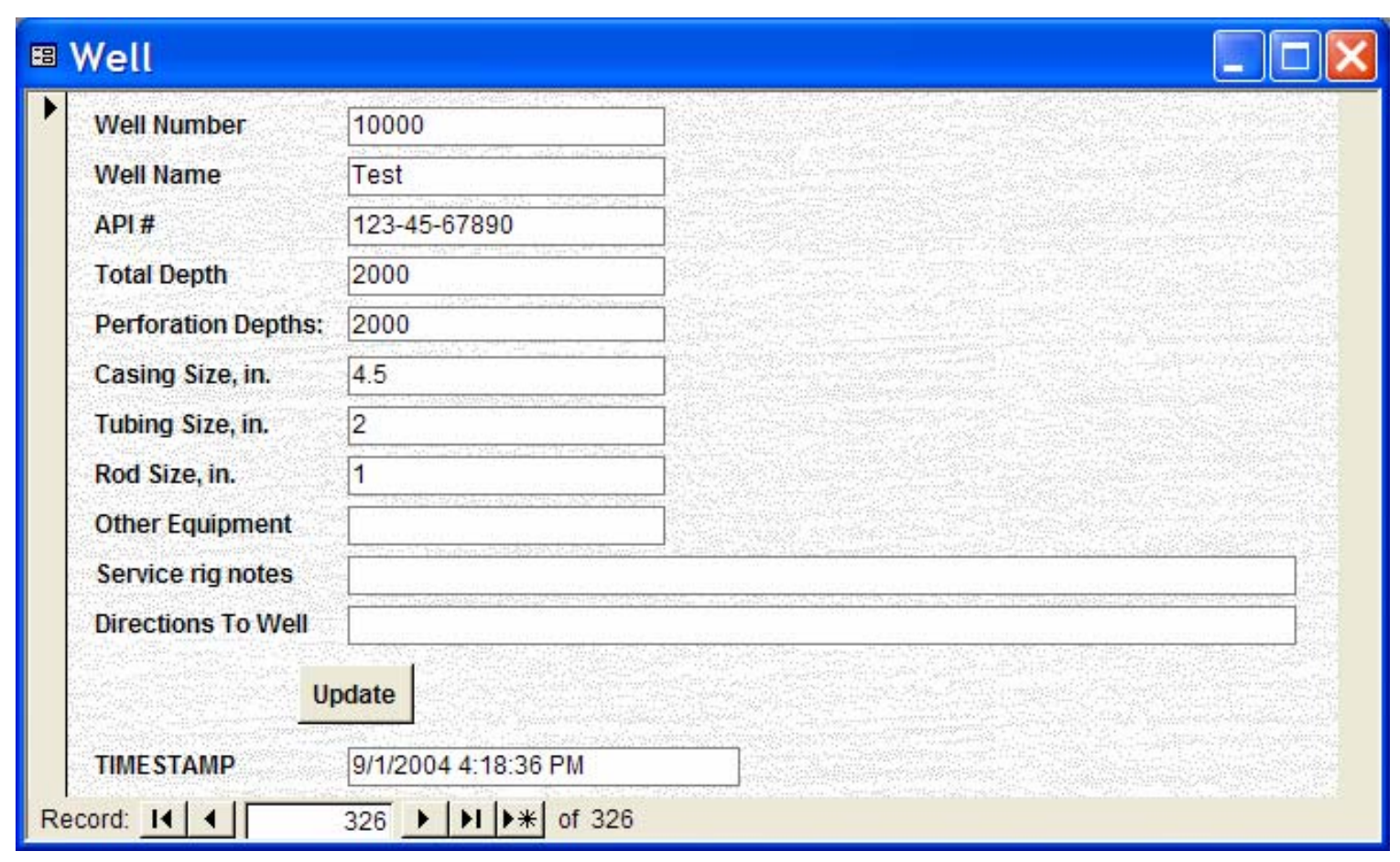

Figure 10 - Well - Input Form

Figure 10 shows the form that runs off of the WInfo table described in Appendix B.m. The basic well information is entered and edited from this form.

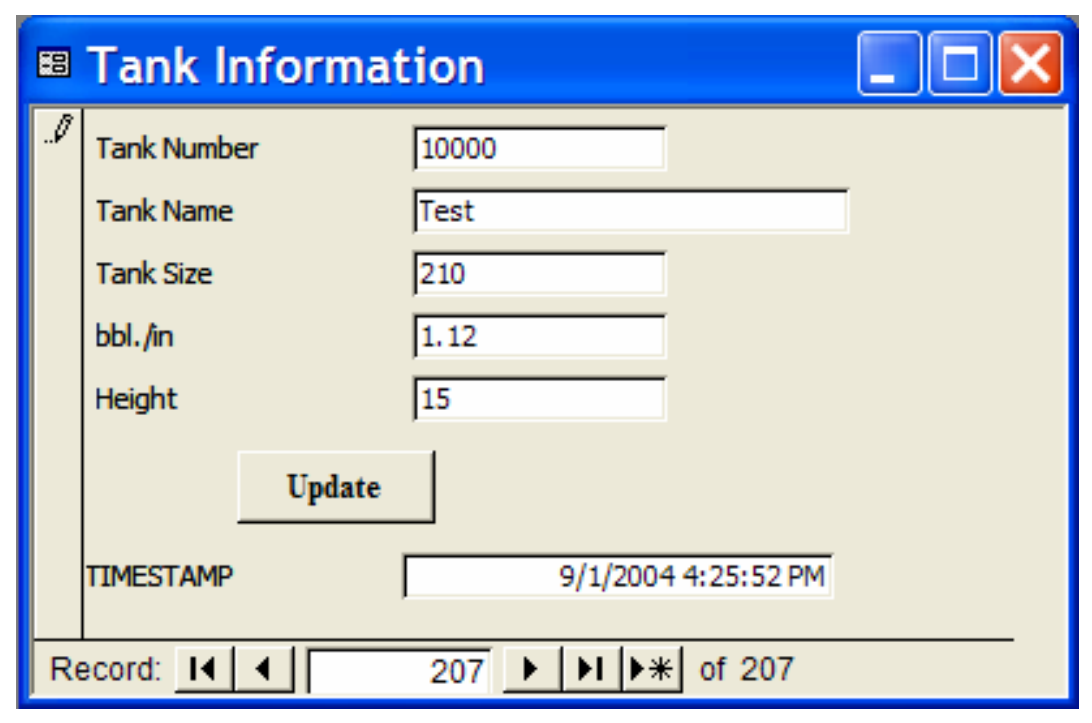

Figure 11 - Tank - Input Form

Figure 11 shows the form that runs off of the TInfo table described in Appendix 2.l. Information about the tank can be added or edited from this form. 


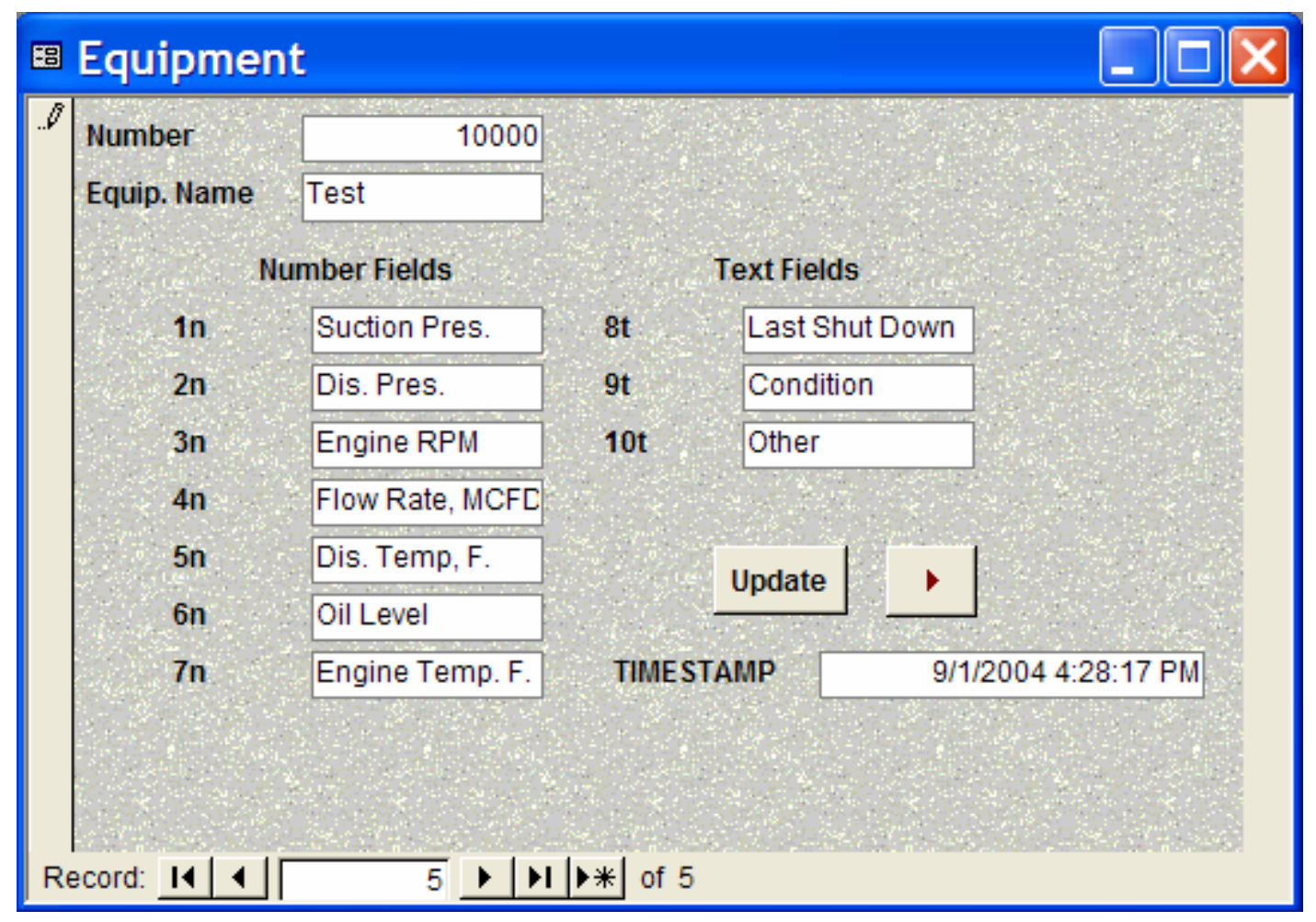

Figure 12 - Equipment - Input Form

Figure 12 shows the form that runs off of the EInfo table described in Appendix B.f. This table is where records about the equipment can be stored.

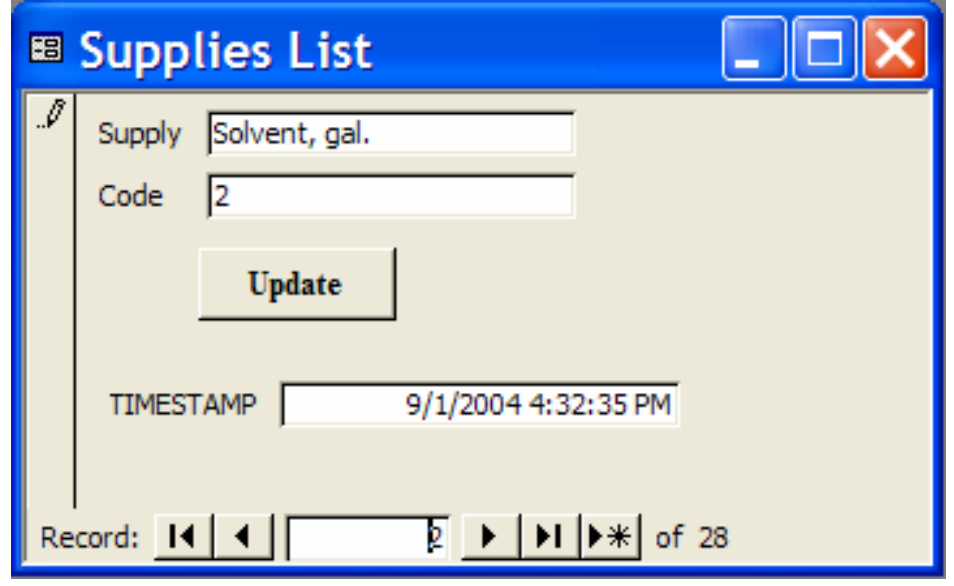

Figure 13 Supplies List Form

Figure 13 shows the form that runs off the Supplies List table described in Appendix B.c. The supplies that will be used are contained in this table. 


\section{$D$ - Reports}

The reports in the section are used to illustrate the use of data that has been gathered. All of the data is simulated. It is by no means intended to be a comprehensive analysis of an operation.

\section{General Reports}

The "Time and Mileage" report is given Figure 14. Like the rest of the reports in this section, the Title of the report is on the top left and the date range is on the right. The employee's name is listed followed by the date of the record and the recorded mileage and hours. At the bottom of the report is the time the report was created and the number of pages of the report.

Figure 15 shows a typical "Supplies" report. The standard information is at the top and bottom of the page. The well's name is listed followed by the type of supply, the date, and the quantity used. A total is given for each item.

A the "Well Site Records" report is given in Figure 16. The standard information is at the top and bottom of the page. The well's name is listed followed by the operations performed, pump time, pump speed, and casing and tubing pressures.

Figure 17 is the "Meter Readings” report. The standard information is at the top and bottom of the page. The meter's name is listed followed by the date, the measured values and the calculated rate in MCFD.

A “Tank Records” report is given in Figure 18. The standard information is at the top and bottom of the page. The tank's name is listed followed by the date, the measured height of the liquid, and the calculated volume.

Figure 19 shows "Equipment” report. The standard information is at the top and bottom of the page. The equipment's name is listed followed by the date and the recorded values.

Figure 20 is the "Pit Records" report. The standard information is at the top and bottom of the page. The tank's name is listed followed by the date, the volume drained from the pit and the condition of the location. 


\section{Time and Mileage}

Starting Date: $\quad 8 / 30 / 2004$

Ending Date: 9/30/2004

\begin{tabular}{ccl}
\hline Date & Mileage & Hours \\
\hline \hline Employee & Jay & \\
$9 / 6 / 2004$ & 10 & 8.00 \\
$9 / 7 / 2004$ & 14 & 7.50 \\
$9 / 8 / 2004$ & 38 & 8.00 \\
$9 / 9 / 2004$ & 30 & 8.00 \\
$9 / 10 / 2004$ & 40 & 10.00 \\
$9 / 13 / 2004$ & 0 & 8.00 \\
$9 / 14 / 2004$ & 15 & 9.50 \\
$9 / 15 / 2004$ & 29 & 8.00 \\
$9 / 16 / 2004$ & 25 & 7.50 \\
$9 / 17 / 2004$ & 20 & 8.00 \\
$9 / 18 / 2004$ & 10 & 3.00 \\
$9 / 20 / 2004$ & 40 & 8.00 \\
$9 / 21 / 2004$ & 5 & 8.00 \\
$9 / 22 / 2004$ & 66 & 8.00 \\
$9 / 23 / 2004$ & 35 & 8.50 \\
$9 / 24 / 2004$ & & 8.25 \\
\hline & 23 & 126.25 \\
\hline
\end{tabular}

\section{Employee Will}

$\begin{array}{lll}9 / 6 / 2004 & 5 & 8.00 \\ 9 / 7 / 2004 & 12 & 7.50 \\ 9 / 8 / 2004 & 67 & 8.00 \\ 9 / 9 / 2004 & 12 & 8.00 \\ 9 / 10 / 2004 & 96 & 10.00 \\ 9 / 13 / 2004 & 32 & 8.00 \\ 9 / 14 / 2004 & 59 & 9.50 \\ 9 / 15 / 2004 & 33 & 8.00 \\ 9 / 16 / 2004 & 67 & 7.50 \\ 9 / 17 / 2004 & 12 & 8.00 \\ 9 / 18 / 2004 & 50 & 3.00 \\ 9 / 20 / 2004 & 12 & 8.00 \\ 9 / 21 / 2004 & 56 & 8.00 \\ 9 / 22 / 2004 & 29 & 8.00 \\ 9 / 23 / 2004 & 16 & 8.50 \\ 9 / 24 / 2004 & 26 & 8.25\end{array}$

Total: $584 \quad 126.25$

Figure 14- Time and Mileage Report 


\section{Supplies}

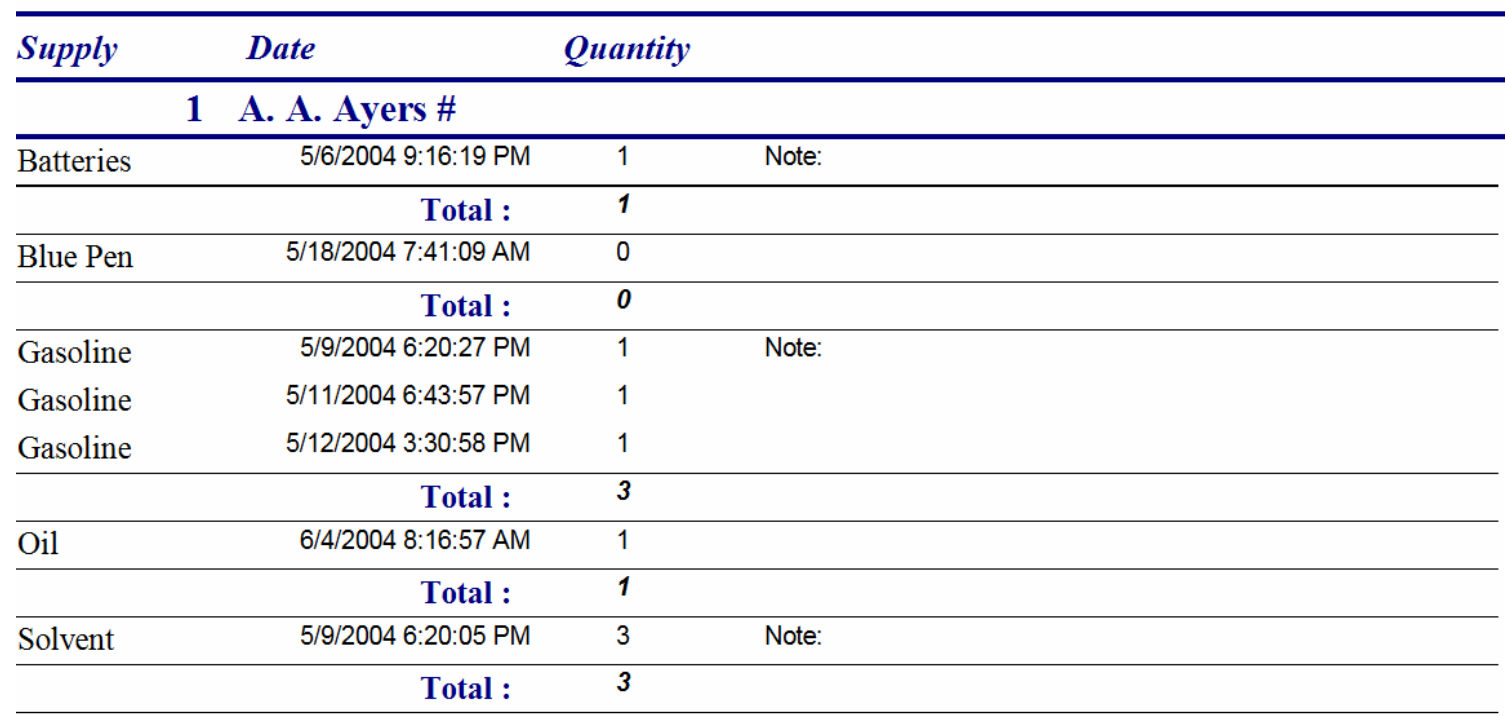

\section{Bonner \#1}

\begin{tabular}{|c|c|c|c|}
\hline Blue Pen & 5/11/2004 5:51:59 PM & 1 & Note: \\
\hline Blue Pen & 5/11/2004 6:00:30 PM & 1 & Note: \\
\hline Blue Pen & 5/11/2004 6:31:16 PM & 1 & \\
\hline
\end{tabular}

\section{$7 \quad$ Eddy 7}

\begin{tabular}{cccc}
\hline Band Clamps & $5 / 15 / 2004$ 4:45:54 PM & 2 & Note: \\
\hline Total : & 2 & \\
\hline Blue Pen & 5/18/2004 7:36:54 AM & 2 & \\
\hline Total : & 2
\end{tabular}

\section{Morris Oil \#1}

\begin{tabular}{rrr}
\hline Gasoline & $5 / 11 / 20046: 33: 00 \mathrm{PM}$ & 1 \\
\hline Total : & $\mathbf{1}$ \\
\hline
\end{tabular}

\section{Davis Gas Co}

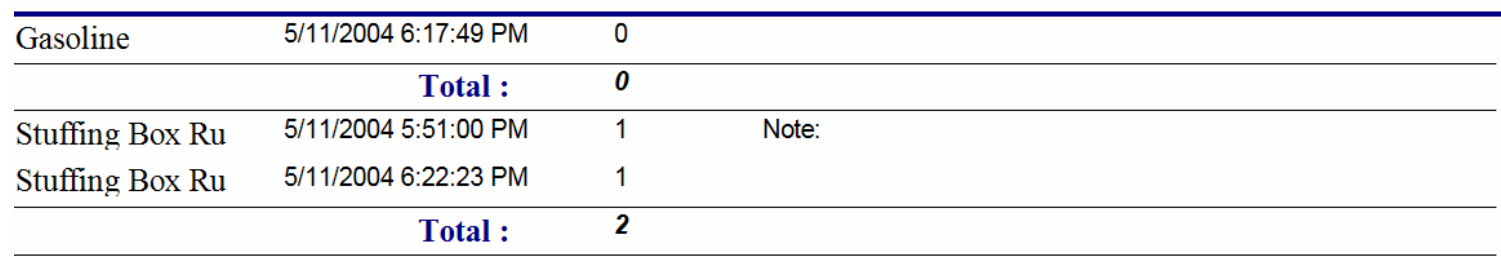

Figure 15 - Supplies Used 


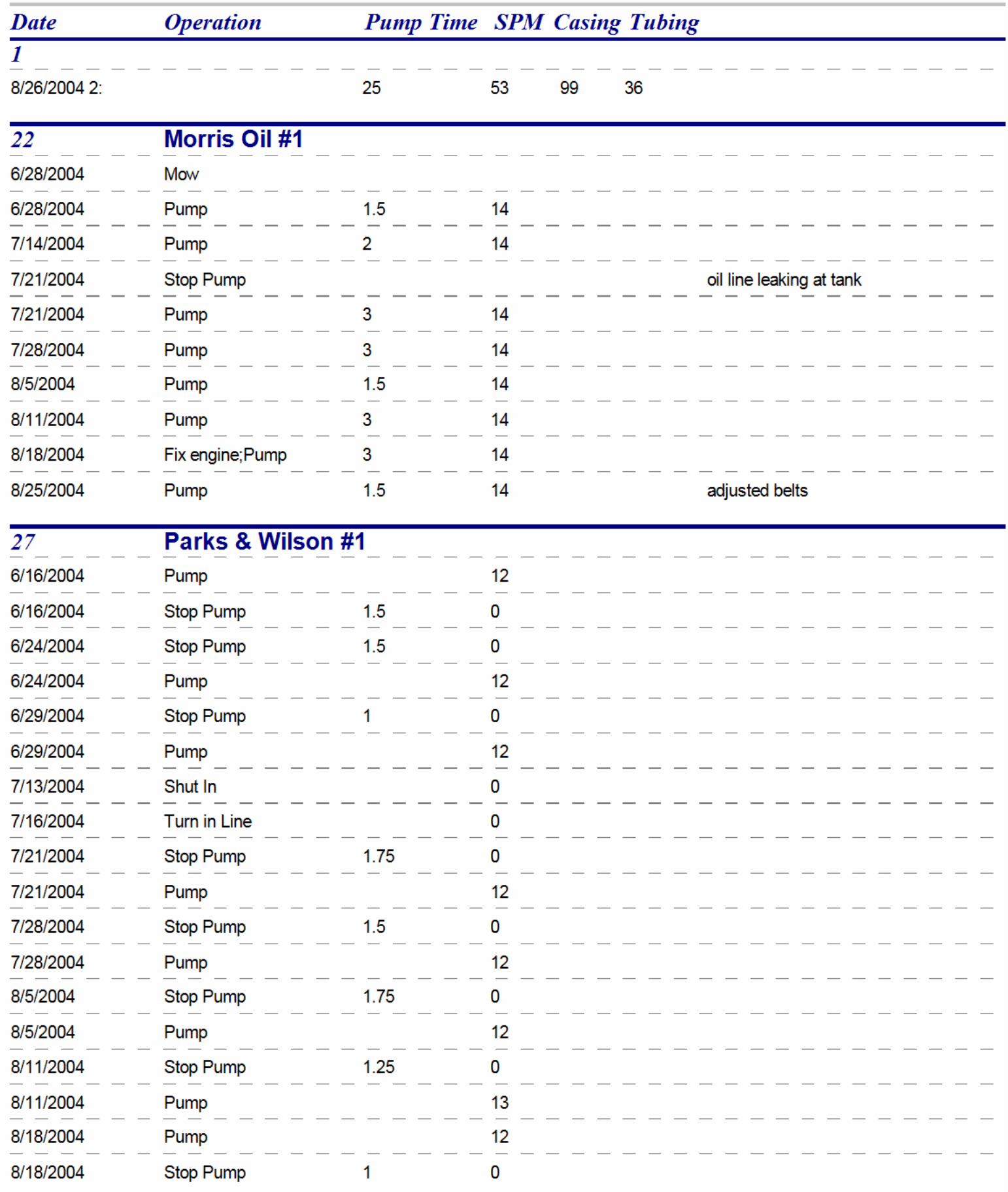




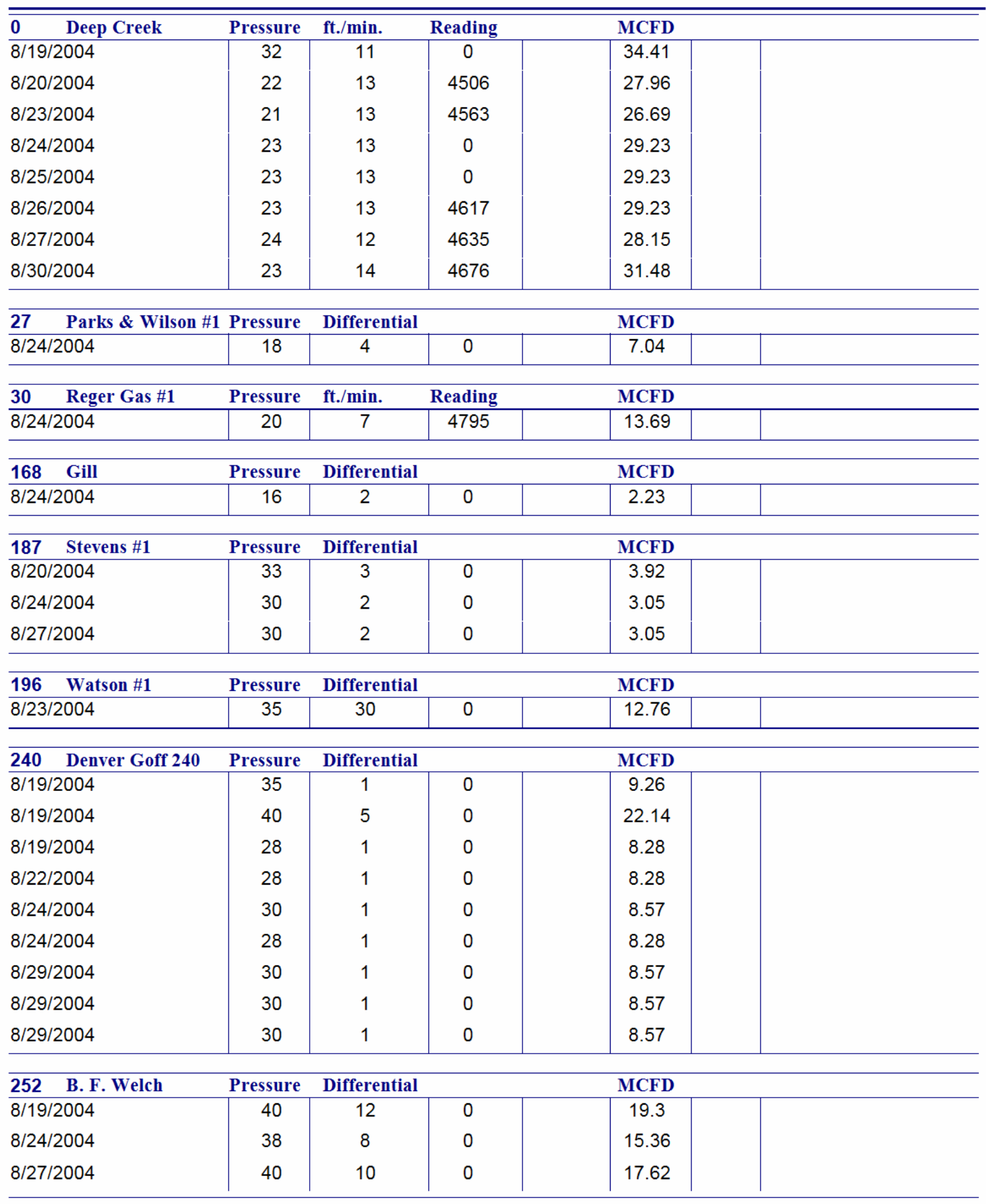




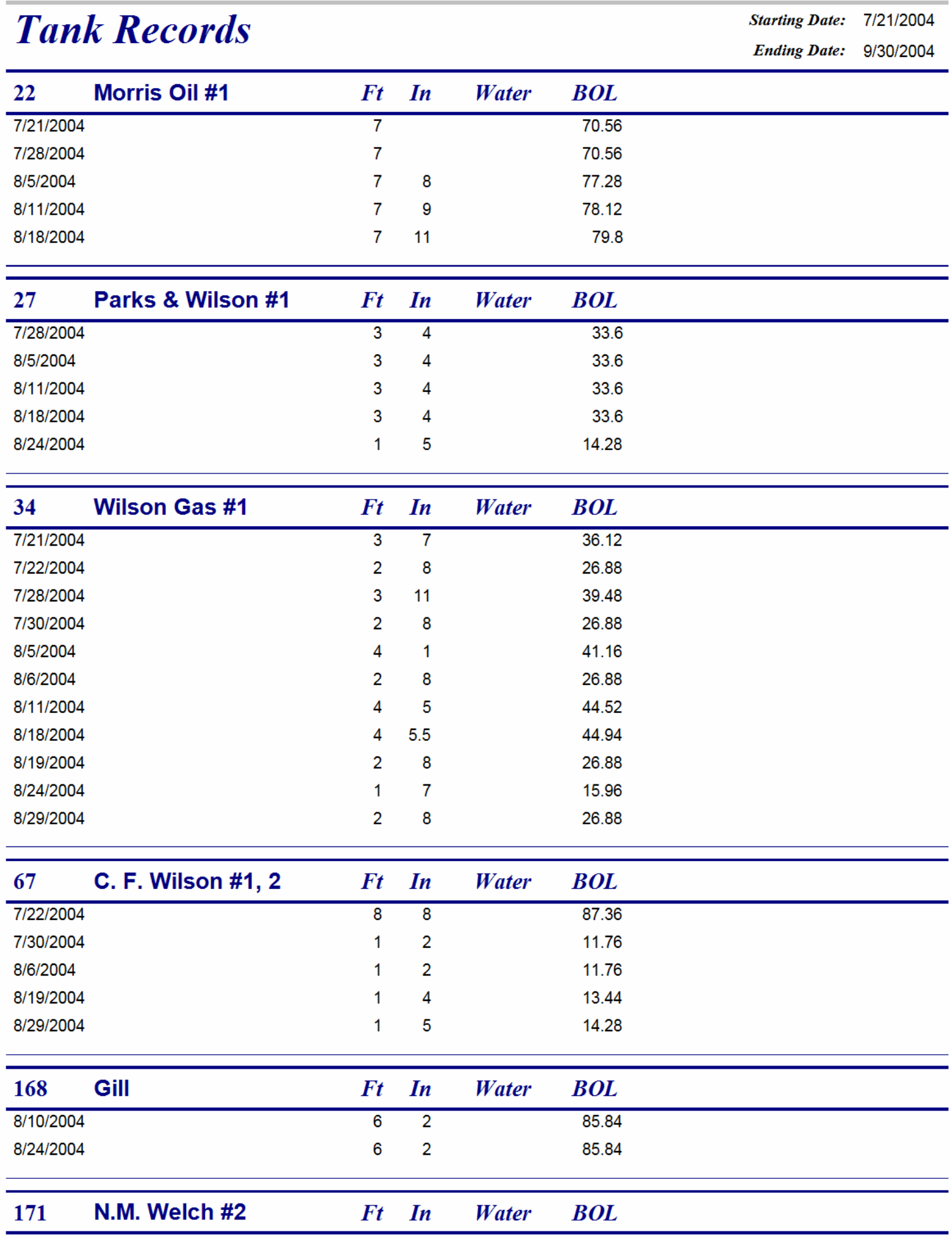

Thursday, September 30, 2004

Page 1 of 11

Figure 18 - Tank Records Report 


\section{Equipment Report}

1 Compressor \#1 Repair 12-15

Suction $\operatorname{Pr}$ Dis. Pres. Engine RP Flow Rate, Dis. Temp, Oil Level Engine Te Last Shut Condition Other

\begin{tabular}{lllllllllll}
\hline $6 / 4 / 20046: 24:$ & 20 & 90 & 2500 & 200 & 90 & 2 & 300 & $1 / 6 / 2004$ & ok \\
\hline $6 / 5 / 20046: 24:$ & 18 & 95 & 2500 & 208 & 90 & 2 & 300 & $1 / 6 / 2004$ & ok & \\
\hline $6 / 6 / 20046: 24:$ & 17 & 90 & 2500 & 180 & 90 & 2 & 300 & $1 / 6 / 2004$ & ok \\
\hline $6 / 7 / 20046: 24:$ & 20 & 87 & 2500 & 213 & 90 & 2 & 300 & $1 / 6 / 2004$ & ok & \\
\hline $6 / 8 / 20046: 24:$ & 22 & 80 & 2500 & 205 & 90 & 2 & 300 & $1 / 6 / 2004$ & ok \\
\hline $6 / 9 / 20046: 24:$ & 16 & 87 & 2500 & 200 & 90 & 2 & 300 & $1 / 6 / 2004$ & ok \\
\hline $6 / 10 / 20046: 24$ & 28 & 93 & 2500 & 189 & 90 & 2 & 300 & $1 / 6 / 2004$ & ok & \\
\hline $6 / 11 / 20046: 24$ & 21 & 98 & 2500 & 200 & 90 & 2 & 300 & $1 / 6 / 2004$ & ok & \\
\hline $6 / 12 / 20046: 24$ & 20 & 80 & 2500 & 190 & 90 & 2 & 300 & $1 / 6 / 2004$ & ok & \\
\hline $6 / 13 / 20046: 24$ & 25 & 90 & 2500 & 230 & 90 & 2 & 300 & $1 / 6 / 2004$ & ok & \\
\hline $6 / 14 / 20046: 24$ & 19 & 95 & 2500 & 200 & 90 & 2 & 300 & $1 / 6 / 2004$ & ok
\end{tabular}

10 Compressor \#10 Repair 12-15

\begin{tabular}{|c|c|c|c|c|c|c|c|c|}
\hline & Suction $\mathrm{Pr}$ & Dis. Pres. & Engine RP & Flow Rate, Dis. Temp, Oil Level & Engine Te & Last Shut & Condition & Other \\
\hline 6/4/2004 6:24: & 7 & 20 & & 5 & & $6 / 3 / 20042$ & & yes \\
\hline 6/6/2004 9:00: & 7 & 18 & & 5 & & $6 / 3 / 20042$ & & yes \\
\hline 6/7/2004 8:10: & 6 & 17 & & 5 & & \multicolumn{3}{|c|}{ 6/7/2004 6: no } \\
\hline 6/9/2004 8:00: & 7 & 20 & & 5 & & 6/8/2004 6: & & yes \\
\hline $6 / 11 / 20048: 00$ & 7 & 22 & & 5 & & 6/8/2004 6: & & yes \\
\hline $6 / 13 / 20048: 00$ & 5 & 16 & & 5 & & & $6 / 13 / 2004$ & no \\
\hline
\end{tabular}

\begin{tabular}{lll}
\hline 100 & Truck \#4 & Water Truck
\end{tabular}

\begin{tabular}{llllll} 
& Vol. Loade & Load Time & Source & Destination Liquid \\
\hline 6/1/2004 3:53: & 55 & 20 & smith well & Shop & Water \\
\hline $6 / 4 / 20046: 24:$ & 60 & 20 & Compress & Shop & Water \\
\hline $6 / 12 / 20043: 48$ & 60 & 20 & smith well & Shop & Water \\
\hline $6 / 16 / 20043: 40$ & 57 & 20 & Compress & Shop & Water
\end{tabular}

Figure 19 - Equipment Report 


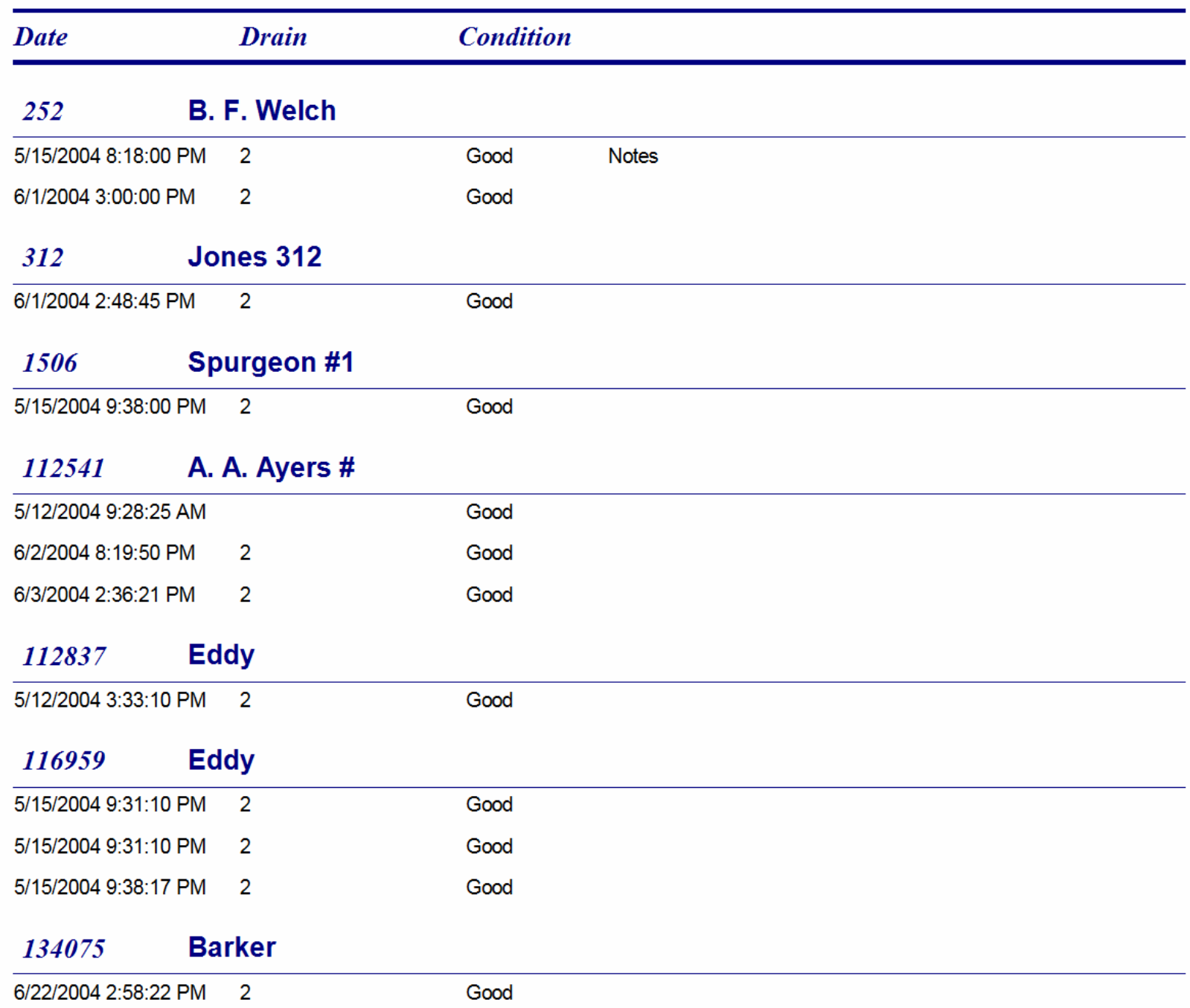

Figure 20 - Pit Records Report 


\section{Accounting}

\section{In-house Gas Transmition Cost \\ Test Pipeline}

\begin{tabular}{|lc|}
\hline Age & \multicolumn{1}{c|}{5 years } \\
Installation Cost & $\$ 50,000$ \\
Current Value & $\$ 30,000$ \\
\hline Depreciation & $\$ 166.67 / \mathrm{mon}$ \\
& \\
Average Per Month & \\
\hline Volume & $10000 \mathrm{MCF}$ \\
Maintenance & $\$ 500$ \\
Metering & $\$ 50$ \\
Compression & $\$ 200$ \\
Compression & $\$ 0.000 \quad / \mathrm{mcf}$ \\
\hline & \\
\hline
\end{tabular}

Figure 21 - Gas Transport Cost

This table is used to calculate the cost of transporting gas. A price per MCF is calculated based to the listed parameters.

Water Disposal Cost

\begin{tabular}{|lc|}
\hline Age & \multicolumn{1}{c|}{2 years } \\
Installation Cost & $\$ 5,000$ \\
Current Value & $\$ 4,500$ \\
\hline Depreciation & $\$ 10.42 / \mathrm{mon}$ \\
& \\
Average Per Month & \\
\hline Volume & $500 \mathrm{bbl}$ \\
Maintenance & $\$ 200$ \\
Testing & $\$ 20$ \\
Permits & $\$ 10$ \\
Supplies & $\$ 0.25 / \mathrm{bbl}$ \\
Transport & $\$ 1 / \mathrm{bbl}$ \\
\hline Total Cost & $\$ 1.73 \mathrm{bbl}$ \\
\hline
\end{tabular}

Figure 22 - Water Disposal Cost

This table is used to calculate the cost of disposing of well water. 


\section{Effective Price Calculation}

\begin{tabular}{|l|c|c|}
\hline \multicolumn{1}{|l|}{} & \multicolumn{1}{|l|}{ Oil } \\
\hline Market Price & $\$ 5.00 / \mathrm{btu}$ & $\$ 30.00 / \mathrm{bbl}$ \\
Volume & $1 \mathrm{MCF}$ & $1 \mathrm{bbl}$ \\
BTU factor & $1.300 \mathrm{btu} / \mathrm{mcf}$ & \\
Line Loss & $5 \%$ & \\
Compressor & $5 \%$ & \\
Trans. L.L. & $13 \%$ & $\$ 0.25 / \mathrm{bbl}$ \\
Trans. Cost & $\$ 0 / \mathrm{mcf}$ & \\
\hline I.H. Trans. Cost & $\$ 0.092 / \mathrm{mcf}$ & $\$ 29.75$ \\
\hline Sales Point Price & $\$ 4.91$ & $12.50 \%$ \\
& & $3.13 \%$ \\
\hline Royalty & $12.50 \%$ & $0 \%$ \\
Overriding Royalty & $3.13 \%$ & $\$ 0.00 / \mathrm{mcf}$ \\
other & $0 \%$ & $\$ 25.10$ \\
other & $\$ 0.00 / \mathrm{mcf}$ & $0 \%$ \\
\hline Taxable & $\$ 4.15$ & \\
Tax & $0 \%$ & $\$ 25.10 / \mathrm{bbl}$ not discounting expense \\
\hline Effective Price & $\$ 4.15 / \mathrm{mcf}$ & \\
\hline
\end{tabular}

Figure 23 - Effective Price Calculation

The objective of this report is to calculate the price of oil and gas that is expected. These prices should provide an accurate value representing the price that will come from production. 


\section{Engineering Report Pump Efficiency}

The object of determining the pump efficiency is to indicate a problem that needs to be dealt with. Potentially, adjustments need to be made or service work performed. The volume that is expected to be pumped is calculated. The actual volume is divided by this number to determine the efficiency. 


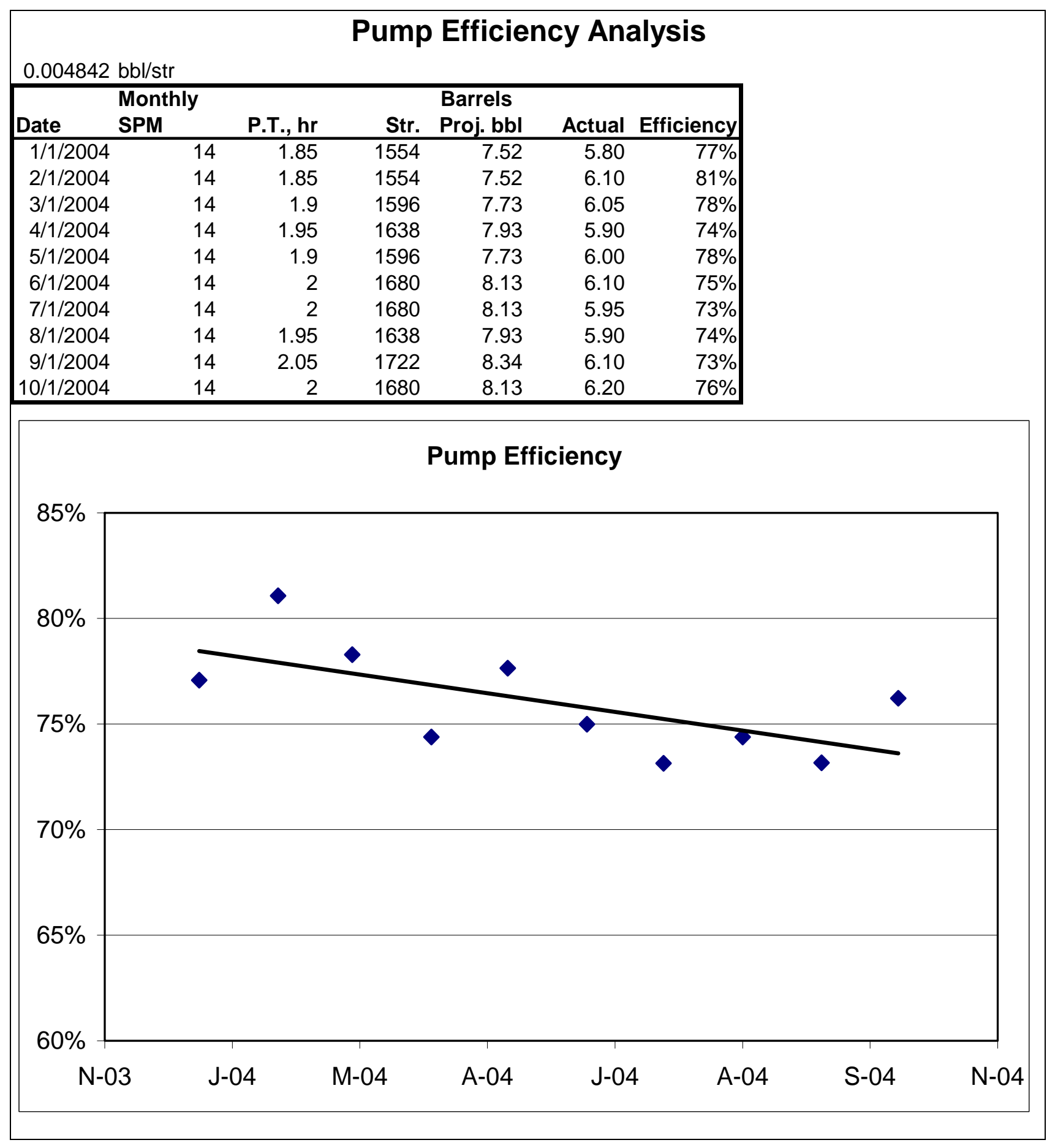

Figure 24 - Pump Efficiency Analysis 


\section{Compressor Performance}

The objective of this report is to track the various parameters of a compressor unit. The values of each respective parameter were calculated for each month. Next, the data was plotted. This type of analysis may help to identify a problem or to illustrate the effects of the operating conditions.

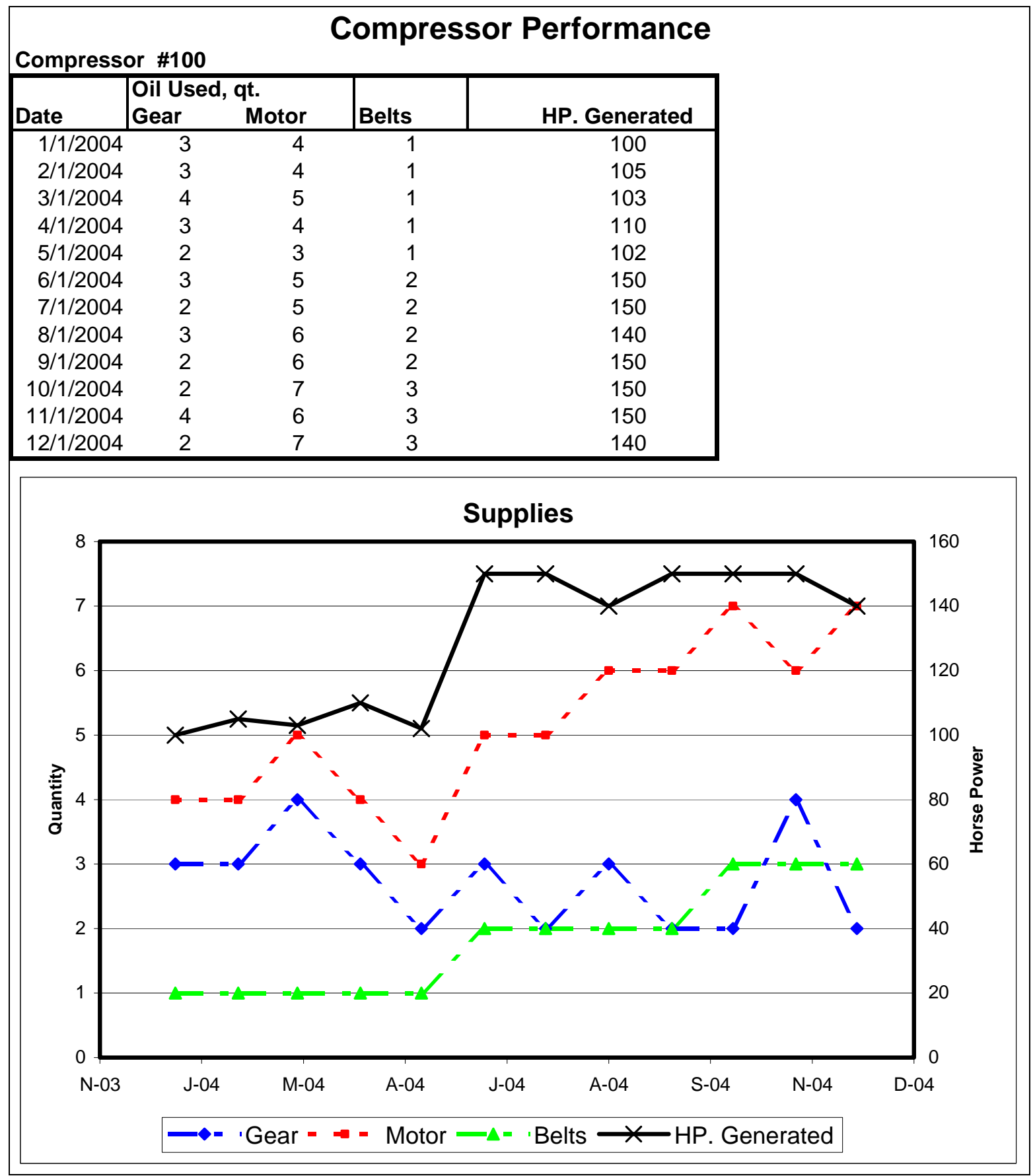

Figure 25 - Compressor Performance 


\section{Decline Curve}

The above graph is the plot of production data of a gas decline curve. Monthly production records were plotted and a line representing the production is fit to the data. The line is based on the decline curve equation. The equation is used to predict future production or to correlate the production with operations.

\section{Production Decline Curve}

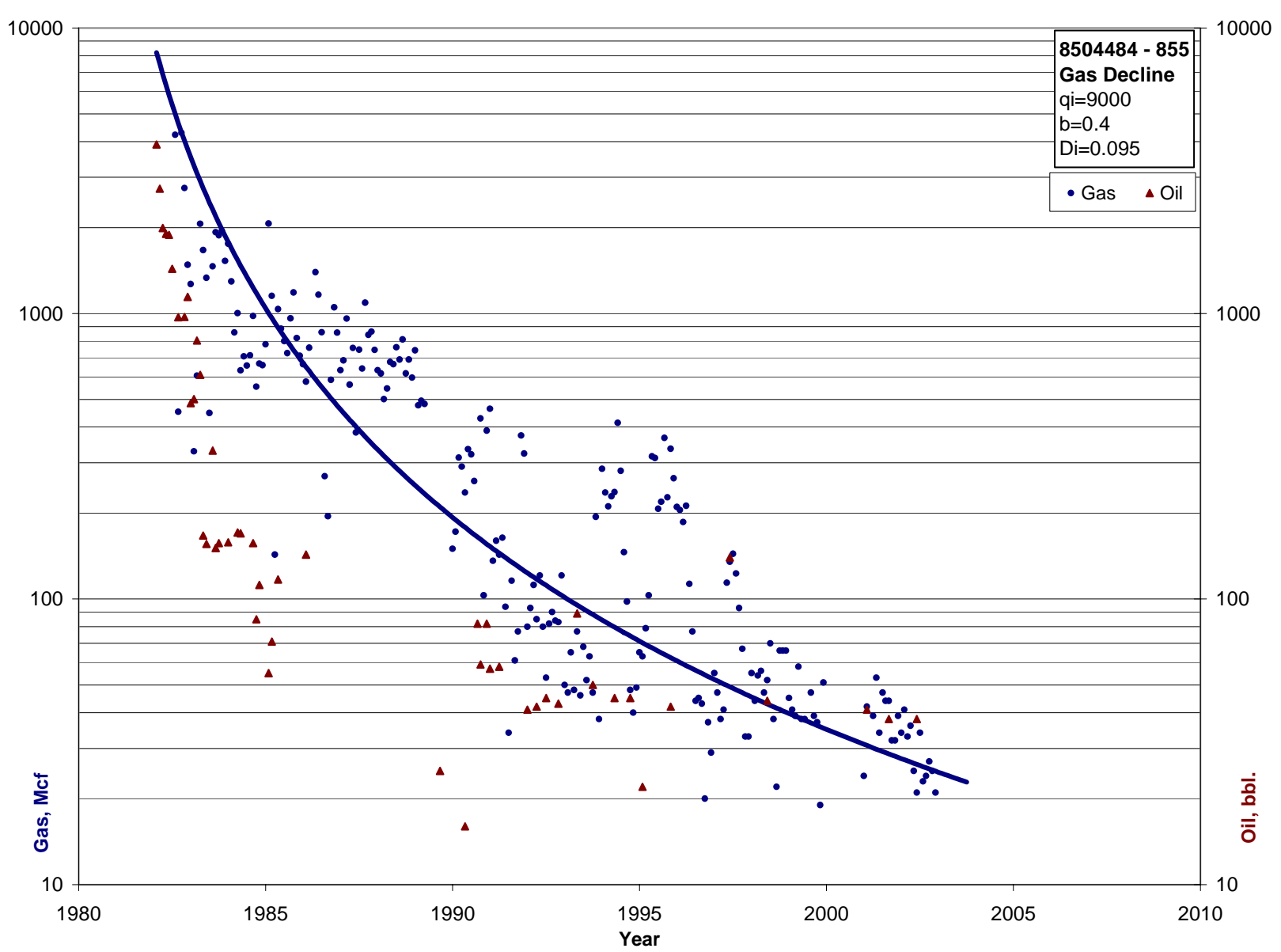

Figure 26 - Production Decline Curve 


\section{Buildup Test}

The Buildup test was taken from well records. Some of the parameters were estimated from nearby wells. This type of test is useful in determining permeability, skin factor and reservoir pressure. More in-depth analysis can yield reservoir size and shape estimates.

Data points are spread out significantly in this test. This is because the data was recorded by someone in the field reading values from a gauge. Even with the small amount of data, the data still yields a significantly accurate test.

With computerized meters with a casing pressure sensor, it is possible to obtain this type of test every time a well is shut in without further field work. These sensors will gather data more frequently. As a result a more accurate and detailed test data will be obtained.

The values obtained from this test are used to estimate production from wells under various conditions. Additionally, the values are used to identify damage (flow restrictions) or liquid accumulation. The well is monitored more accurately and better estimates are made. 


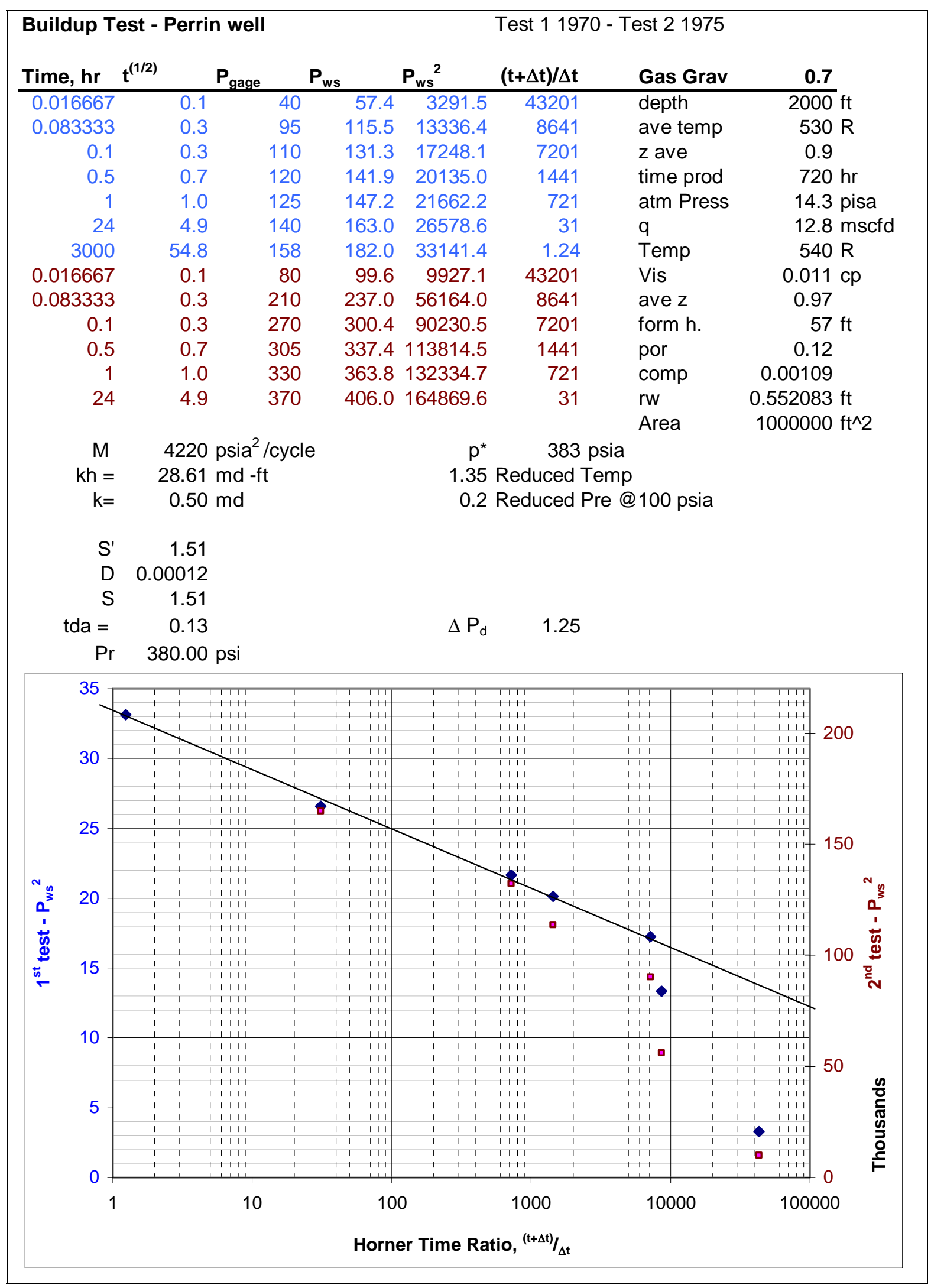

Figure 27 - Build-up Test 


\section{Variable Rate Flow Test}

The variable rate flow test is another type of well test. The well was shut in for a period of time. It was then opened up. Some assumptions were made in this test. These assumptions likely affected the test, however, values were obtained that are consistent will nearby wells.

The data from this test was used to create a report displaying the production rates under varying pressure and skin factor. 


\section{Variable Rate Flow Test - Morris 1490}

\begin{tabular}{|c|c|c|c|c|c|}
\hline & & orifice fac & & & \\
\hline 300 psia & time & Pressure & Differential & Rate & Pres. Fun \\
\hline 115 psia & 7 & 25 & 85 & 90.6 & 2.04 \\
\hline 0.1 & 14 & 22 & 58 & 71.9 & 2.57 \\
\hline 0.0013 1/psia & 24 & 20 & 55 & 68.1 & 2.72 \\
\hline $0.2 \mathrm{ft}$ & 36 & 20 & 45 & 61.6 & 3.00 \\
\hline $80 \mathrm{~F}$ & 60 & 20 & 34 & 53.5 & 3.46 \\
\hline 0.96 & 84 & 20 & 30 & 50.3 & 3.68 \\
\hline $0.011 \mathrm{cp}$ & 132 & 20 & 27 & 47.7 & 3.88 \\
\hline $12.5 \mathrm{RB} / \mathrm{mcf}$ & 180 & 18 & 26 & 45.4 & 4.07 \\
\hline $52 \mathrm{ft}$ & 228 & 17 & 22 & 41.1 & 4.50 \\
\hline 0.85 & 324 & 19 & 20 & 40.5 & 4.57 \\
\hline $1.4867 \mathrm{psi} / \mathrm{cyc}$ & 446 & 20 & 18 & 39.0 & 4.75 \\
\hline
\end{tabular}

\begin{tabular}{|ll|}
\hline Permeability & $0.299 \mathrm{md}$ \\
Skin Factor & -3.34 \\
\hline
\end{tabular}

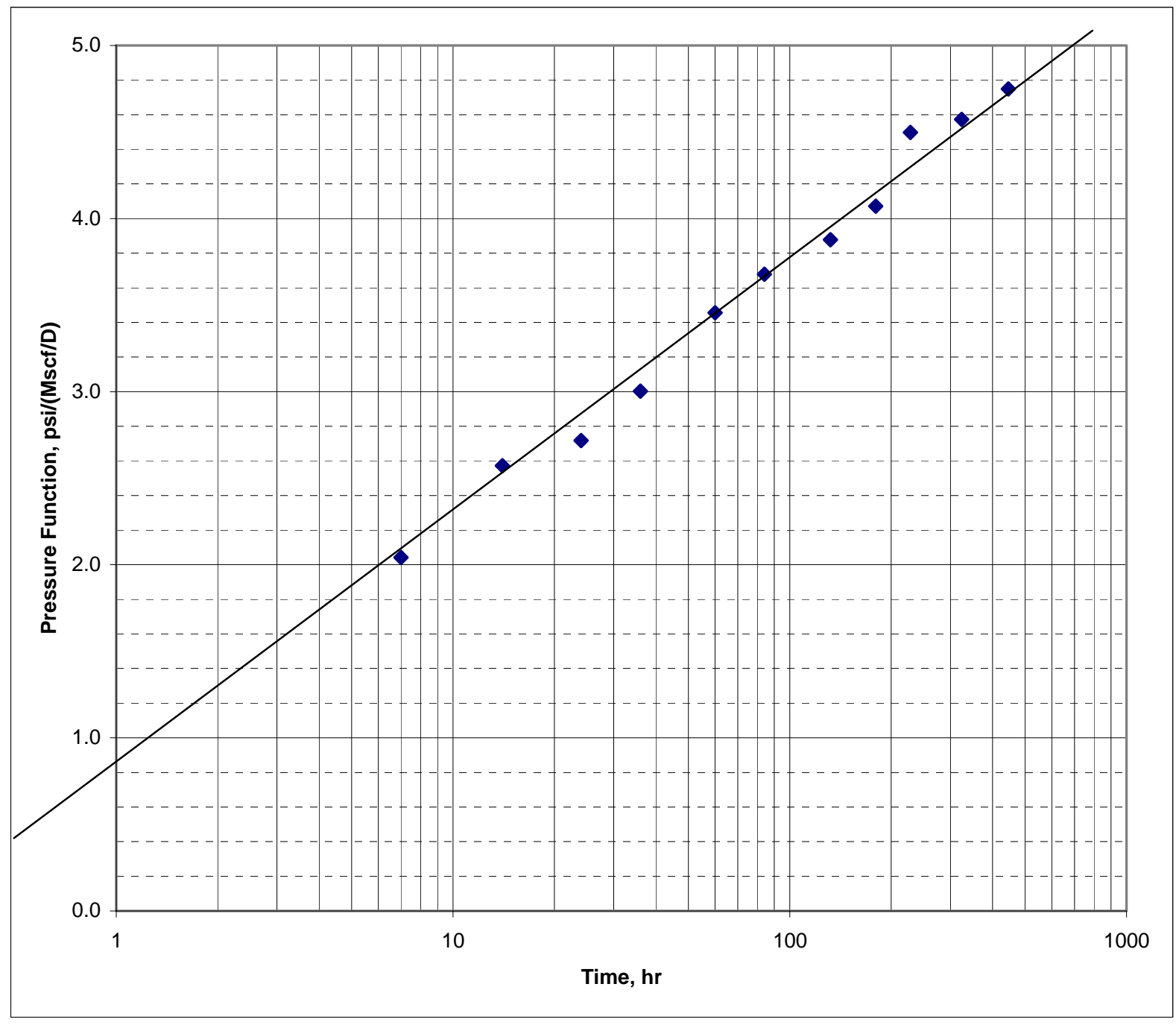

Figure 28 - Variable Rate Flow Test 


\section{Well Deliverability}

The data from the well was used to create a table displaying production rates under different pressures. The red highlighted values are normally conditions the well has been under. The estimated rate is consistent with production rates found in the field. The various skin factors are displayed to help estimate production if the well had not been stimulated or if more stimulation is done.

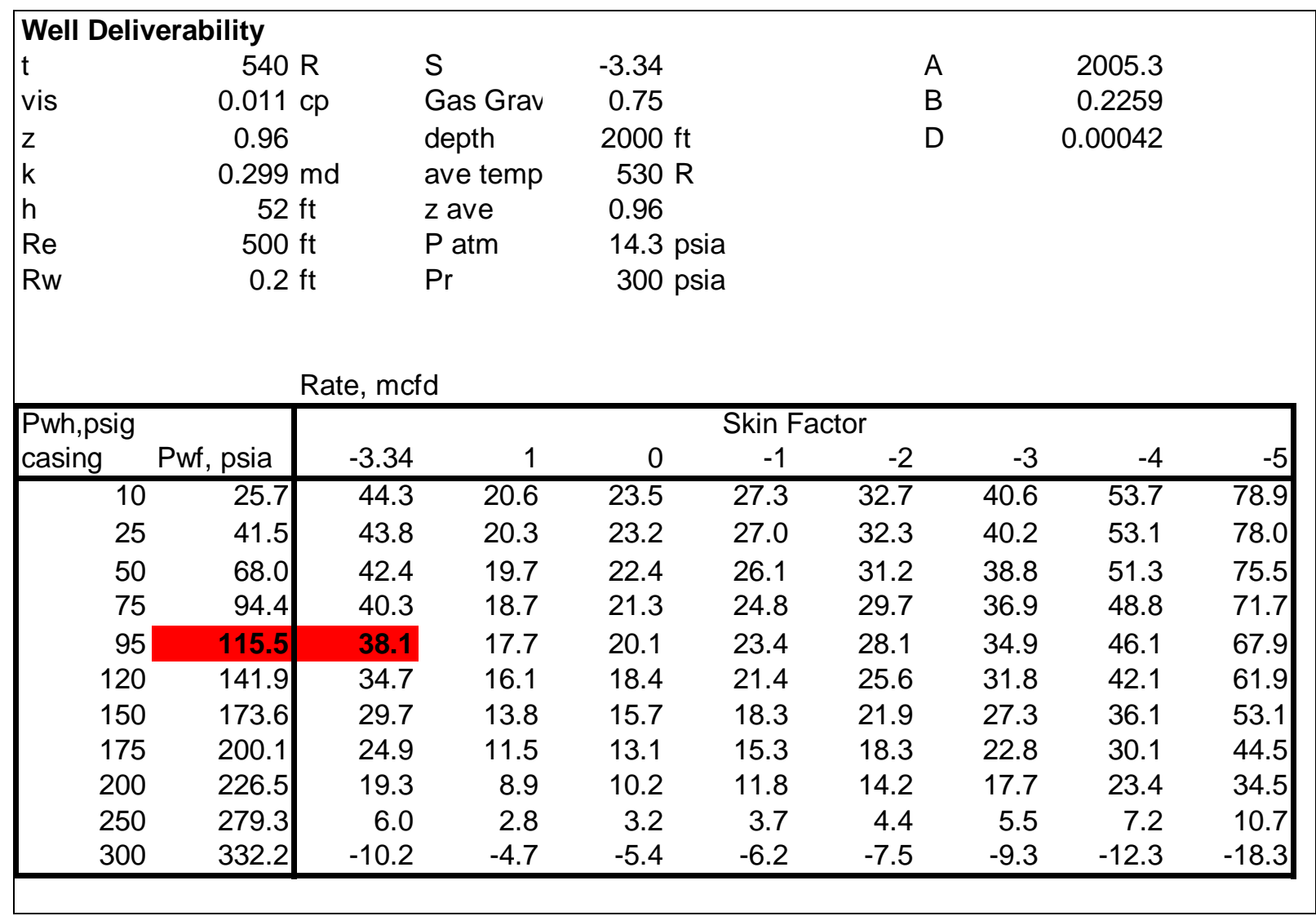

Figure 29 - Well Deliverability 


\section{Economics Reports}

\section{Compression Value}

This table is used to calculate the value of utilizing a compressor to reduce the wellhead pressure of a given well. Estimates of production are found from the well deliverability. The cost of the compressor is considered. The value of the production in each case is calculated. The difference in this case is $\$ 400$. This means that by using the compressor the net revenue is increased.

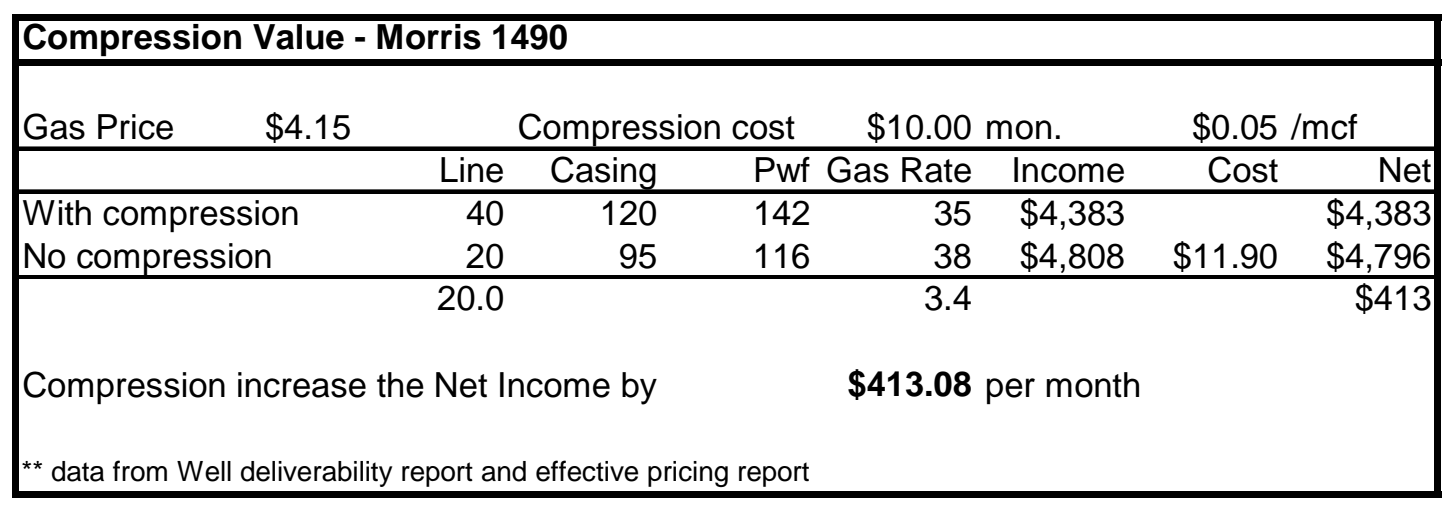

Figure 30 - Compression Value

\section{Pumping Cost Analysis}

This report estimates the cost of pumping operations and relates the effect to economic parameters such that the most profitable course of operations are determined. All of this data is simulated, but it should represent real world conditions.

First the current basic costs are established (Service rig, employee time, etc.). This is reported from accounting data. Next the historical cost of operations is calculated based on current prices. Again, this is accounting data.

The amount the equipment was used is calculated based on the number of strokes of the pump. This could be done for one or more wells. Multiple wells of the same type may give a better indication of what to expect because infrequent events are averaged in. Based on these numbers the cost per stroke is calculated.

The values for the equipment are estimated (pump speed, employee's time, etc.). This section includes data from engineering and accounting. Various pumping frequencies are set. 
Based on this, pumping time and gas, oil, and water volumes are estimated. From this data the cost, income, and net are calculated.

The plot indicates that the optimum frequency to pump this well under the given conditions is about every 16 days.

As more data becomes available or conditions change the optimum frequency may change. Since the report is on a spreadsheet, data can be changed easily. 


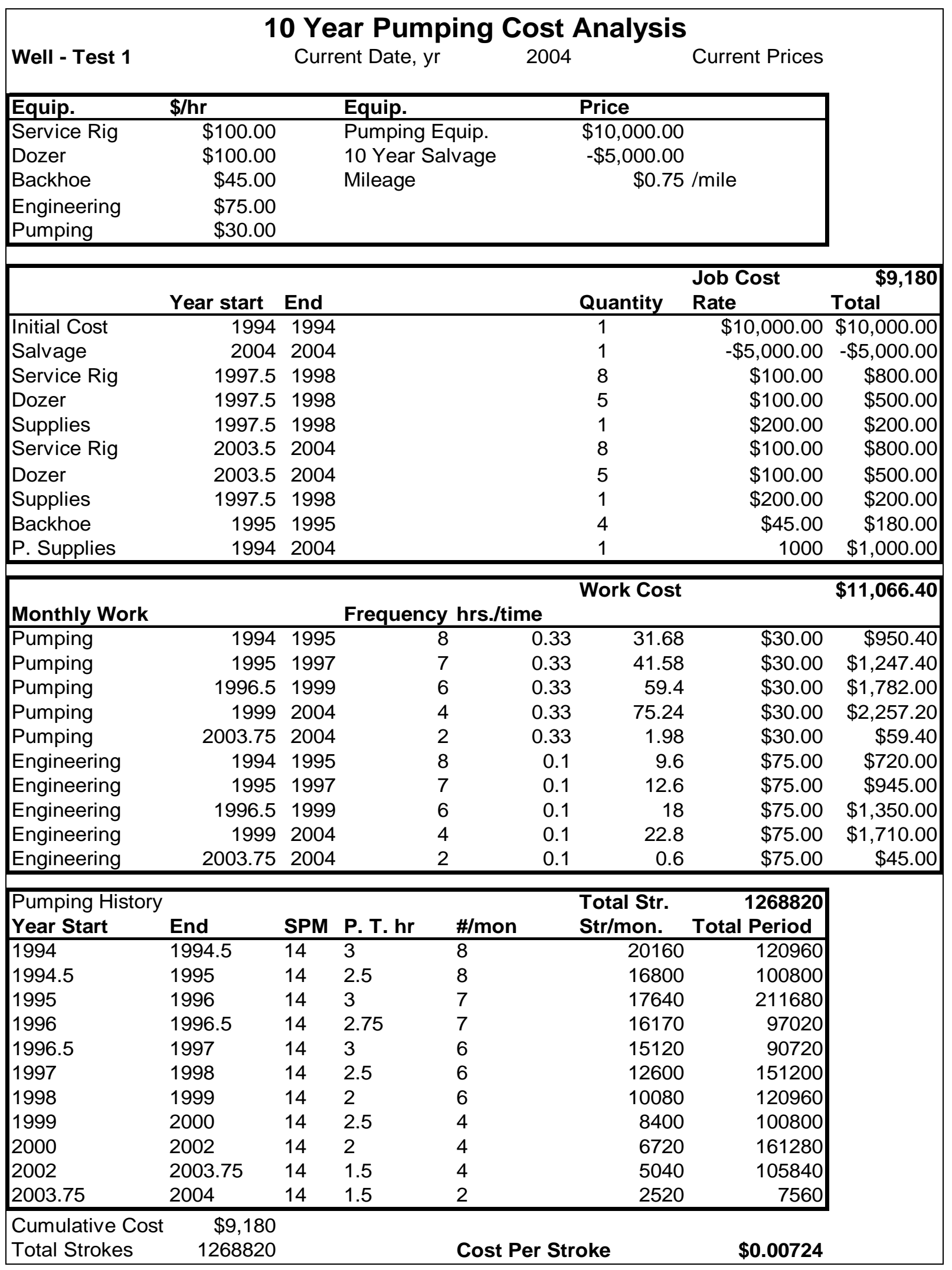

Figure 31 - Ten Year Pumping Cost 


\begin{tabular}{|lclclc|}
\hline \hline SPM & 14 & Gas & $\$ 4.15 / \mathrm{mcf}$ & Water Cut & $50.00 \%$ \\
pumper,hr & 0.33 & Oil & $\$ 25.10 / \mathrm{bbl}$ & Mileage & 10 mil. / visit \\
eng, hr. & 0.1 & Water & $-\$ 1.73 / \mathrm{bbl}$ & & \\
Storage & $\$ 10$ & $/ \mathrm{mon}$ & Fixed Cost & $100 / \mathrm{mon}$ & \\
\hline
\end{tabular}

Monthly Pumping-Profits

\begin{tabular}{|rrrrrrrrrr|}
\hline $\begin{array}{r}\text { Monthly } \\
\text { Freq. }\end{array}$ & P.T., hr Str/mon. Emp Cost & \multicolumn{1}{c}{ Cost } & Gas, mcf & Oil, bbl Water,bbl & Income & Net \\
\hline 0 & 0 & 0 & $\$ 25$ & $\$ 125$ & 40 & 0.0 & 0.0 & $\$ 166$ & $\$ 41$ \\
1 & 2 & 1680 & $\$ 25$ & $\$ 147$ & 80 & 4.1 & 4.1 & $\$ 427$ & $\$ 280$ \\
2 & 2 & 3360 & $\$ 50$ & $\$ 184$ & 121 & 8.1 & 8.1 & $\$ 692$ & $\$ 508$ \\
4 & 2 & 6720 & $\$ 100$ & $\$ 258$ & 204 & 16.3 & 16.3 & $\$ 1,226$ & $\$ 968$ \\
6 & 1.8 & 9072 & $\$ 149$ & $\$ 325$ & 280 & 22.0 & 22.0 & $\$ 1,674$ & $\$ 1,349$ \\
8 & 1.75 & 11760 & $\$ 199$ & $\$ 394$ & 326 & 28.5 & 28.5 & $\$ 2,017$ & $\$ 1,623$ \\
10 & 1.6 & 13440 & $\$ 249$ & $\$ 456$ & 360 & 32.5 & 32.5 & $\$ 2,253$ & $\$ 1,797$ \\
16 & 1.2 & 16128 & $\$ 398$ & $\$ 625$ & 430 & 39.0 & 39.0 & $\$ 2,695$ & $\$ 2,070$ \\
20 & 1 & 16800 & $\$ 498$ & $\$ 730$ & 435 & 40.7 & 40.7 & $\$ 2,754$ & $\$ 2,024$ \\
30 & 0.675 & 17010 & $\$ 747$ & $\$ 980$ & 440 & 41.2 & 41.2 & $\$ 2,787$ & $\$ 1,806$ \\
\hline
\end{tabular}

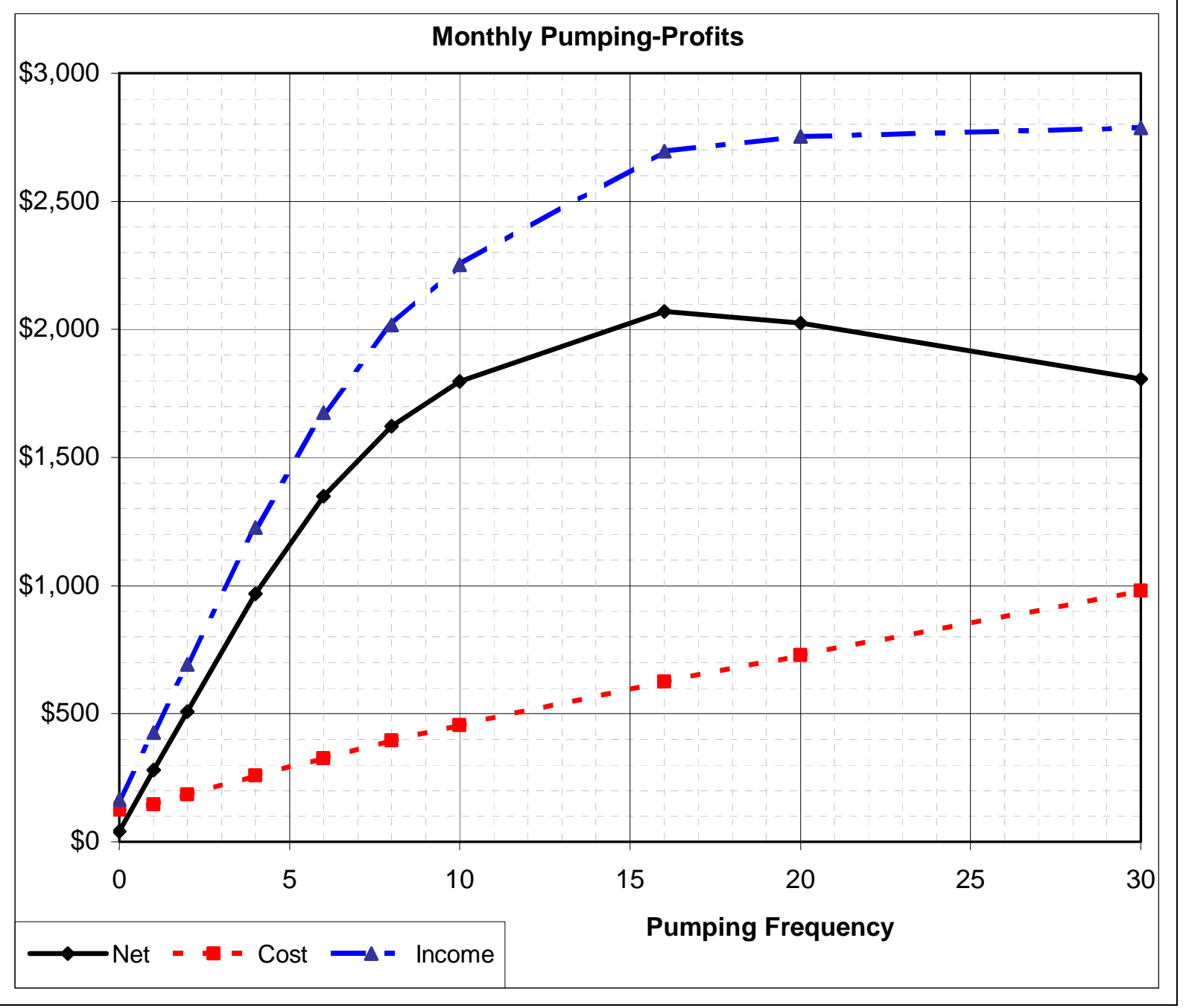

Figure 31 - Ten Year Pumping Cost cont. 


\section{Swabbing Economics}

The purpose of this analysis is to determine the most profitable interval to swab a well. The standard parameters are determined. These are related to accounting. These are listed at the top of the report. Appropriate intervals are selected. The amount of rig time and the volumes of gas, oil and water are estimated from engineering data. This data will most likely come from past experiences and retrospective data. The cost and income per month are then calculated resulting in the net profit.

With the hypothetical well in the example, the optimum interval to swab the well is about one time per month. As illustrated in the chart, this is the highest point on the "Net" line. These calculations can be rerun easily when data changes or new data becomes available. 


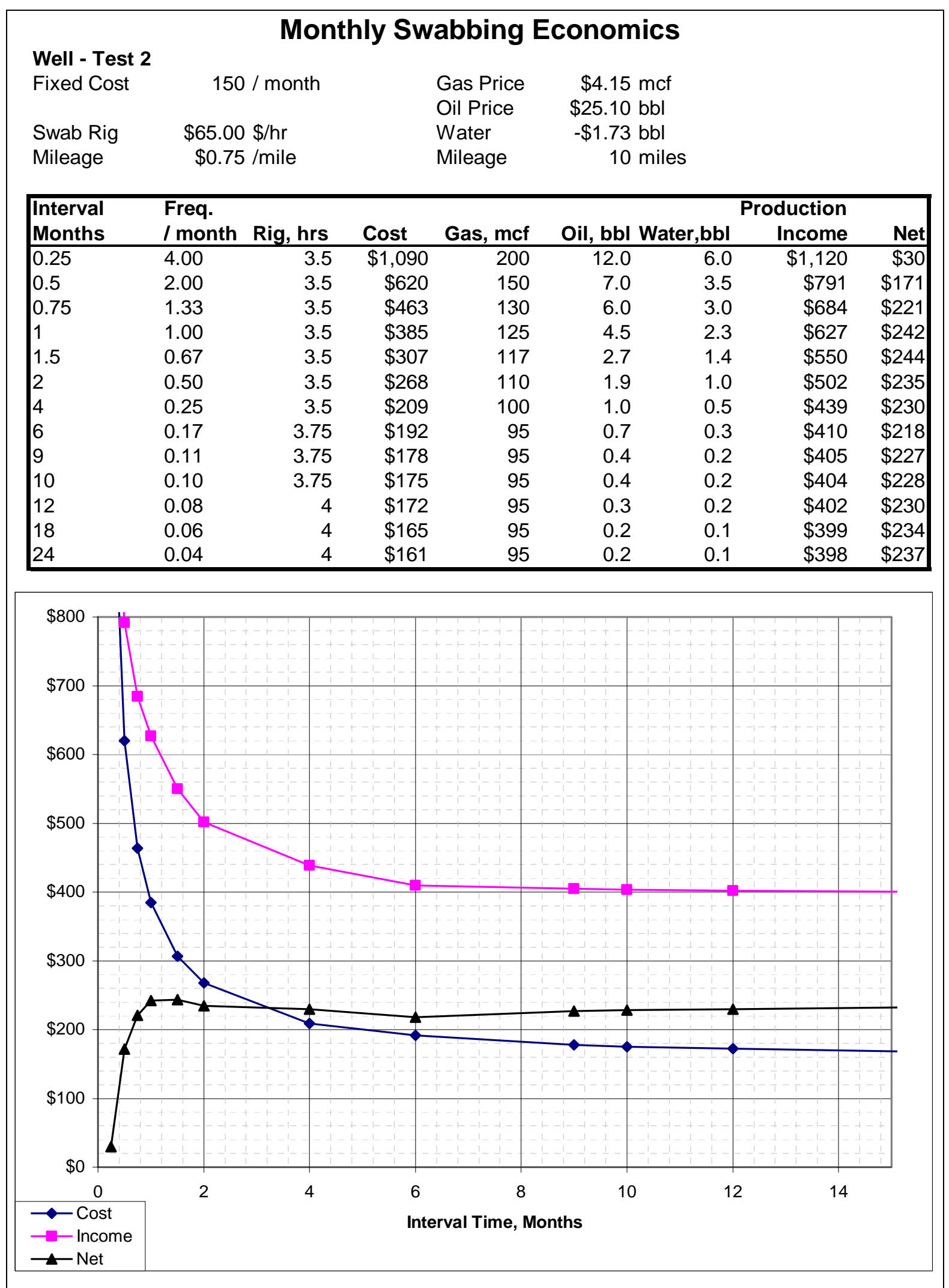

Figure 32- Monthly Swabbing Economics 


\section{E - PDA Program Screenshots and Description}

The following is a description of the PDA program that was developed. Sample information is displayed on the screenshots of the forms. The actual view on the PDA may vary due to the differences in displays and setups.

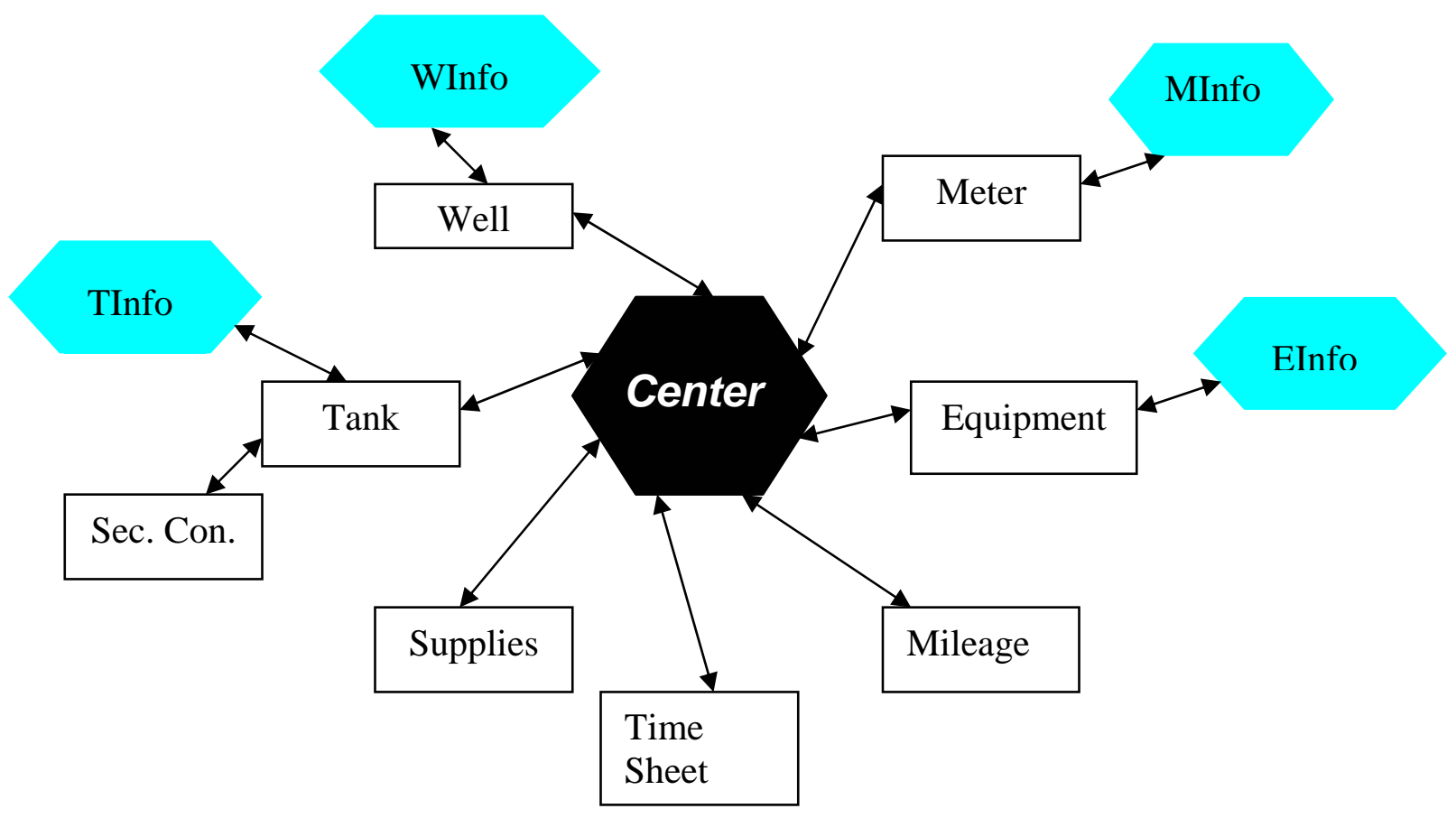

Figure 33 - Program Flow Chart

The database program has a menu bar at the bottom. After a record is entered, a new record should be created. There is a new record button $\underline{a}$ that will create a new record. The records can be viewed in list view, filtered, sorted, or various other things. Since these operations are not essential to operation of the program, no further discussion of these features will be made. 
Figure 34 shows the Center Form where the user selects the next form to go to. After the completion of each form the user would return to this form.

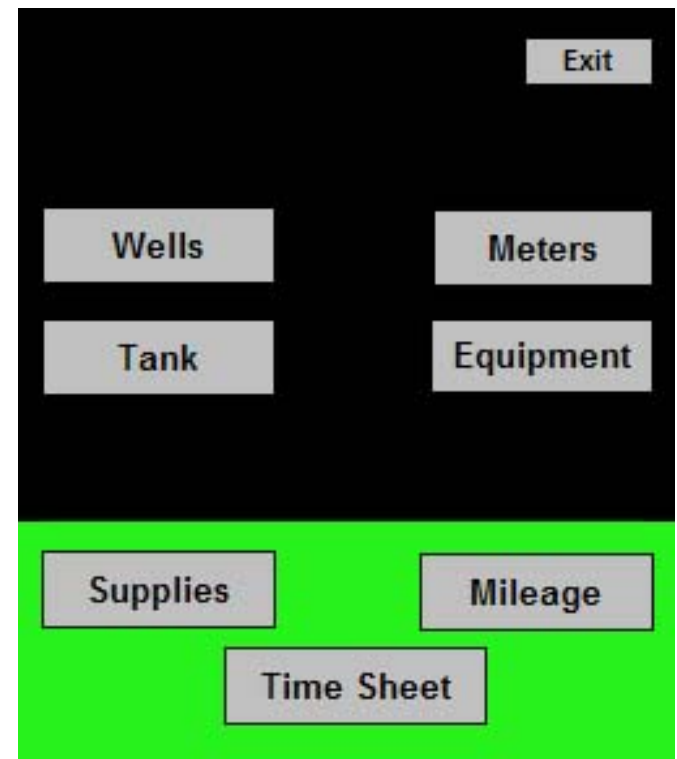

Figure 34 - Center Form

Figure 35 shows the Well Form. This form is where records regarding the well are entered. The well number is entered in the appropriate box. The well name will then appear. The table will display the past data that has been recorded on this well. The appropriate operations are selected from the list. In this case "Check" has been selected. More than one thing can be selected. The time and date is displayed in the next box. This can be changed, but the default time and date is the current time. The "Center" button will return to the Center Form. "Info" will go to the WInfo form, which will be discussed next. "More" will go to the right side of the form. Since there is too much information to get it all in one area of the form, only the left or right of the form will be displayed at one time. "Update” will update the information in the table if it does not automatically update. "Back" will return to the left side of the form. The entry fields on this section may or may not apply to the particular well. The appropriate fields should be filled out. The rest will be blank. "Pump Time" is the amount of time that a pump is set to run. "Speed" is the rate at which the pump is running. "Cas. Pres." is the pressure of the casing. "Tube Pres." is the pressure on the tubing. "Note" is where messages are recorded. 


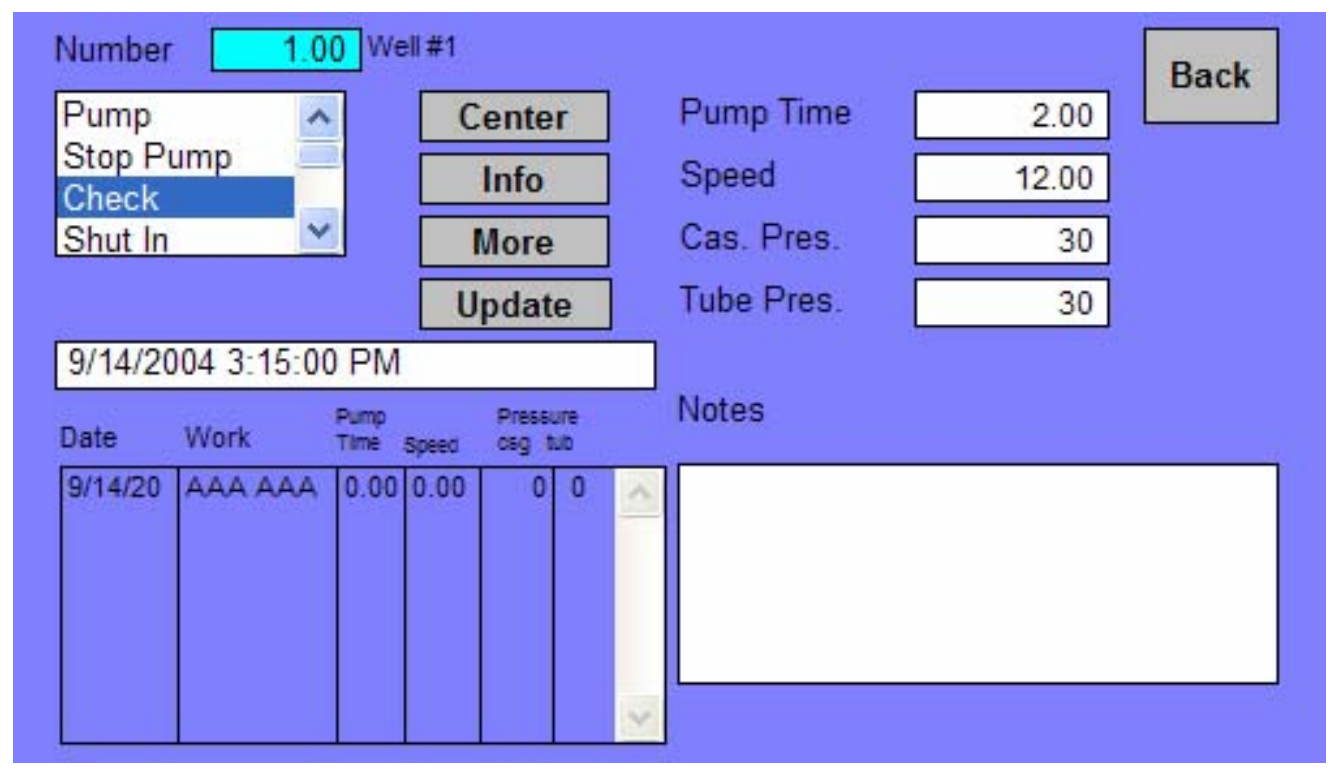

Figure 35 - Well Form

Figure 36 is the WInfo Form. This form is used to display basic data about the well.

The "Well" button will return to the Well form.

Each of the fields listed store basic data about the wells. It is essential only to have the Number and Name entered for each well. The rest are used for information. "Number" is the number of the well. Each of the wells must be assigned a unique number.

"Name" is the name of the well. This name should be enough to identify that the number is correct for the particular well.

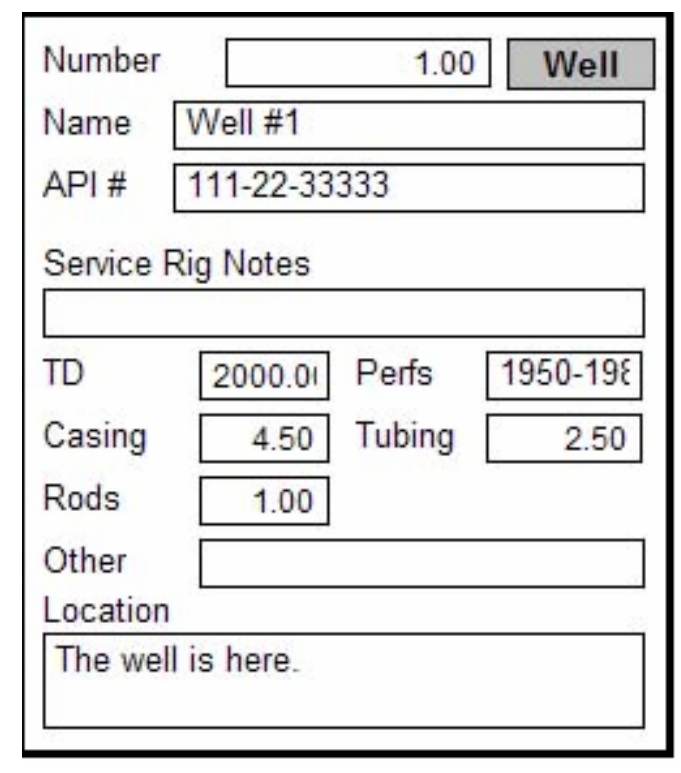

Figure 36 - WInfo Form 
Figure 37 is the Tank Form which records the data from the storage tanks. The "Number" is entered. The name of the tank will be displayed and the table will display data that was previously recorded for this tank. "Ft" records the number of feet to the top of the liquid in the tank. "In" will be the remaining inches. "BOL" (Barrels On Location) is calculated based on the measurements and data about the tank. "Water" is the volume of water that is removed from the tank. The time and data are displayed in the following box. The "Center" button returns to the Center form. The "Info" button goes to the TInfo form. "Update" will update the information in the table if it does not automatically update. "Sec. Cont." will go to the SecCon form.

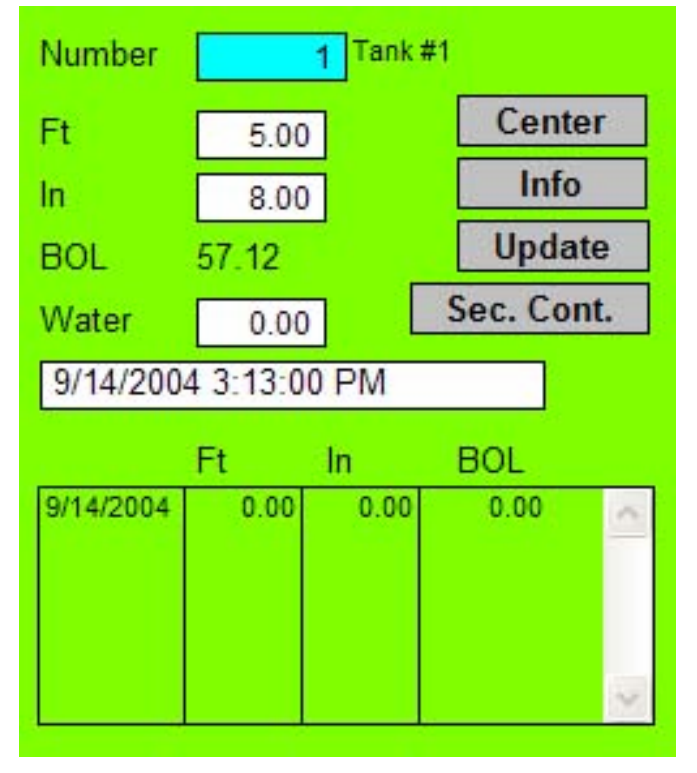

Figure 37 - Tank Form

Figure 38 is the TInfo Form. This form displays basic data about the tank. The tank "Number" is listed in the first box. This number must be unique for each tank. The next box is the name of the tank. Next, is "bbl. per in." (barrels per inch). This number is used to calculate the BOL. "Size, bbl.” is the size of the tank. Finally "Height, ft." is the height of the tank. 


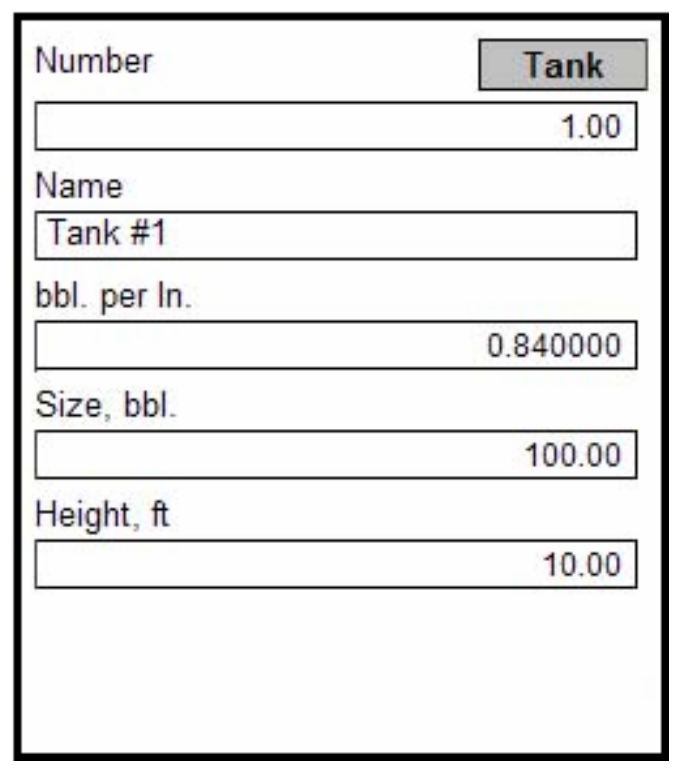

Figure 38 - TInfo Form

Figure 39 is the SecCon Form. This form is used to record information about the secondary containment facilities of a tank battery. The “Tank” button will return to the Tank form. The "Number" of the tank is entered. The name of the tank will be displayed. "Drain” is the field to record the volume of water drained from the unit. "Condition" is used to record the condition of the facilities. "Note" is used to record any other information.

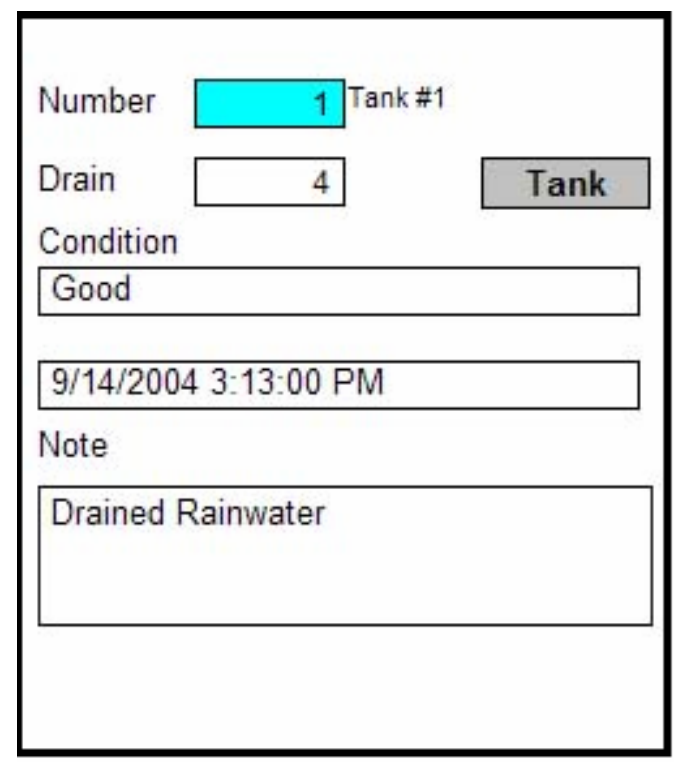

Figure 39 - SecCon Form 
Figure 40 is the Meter Form - This form is used to record meter readings. The meter "Number" is entered. The meter name will be displayed and the appropriate historical readings will be displayed in the table.

The fields "a”, "b”, “c”, “d”, will display the appropriate parameters to be recorded. In this case "a" is the pressure, "b" is the feet per minute. Each of the values is recorded. The rate will be calculated based on the meter setup.

The time and data are recorded. "Note" is used to write any more information that needs to be recorded. The "Center" button will return to the Center form. The "Info" button will go to the MInfo form. "Update" will update the information in the table.

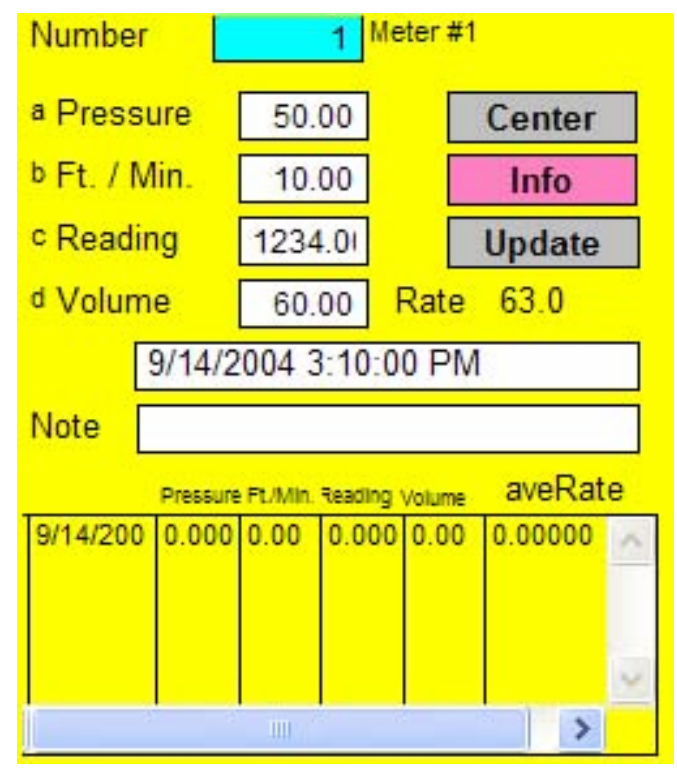

Figure 40 - Meter Form

Figure 41 is the MInfo Form, which is used to store information about the meter. The meter "Number" is in the first box. Each of the meters must have a unique number. The meter's "Name" is recorded in the next box. The meter's "MID" number is recorded. Where the gas is going is stored in the "Sell To:" field. The meter type is recorded in the next field. "Orifice Size" is recorded for orifice meters. "Orifice Factor" is recorded on the next line. This number is essential to calculating the rate of orifice meters. A "Note" is recorded in the next field. Fields "a”, "b”, "c", "d" hold the name of the value to be recorded in their respective field.

"Atm. Corr." is the atmospheric pressure correction. 


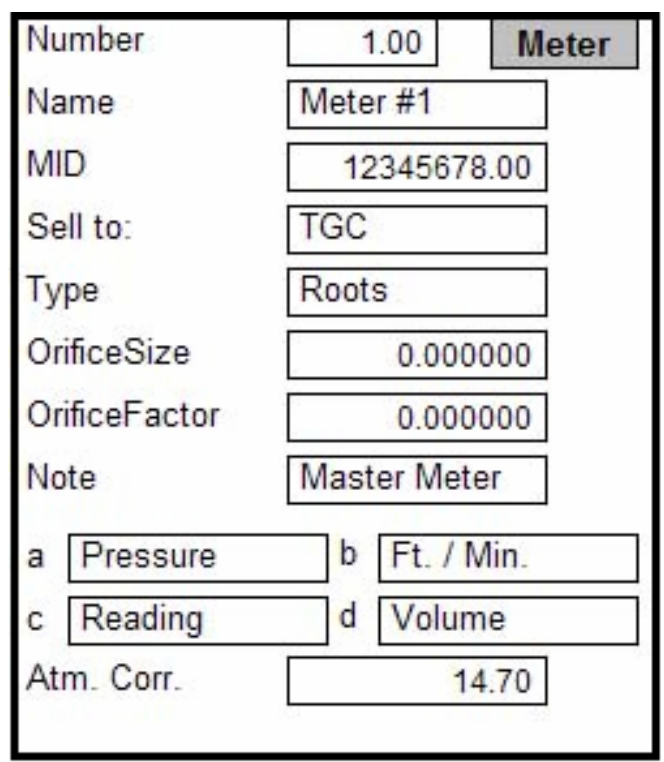

Figure 41 - MInfo Form

Figure 42 is the Equipment Form. It is used to record information about equipment not covered by the other forms. Starting on the left side, the "Number" of the unit is entered in the first box. The name of the equipment will be displayed on the right of the number box. The date is displayed next. The parameters to be recorded will be listed in the appropriate place (to better understand this look at the EInfo form). In this case, the first box has the label "Suction Pres.". The next box has the label "Dis. Pres.”. These labels can vary for each unit of equipment. The bottom box is for recording a note. The "Center" button will take the user to the Center form. "Info" will go to the EInfo form. "Table" will display the right side of the form. This is a table of the records that have been stored for the unit of equipment. "Back" will return to the left side of the form. 


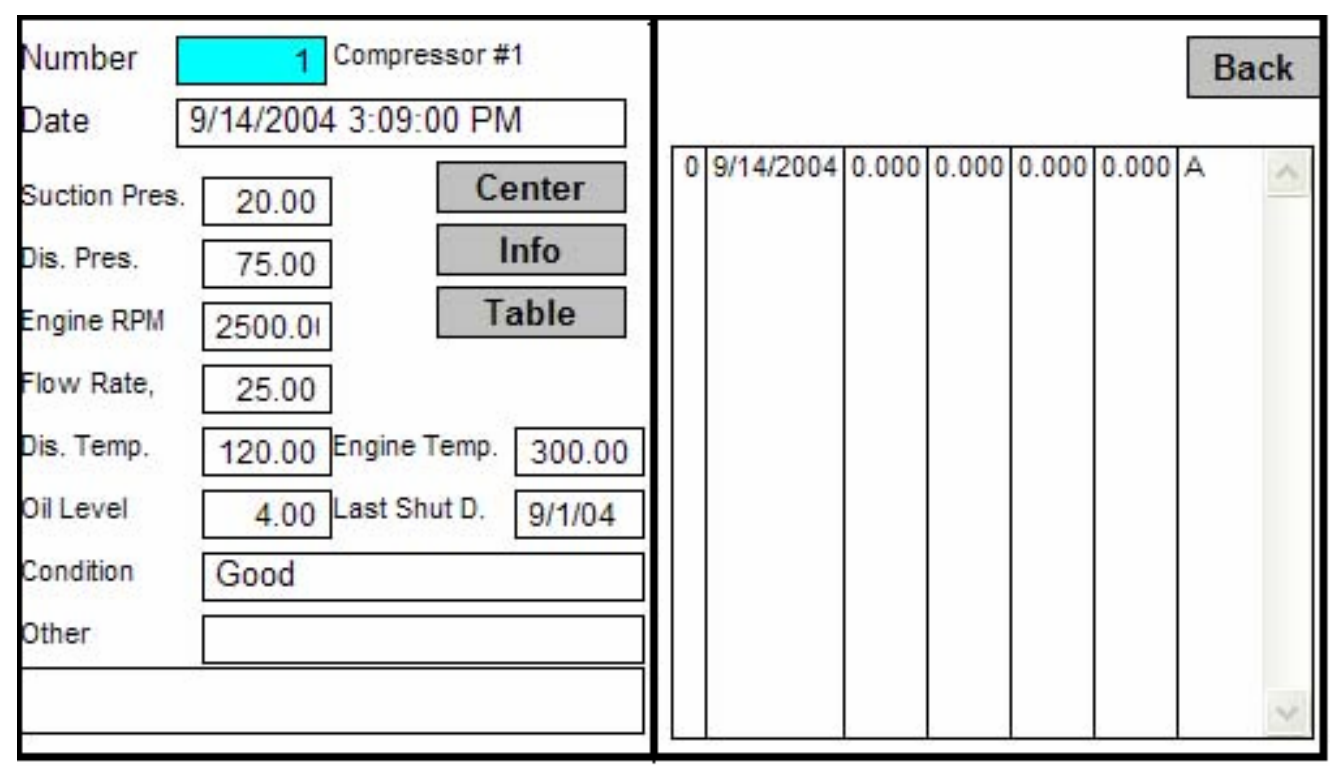

Figure 42 - Equipment Form

Figure 43 is the EInfo Form. This form is used to store information to run the Equipment form. The "Equip." button will return to the Equipment form. The "Number" of the unit of equipment is displayed in the first line. The name of the equipment is in the next box. The fields n1 to n7 are the numerical parameters to be recorded in the seven numbered boxes on the Equipment form. The fields t8 to $\mathrm{t} 10$ are the text parameters to be recorded in the three text boxes on the Equipment form.

\begin{tabular}{|c|c|c|}
\hline Number & 1 & Equip. \\
\hline Name & Compressor \#1 & \\
\hline Note & Repair on $12-15$ & \\
\hline $\mathrm{n} 1$ & Suction Pres. & \\
\hline $\mathrm{n} 2$ & Dis. Pres. & \\
\hline n3 & Engine RPM & \\
\hline n4 & Flow Rate, MCFD & \\
\hline n5 & Discharge Temp, F & \\
\hline $\mathrm{n} 6$ & Oil Level & \\
\hline n7 & Engine Temp. $\mathrm{F}$ & \\
\hline t8 & Last Shut Down & \\
\hline t9 & Condition & \\
\hline t10 & Other & \\
\hline
\end{tabular}

Figure 43 - EInfo Form 
Figure 44 shows the Supplies Form. This form is used to record the supplies that are used. The "Date" is changed if it is not correct. The "Center" button will return to the Center form. The "Name" of where the supply is going is entered. The "Number" of where the supply is going is recorded. The actual "Supply" is selected from the list. The "Amount" or quantity is recorded next and any necessary notes are made.

This example shows the supply of 1.25 gallons of gasoline going to well \#1.

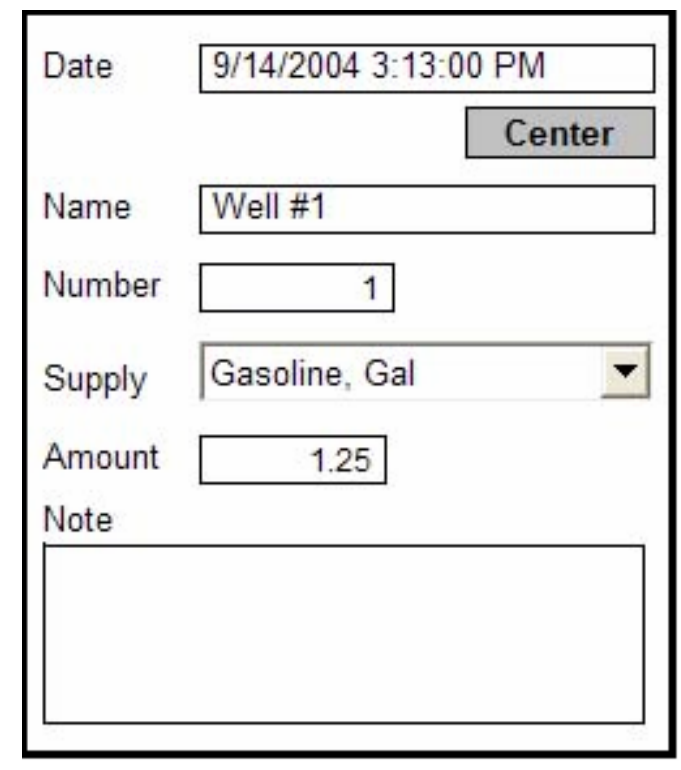

Figure 44 - Supplies Form

Figure 45 shows the Mileage Form. This form is used to keep track of the amount of miles traveled by each employee. "Date" is the first line. The location is recorded next. "Name" and "Number" are recorded about the location.

The number of miles traveled is recorded in "Miles". This is the number of miles that were traveled. Finally, the name of the employee is recorded in the "Employee" box. 


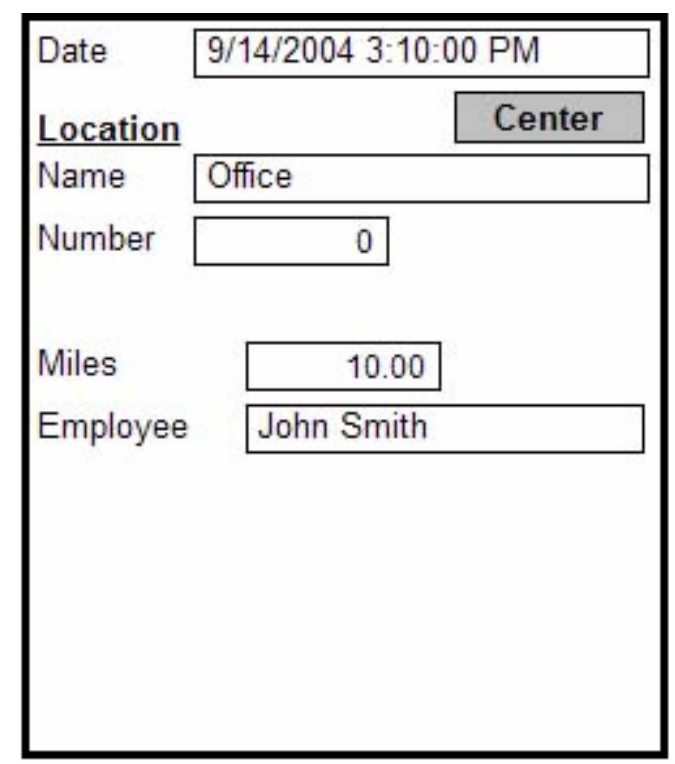

Figure 45 - Mileage Form

Figure 46 shows the Timesheet Form - This form is used to record information that is used for a timesheet. The "Date" is recorded on the first line. The "Center" button will return to the Center form. The name of the employee is recorded in the "Employee" box. The number of the employee is recorded. Then the amount of time worked in hours and minutes is recorded in the appropriate box. The Mileage total for the day is recorded next. The "Note" box is used to record any other information that may be necessary.

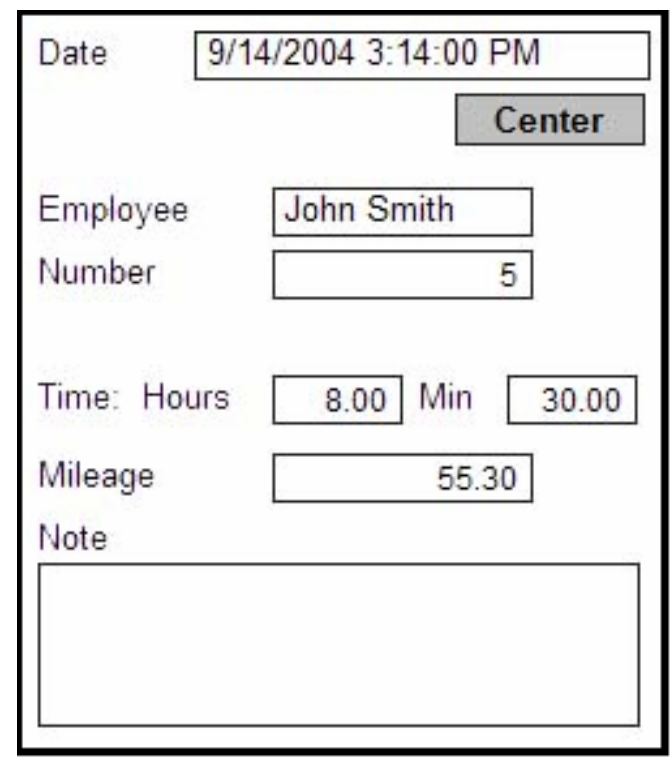

Figure 46 - Timesheet Form 